\title{
Design and Synthesis of 2,3-trans-Proline Analogues as Ligands for Ionotropic Glutamate Receptors and Excitatory Amino Acid Transporters
}

\author{
Christian B. M. Poulie ${ }^{\dagger}$, Anna Alcaide ${ }^{\dagger}$, Mikkel Krell-Jørgensen ${ }^{\dagger}$, Younes Larsen ${ }^{\dagger}$, Eloi \\ Astier $^{\dagger}$, Walden E. Bjørn-Yoshimoto ${ }^{\dagger}$, Feng $\mathrm{Yi}^{\ddagger}$, Jed T. Syrenne ${ }^{\ddagger}$, Morten Storgaard ${ }^{\dagger}$, \\ Birgitte Nielsen $^{\dagger}$, Karla A. Frydenvang ${ }^{\dagger}$, Anders A. Jensen ${ }^{\dagger}$, Kasper B. Hansen ${ }^{\ddagger}$, Darryl S. \\ Pickering ${ }^{\dagger}$, and Lennart Bunch ${ }^{*}{ }^{\dagger}$ \\ tDepartment of Drug Design and Pharmacology, Faculty of Health and Medical Sciences, \\ University of Copenhagen, Copenhagen 2100, Denmark \\ FDepartment of Biomedical and Pharmaceutical Sciences, Center for Structural and Functional \\ Neuroscience, and Center for Biomolecular Structure and Dynamics, University of Montana, \\ Missoula, Montana 59812, United States
}

\begin{abstract}
Development of pharmacological tools for the ionotropic glutamate receptors (iGluRs) is imperative for the study and understanding of the role and function of these receptors in the central nervous system. We report the synthesis of 18 analogues of (2S,3R)-2-carboxy-3-pyrrolidine acetic acid (3a), which explores the effect of introducing a substituent on the $\mathcal{\varepsilon}$-carbon $(\mathbf{3 c}-\mathbf{q})$. A new synthetic method was developed for the efficient synthesis of racemic 3a and applied to give expedited access to 13 racemic analogues of 3a. Pharmacological characterization was carried out at native iGluRs, cloned homomeric kainate receptors (GluK1-3), NMDA receptors (GluN1/ GluN2A-D), and excitatory amino acid transporters (EAAT1-3). From the structure-activity relationship studies, several new ligands emerged, exemplified by triazole 3p-d1, GluK3preferring (GluK1/GluK3 $K_{\mathrm{i}}$ ratio of 15), and the structurally closely related tetrazole 3q-s3-4 that displayed 4.4-100-fold preference as an antagonist for the GluN1/GluN2A receptor $\left(K_{\mathrm{i}}=0.61\right.$ $\mu \mathrm{M})$ over GluN1/GluN2B-D $\left(K_{\mathrm{i}}=2.7-62 \mu \mathrm{M}\right)$.
\end{abstract}

\section{Graphical Abstract}

\footnotetext{
*Corresponding Author lebu@ sund.ku.dk. Phone: +45 35336244.

Author Contributions

C.B.M.P., medicinal chemistry and manuscript preparation; A.A., medicinal chemistry and manuscript preparation; M.K.-J., medicinal chemistry; Y.L., pharmacology; E.A., medicinal chemistry; W.E.B.-Y., pharmacology; F.Y., pharmacology; J.T.S., pharmacology; M.S., medicinal chemistry; B.N., pharmacology; K.A.F., X-ray structure; A.A.J., pharmacology; K.B.H., pharmacology; D.S.P., pharmacology and manuscript preparation; L.B., medicinal chemistry and manuscript preparation.

ASSOCIATED CONTENT

Supporting Information

The Supporting Information is available free of charge on the ACS Publications website at DOI: 10.1021/acschemneuro.9b00205.

Experimental details for crystal structure determination of compound 9c-s1 and compound 9d-s2 (PDF)

The authors declare no competing financial interest.
} 


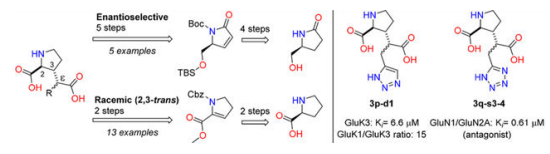

\section{Keywords}

Glutamate receptors; NMDA receptors; kainate; proline analogues; CNS

\section{INTRODUCTION}

Most of the fast excitatory neurotransmission in the central nervous system (CNS) is mediated by the endogenous $a$-amino acid ( $S$ )-glutamate (Glu) through the ionotropic glutamate receptors (iGluRs). ${ }^{1}$ Based on pharmacological studies of synthetic ligands and natural products, these receptors were early on divided into three groups, named the $a$ amino-3-hydroxy-5-methyl-4-isoxazolepropionic acid (AMPA), the kainic acid (KA) and the $N$-methyl-D-aspartate (NMDA) receptors. ${ }^{2}$ For the AMPA receptors, four subunits have been identified (GluA1-4), ${ }^{3}$ while five KA receptor subunits have been cloned (GluK1-5). ${ }^{4}$ For the NMDA receptors, four Glu binding subunits have been identified (GluN2A-D) as well as three glycine (Gly) binding subunits (GluN1 and GluN3A-B). ${ }^{5}$ The subunits GluA1-4 can all be freely combined in vitro, to form homomeric as well as heteromeric receptors complexes. However, it remains unknown to which extent the conceivable combinations are expressed in vivo. ${ }^{6}$ The KA receptors may form functional receptors in vitro, which are homomers of one of the three GluK1-3 subunits, but also combinations thereof. The GluK4 and GluK5 subunits only form functional receptors in vitro upon the combination with one of the three subunits GluK1-3. ${ }^{7}$ Likewise, the NMDA receptors only form Glu-sensitive functional receptors in vitro from two Gly-binding subunits (GluN1) and two Glu-binding subunits (GluN2A-D). ${ }^{8,9}$ The extracellular domains of the functional receptors are arranged as a dimer of dimers, whereas the transmembrane domain is arranged as a symmetrical tetramer, which forms the ion channel. ${ }^{10}$

The natural product KA, and other GluK agonists, are known to be potent neuronal excitants and neurotoxins as well as potent convulsants. ${ }^{11} \mathrm{KA}$ receptor knockout animal models have shown that these animals have a higher threshold in the perception of pain, indicating a potential role for antagonists in the treatment of pain. ${ }^{12}$ Furthermore, GluK antagonists might have a beneficial effect on neurodegenerative diseases such as multiple sclerosis, ${ }^{13}$ Alzheimer's disease, ${ }^{14}$ and Huntington's disease, ${ }^{15}$ as well as in several psychiatric disorders including schizophrenia, ${ }^{16}$ major depression, ${ }^{17}$ autism, ${ }^{18}$ bipolar disorder, ${ }^{19}$ and obsessive-compulsive disorder. ${ }^{20}$

In the search for subtype selective ligands for iGluRs, a substantial number of Glu analogues have been prepared and characterized pharmacologically, including >200 different 4substituted Glu analogues by us ${ }^{37-42}$ and others ${ }^{35,43-47}$ (see Table 1). Also a number of analogues of the natural product KA have been prepared, including the structurally simplified KA analogue 3a (CPAA) as well as the conformationally restricted analogues $\mathbf{1 b}^{27}$ and $\mathbf{1} \mathbf{c}^{23}$ (Table 1). While several competitive agonists and antagonists are able to 
differentiate between the three iGluR groups, ${ }^{25,48}$ the success rate when it comes to the development of subtype-selective iGluR ligands targeting the orthosteric binding site has been low. In fact, only subtype-selective agonists and antagonists for the homomeric GluK1 receptor as well as the selective GluK3 agonist 1c (Table 1) have been disclosed to this date.

Glutamate is a flexible molecule which can rotate around its $\mathrm{C}(2)-\mathrm{C}(3)$ and $\mathrm{C}(3)-\mathrm{C}(4)$ bonds. Nine distinct staggered conformations can be adapted through this rotation. ${ }^{49}$ The energy differences of these conformations are all in the same order of magnitude ${ }^{50}$ From the extensive number of X-ray crystallographic studies of agonists bound in the agonist binding domains of GluA2 and GluK1, it has been shown that a "folded" conformation of the Glu backbone favors iGluR agonist activity over metabotropic Glu receptor (mGluR) agonist activity. Whereas an "extended" conformation is favored by the mGluRs. ${ }^{51,52}$

3a (CPAA) is a conformational restricted analogue of Glu, locked in the $\mathrm{C}(1)-\mathrm{C}(3)$ anti conformation, but it allows for different $\mathrm{C}(2)-\mathrm{C}(5)$ conformations, by rotation around the $\mathrm{C}(3)-\mathrm{C}(4)$ bond. This implies that 3a can still adopt both the "folded" as well as the "extended" conformations. Conformational flexibility is reduced in the Glu backbone when substituted on the 4-position, favoring a "folded" conformation for compounds with a $s y n$ relative stereochemical relationship. ${ }^{53}$ In this study, we fused structures of series $\mathbf{2 a - d}$ with proline analogue 3a and present the synthesis and pharmacological evaluation of these new conformationally restricted Glu analogues.

\section{RESULTS AND DISCUSSIONS}

\section{Chemistry.}

Compound 3a and the ethyl and phenyl analogues $\mathbf{3} \mathbf{c}$ and $\mathbf{3 d}$, respectively, were prepared following our previous work for the synthesis of methyl analogue $\mathbf{3 b}$. $^{26}$ The key step is a stereoselective 1,4-addition of the appropriate cuprate to enone $\mathbf{4}$ (Scheme 1) ${ }^{54}$ For 3a, the cuprate addition with vinyl bromide gave intermediate $\mathbf{6 a}$ in $65 \%$ yield as a single transdiastereomer, determined by ${ }^{1} \mathrm{H}$ NMR and in agreement with literature values for optical rotation. ${ }^{55}$ Simultaneous hydroboration of the olefin and reduction of the lactam functionality with borane gave alcohol 7a in 52\%. Cleavage of the TBS-ether was accomplished with TBAF to yield diol $\mathbf{8 a}$, which was oxidized to diacid $\mathbf{9 a}$, by in situ generated ruthenium(VIII) oxide. ${ }^{56}$ Finally, removal of the Boc-group by TFA in DCM gave crude 3a, which was purified by preparative HPLC to yield $\mathbf{3 a}$ as the $\mathrm{HCl}$ salt.

The ethyl $\mathbf{3 c}$ and phenyl $\mathbf{3 d}$ analogues (Scheme 1) were prepared, starting from enone $\mathbf{4}$ and butenyl-2-bromide (5c) or $a$-bromostyrene (5d), respectively. After the one-pot reduction/ hydroboration reaction both intermediate alcohols $\mathbf{7 c}$ and $\mathbf{7 d}$ were separated into their respective diastereomers 7c-s1, 7c-s2, and 7d-s2. The stereoisomer 7d-s1 could not be purified to more than $>90 \%$ by dry column vacuum chromatography (DCVC), but it led directly to the free diol 8d-s1 when purified by preparative HPLC.

After cleavage of the silyl ether, oxidation, and Boc-group removal, the optically pure compounds 3c-s1, 3c-s2, 3d-s2, and 3d-s1 were obtained as their corresponding $\mathrm{HCl}$ salts. The absolute stereochemistry could be determined for $(2 S, 3 R, \varepsilon S)-\mathbf{9 c}$-s1 and $(2 S, 3 R, \varepsilon S)-\mathbf{9 d -}$ 
s2 by single-crystal X-ray diffraction, as they gave monocrystalline solids from EtOAc/ heptane (Figure 1).

Due to the limited availability of commercial vinyl bromides and the lengthy synthesis, we set out to find a more general and convenient procedure. Several other methods for the preparation of 3a have been reported, however none of these would allow for readily modification of the substituent on the $\mathcal{E}$-carbon. ${ }^{57-63} \mathrm{We}$ envisioned enone 10 as a suitable key intermediate for conjugate additions of different substituted malonates. Clearly, this strategy comes with the loss of absolute stereochemical control, which we accepted as the cost for a more feasible access to new analogues for a more comprehensive study of the structure-activity relationship (SAR).

Enone 10 was prepared according to literature procedure, starting from proline. ${ }^{64}$ The feasibility of this route was demonstrated by the synthesis of ( \pm )-3a in $87 \%$ overall yield from $2.0 \mathrm{~g} / 7.65 \mathrm{mmol}$ of enone 10 . After a short optimization, the most optimal conditions for the conjugated addition were found to be 1 equiv of $\mathrm{NaH}$ with 2.5 equiv of the corresponding malonate $11 \mathrm{a}, 11 \mathrm{e}-\mathbf{1 1 m}$, stirred for $3-24 \mathrm{~h}$ in THF at $50{ }^{\circ} \mathrm{C}$, which yielded the desired Michael products 12a, 12e-12m, in 35-99\% isolated yield (Scheme 2). The subsequent global deprotection and decarboxylation was achieved by reflux in $6 \mathrm{M} \mathrm{HCl}$ for 4-9 days. The crude of all final products $\mathbf{3 a}, \mathbf{3 e - 3} \mathbf{m}$ were purified by preparative HPLC, and the d.r. determined by ${ }^{1} \mathrm{H}$ NMR (Table 2). Exempt to this: For analogue $3 \mathbf{i}$ the diastereomeric mixture could be separated into its corresponding two diastereomers 3i-d1 and 3i-d2.

For 2-hydroxyethyl analogue 3n (Scheme 3), conjugated addition to enone 10 with cyclic malonate $11 \mathrm{n}$ gave $12 \mathrm{n}$ in $71 \%$ yield. Aqueous acidic global hydrolysis yielded the corresponding $\gamma$-lactone 13, and a second step with basic hydrolysis was required to obtain the disodium salt of $\mathbf{3 n}$.

The homologue of $\mathbf{3 n}$, analogue $\mathbf{3 o}$ (Scheme 4), was prepared via the standard protocol for the conjugated addiction of $\mathbf{1 1 0}$ to enone 10, followed by hydroboration of the olefin with borane to give 12o. Hydrolysis and subsequent decarboxylation was done in aq. $6 \mathrm{M} \mathrm{HCl}$ to give 30 in $28 \%$ after purification by preparative HPLC.

The introduction of simple five-membered heterocycles was also pursued and analogues $\mathbf{3 p}$ (Scheme 5) and3q (Scheme 6, Table 2) were designed. For the synthesis of triazole 3p, conjugated addition of $\mathbf{1 1 p}$ to enone $\mathbf{1 0}$ yielded $\mathbf{1 5}$ in $89 \%$. The propargyl functionality in $\mathbf{1 5}$ was then converted to the corresponding triazole $12 p$ by reaction with azidotrimethylsilane. ${ }^{65}$ Global deprotection of $\mathbf{1 2 p}$ was readily achieved and gave $\mathbf{3 p}$ in $78 \%$.

The synthesis of the tetrazole 3q (Scheme 6, Table 2) commenced with an alkylation of ( \pm )trans-12a with sodium hydride and bromoacetonitrile to yield nitrile ( \pm )-trans-16 (Scheme 6). Subsequent reaction with sodium azide and triethylammonium chloride converted the nitrile functionality into tetrazole $( \pm)$-trans-17. ${ }^{66}$ At this stage, the enantiomers were separated by chiral preparative HPLC to afford the two optically pure 2,3-trans enantiomers 17-s1 and 17-s2. Hydrogenation over a Pd/C catalyst afforded the free aminetetrazoles 18-s1 
and 18-s2, respectively, in quantitative yields. Each enantiomer was subjected to a global deprotection and decarboxylation under aqueous acidic conditions which afforded a mixture of diastereomers at the $\boldsymbol{\varepsilon}$-position. At this stage, the two diastereomers $\mathbf{3 q}$-s1 and $\mathbf{3 q}$-s2 could be separated on chiral preparative HPLC to afford the two optically active enantiomers. Unfortunately, the diastereomeric mixture 3q-s3-4 could not be separated using the HPLC columns available to us.

\section{Pharmacological Characterization.}

Binding affinities of 3a,c-q were determined at native iGluRs (rat synaptosomes) (Table 2; Figure 2), and recombinant rat homomeric GluK1-3 receptors expressed in sf9 cells (Table 3 ) and at recombinant EAAT1-3 expressed in HEK293 cells in a conventional $\left[{ }^{3} \mathrm{H}\right]$-D-Asp uptake assay (Table 4). Furthermore, functional studies on recombinant NMDA receptors expressed in Xenopus lævis oocytes were carried out using two-electrode voltage-clamp electrophysiology (Table 5).

Extension of the methyl group of $\mathbf{3 b}$ to the corresponding ethyl $\mathbf{3 c}-\mathbf{s} \mathbf{2}$ and $\mathbf{3 c}-\mathbf{s} \mathbf{1}$ resulted in an overall decrease of binding affinity for iGluRs, however not all receptor subtypes were equally affected, resulting in a 7-fold selectivity for GluK3 over GluK1. Extending the alkyl chain further to n-propyl, analogue $\mathbf{3 e}$, and $i$-propyl, analogue $\mathbf{3 f}$, abolishes all affinities for iGluRs. Interestingly, inhibition of the glutamate transporters (EAATs) is restored, with an $i-$ propyl group in the $\varepsilon$-position, making it a selective inhibitor of these transporters. Introduction of a phenyl ring, compound $\mathbf{3 d}$, results in loss of affinity for the iGluRs and inhibitory activity at EAAT1-3. Insertion of a tethering methylene group provides the corresponding racemic benzyl $\mathbf{3 g}$, which then shows affinity for KA receptors, with a selectivity of 9-fold for GluK3 over GluK1. This compound also moderately inhibited EAAT1 and EAAT2, displaying a 10-fold selectivity for these subtypes over EAAT3. Extending the spacer to an ethylene group gives compound $\mathbf{3 h}$, which again shows a decrease in affinity for KA receptors, compared to benzyl analogue $\mathbf{3 g}$.

Introduction of a fluoride atom in to the $\varepsilon$-position of $\mathbf{3 a}$ provides analogue $\mathbf{3 i}$, which was isolated as its two separate diastereomers 3i-d1 and 3i-d2. For both, the binding affinities for the iGluRs were improved, compared to $\mathbf{3 a}$, most prominently reflected in the nanomolar affinity exhibited by 3i-d2 at GluK3. Although the GluK1/GluK3 selectivity ratio for 3i-d1 is slightly higher than for $\mathbf{3 i - d} 2$ ( 7 vs 5), both analogues are interesting as chemical tools as they are completely devoid of inhibitory activity at EAAT1-3.

For the methoxy analogue $\mathbf{3} \mathbf{j}$, only one of the two diastereomers could be isolated, and it proved to be without significant binding affinity for iGluRs or functional activity at EAAT1-3. Analogue $\mathbf{3 k}$ is distinct from the other analogues in the series, as it comprises two $a$-amino acid functionalities. Thus, two generally distinct binding modes can be envisaged. While this speculation was not investigated in further detail herein, $\mathbf{3 k}$ shows midrange micromolar affinity for both AMPA and NMDA receptors as well as the GluK3 subunit.

The two analogues $\mathbf{3 l}$ and $\mathbf{3 m}$ both contain additional carboxylic acid functionalities in the $\varepsilon$-position. While $\mathbf{3 l}$ displays high-nanomolar to mid-micromolar affinity to all iGluRs 
tested, $\mathbf{3 m}$ is a selective albeit weak NMDA receptor ligand $\left(K_{\mathrm{i}}=53 \mu \mathrm{M}\right)$. Both $\mathbf{3 l}$ and $\mathbf{3 m}$ display no functional activity at EAAT1-3. The $2^{\prime}$-hydroxyethyl analogue $\mathbf{3 n}$ is a low affinity ligand with midrange micromolar affinity for native NMDA receptors as well as GluK3. Extending the side chain by a methylene group, alcohol 3o, leads to an inactive compound in all assays tested here.

The diastereomeric mixture of triazole analogue $3 \mathbf{p}$ showed selectivity for native KA receptors as well as for the cloned homomeric GluK1-3 receptors. Most interestingly, upon separation of the two diastereomers, the broad-range KA receptor affinity profile was found to be retained in 3p-d2, while the diastereomer 3p-d1 displays low micromolar binding affinity for the GluK3 subtype $\left(K_{\mathrm{i}}=6.6 \mu \mathrm{M}\right)$ with a GluK1/GluK3 selectivity ratio of 15 and negligible binding affinity for other iGluR subtypes and EAAT1-3. This profile makes it an attractive chemical tool compound for studying the biological role of the GluK3 subtype.

Lastly, the diastereomeric mixture of tetrazole analogue $\mathbf{3 q}$ displays high-nanomolar to midmicromolar affinities for cloned homomeric GluK1-3 receptors. However, this mixture exhibits midnanomolar affinity $\left(K_{\mathrm{i}}=0.21 \mu \mathrm{M}\right)$ for native NMDA receptors, while having no significant binding affinity for the other native iGluRs. Enantiomer 3q-s1 displayed a significant loss in affinity for native NMDA receptors and was not further characterized (Table 5). Enantiomer 3q-s2 retained the affinity for native NMDA receptors, and functional characterization showed this compound to be a low to midrange micromolar antagonist for GluN1/GluN2A-D receptors. A most interesting result was obtained with the diastereomeric mixture 3q-s3-4, which also acted as an antagonist at GluN1/GluN2A-D receptors, showing preference for GluN1/GluN2A receptors $\left(K_{\mathrm{i}}=0.61 \mu \mathrm{M}\right)$ over GluN1/GluN2B-D receptors $\left(K_{\mathrm{i}}=2.7-62 \mu \mathrm{M}\right)$.

\section{CONCLUSION}

In conclusion, two synthetic strategies were taken for the synthesis of the herein reported 2,3-trans proline analogues 3a,b-q. Five analogues, including 3a (CPAA), were prepared by a linear five-step enantioselective strategy from common intermediate enone 4. A more efficient racemic route was developed, and starting from common intermediate enone 10 final compounds were obtained in only two or three steps, in overall yields of up to $87 \%$. Furthermore, this procedure allowed for expedited gram scale synthesis of $( \pm)-3 \mathrm{a}$.

Pharmacological characterization at the iGluRs and EAATs show that the added substituents on the $\mathcal{\varepsilon}$-carbon of $\mathbf{3 a}$ follow a different SAR compared to the 4-substituted Glu analogues and are generally unfavorable, with the following exceptions: (1) Introduction of a triazolyl$\mathrm{CH}_{2}$ - group gave $\mathbf{3 p}$ as a mixture of four stereoisomers, with a pharmacological profile of low-to-mid micromolar affinity for GluK1-3. Diastereomers were separated and notably 3pd1 showed reduced affinity for GluK1,2, i.e., enhanced 15-fold selectivity for GluK3 $\left(K_{\mathrm{i}}=\right.$ $6.6 \mu \mathrm{M}$ ) with no significant affinity for any of the native Glu receptors and EAAT transporters tested. In comparison with other known GluK3-preferring ligands, the general profile of 3p makes it an attractive tool compound for further exploring and understanding of the structural requirements for GluK3 selectivity and studying the biological role of the GluK3 subtype. (2) Exchanging the triazolyl for a tetrazolyl gave $\mathbf{3 q}$, as a mixture of four 
stereoisomers, which displayed selective midrange nanomolar binding affinity at native NMDA receptors over native AMPA and KA receptors. (3) The diastereomeric mixture 3q$\mathbf{s 3 , 4}$ was shown to be an antagonist at the GluN1/GluN2A receptor $\left(K_{\mathrm{i}}=0.61 \mu \mathrm{M}\right)$ with a 4-10-fold preference over GluN1/GluN2B-D, and may serve as a starting point for a fully GluN2A subtype selective antagonist.

\section{METHODS}

\section{Chemistry.}

All reactions involving dry solvents or sensitive agents were performed under a nitrogen atmosphere and glassware was dried prior to use. Commercially available chemicals were used without further purification. Solvents were dried prior to use with an SG water solvent purification system or dried by standard procedures, and reactions were monitored by analytical thin-layer chromatography (TLC, Merck silica gel $60 \mathrm{~F}_{254}$ aluminum sheets). Dry-column vacuum chromatography (DCVC) was carried out using Merck silica gel 60A $(15-40 \mu \mathrm{m}),{ }^{68}$ and flash chromatography was carried out using Merck silica gel 60A (35-70 $\mu \mathrm{m}) .{ }^{1} \mathrm{H}$ NMR spectra were recorded on a $400 \mathrm{MHz}$ Bruker Avance III or $600 \mathrm{MHz}$ Bruker Avance III HD, and ${ }^{13} \mathrm{C}$ NMR spectra were recorded on a $101 \mathrm{MHz}$ Bruker Avance III or $151 \mathrm{MHz}$ Bruker Avance III HD. Chemical shifts are reported in $\delta(\mathrm{ppm})$ relative to the singlet at $\delta=7.26 \mathrm{ppm}$ of $\mathrm{CDCl}_{3}$ and to the singlet at $4.79 \mathrm{ppm}$ of $\mathrm{D}_{2} \mathrm{O}$ for ${ }^{1} \mathrm{H} \mathrm{NMR}$, and to the center line of the triplet at $\delta=77.16 \mathrm{ppm}$ of $\mathrm{CDCl}_{3}$ and to the singlet at $67.19 \mathrm{ppm}$ of 1,4-dioxane used as external reference in $\mathrm{D}_{2} \mathrm{O}$ for ${ }^{13} \mathrm{C}$ NMR. Analytical HPLC was performed using an UltiMate HPLC system consisting of an LPG-3400A pump (1 mL/min), a WPS-3000SL autosampler, and a 3000 Diode Array Detector installed with a Gemini-NX $\mathrm{C} 18(250 \times 4.60 \mathrm{~mm}, 3 \mu \mathrm{m})$ column. Solvent A: $\mathrm{H}_{2} \mathrm{O}+0.1 \%$ TFA; Solvent B: MeCN $\cdot \mathrm{H}_{2} \mathrm{O}$ $9: 1+0.1 \%$ TFA. For HPLC control, data collection and data handling, Chromeleon software v. 6.80 was used. Preparative HPLC was carried out on an Ultimate HPLC system with an LPG-3200BX pump, a Rheodyne 9721i injector, a $10 \mathrm{~mL}$ loop, an MWD-3000SD detector $(200,210,225$, and $254 \mathrm{~nm})$, and a Gemini-NX C18 $(250 \times 21.2 \mathrm{~mm}, 5 \mu \mathrm{m})$ column for preparative purifications or a Gemini-NX C18 $(250 \times 10.00 \mathrm{~mm}, 5 \mu \mathrm{m})$ column for semipreparative purifications. Solvent A: $\mathrm{H}_{2} \mathrm{O}+0.1 \%$ TFA; Solvent B: $\mathrm{MeCN}_{-} \mathrm{H}_{2} \mathrm{O} 9: 1$ $+0.1 \%$ TFA. For HPLC control, data collection and data handling, Chromeleon software v. 6.80 was used. Chiral preparative HPLC was performed using the same instrumentation as mentioned above. UPLC-MS spectra were recorded using an Acquity UPLC H-Class Waters series solvent delivery system equipped with an autoinjector coupled to an Acquity QDa and TUV detectors installed with an Acquity UPLCBECH C18 $(50 \times 2.1 \mathrm{~mm}, 1.7 \mu \mathrm{m})$ column. Solvent A: $\mathrm{MeCN}-\mathrm{H}_{2} \mathrm{O} 95: 5+0.1 \% \mathrm{HCO}_{2} \mathrm{H}$; Solvent B: $\mathrm{MeCN}+0.1 \% \mathrm{HCO}_{2} \mathrm{H}$. For data collection and data handling, MassLynx software was used. Optical rotations were determined in a thermostated cuvette on an Anton Paar MCP300 Modular Circular Polarimeter. Compounds were dried under high vacuum or freeze-dried using a ScanVac Cool Safe Freeze Drier. The purity of compounds submitted for pharmacological characterization was determined by ${ }^{1} \mathrm{H}$ NMR and HPLC to be $>95 \%$.

General Procedure I.-NaH (60\% in mineral oil) (1.0 equiv) was suspended in THF (4 $\mathrm{mL}$ ), to which was added dropwise the corresponding malonate (2.5 equiv) and stirred for 15 
min at rt. Enone 10, which was prepared according to literature procedure, starting from proline ${ }^{64}$ was dissolved in THF $(2 \mathrm{~mL})$ and added dropwise to the reaction. The reaction was heated to $50{ }^{\circ} \mathrm{C}$ and stirred for 3-24 h. The crude was extracted with EtOAc, and the combined organic fractions were washed with brine and dried over $\mathrm{MgSO}_{4}$. The crude was purified by DCVC or flash chromatography.

General Procedure II.-12e-p (mixture of trans enantiomers) was suspended in excess 6 $\mathrm{M} \mathrm{HCl}_{(\text {aq. }}$ and stirred under reflux for 4-9 days. The excess of $\mathrm{HCl}$ and $\mathrm{H}_{2} \mathrm{O}$ was evaporated under reduced pressure to give a residue which was dissolved in water or DMSO $(2 \mathrm{~mL})$ and without any further purification submitted to preparative HPLC. The isolated fractions were treated with $3 \times 1 \mathrm{M} \mathrm{HCl}_{(\mathrm{aq} .)}$, and the volatiles were evaporated under reduced pressure. The final product was freeze-dried to afford the mixture of trans diastereomers.

(2S,3R)-tert-Butyl 2-(((tert-Butyldimethylsilyl)oxy)methyl)-5-oxo-3vinylpyrrolidine-1-carboxylate (6a).-Vinyl bromide (1.0 M in THF) (14.05 mL, 14.05 mmol, 2.3 equiv) was dissolved in dry THF $(26 \mathrm{~mL})$. The solution was cooled to $-78^{\circ} \mathrm{C}$. $t$ Butyllithium (1.7 M in THF) (17.39 mL, $28.70 \mathrm{mmol}, 4.7$ equiv) was added dropwise, and the reaction was stirred for $30 \mathrm{~min}$ at $-78^{\circ} \mathrm{C}$. A suspension of $\mathrm{CuCN}$ (656 mg, $7.33 \mathrm{mmol}$, 1.2 equiv) in dry THF (10 mL) was added dropwise, and the reaction mixture was stirred at $-42{ }^{\circ} \mathrm{C}$ for $15 \mathrm{~min}$. The reaction mixture was cooled to $-78{ }^{\circ} \mathrm{C}$, and a solution of $4(2.0 \mathrm{~g}$, $6.11 \mathrm{mmol}, 1$ equiv) in dry THF (24 mL) was added dropwise, followed by chlorotrimethylsilane $(1.78 \mathrm{~mL}, 14.05 \mathrm{mmol}, 2.3$ equiv). The reaction mixture was stirred at $-42{ }^{\circ} \mathrm{C}$ for $1 \mathrm{~h}$ and was quenched with sat. $\mathrm{NH}_{4} \mathrm{Cl}(20 \mathrm{~mL})$. Brine $(40 \mathrm{~mL})$ was added, and the product was extracted with EtOAc $(4 \times 40 \mathrm{~mL})$. The organic layers were combined, washed with brine $(60 \mathrm{~mL})$, and dried over $\mathrm{Na}_{2} \mathrm{SO}_{4}$. The crude product was purified by DCVC $(0 \rightarrow 10 \%$ EtOAc in heptane), which afforded the product as a colorless oil (1.41 g, $3.97 \mathrm{mmol}, 65 \%)$. LCMS (ESI) $\mathrm{m} / z=356.2[\mathrm{M}+\mathrm{H}]^{+} ; R_{\mathrm{f}}=0.45$ (3:1 heptane/EtOAc); $[a]^{25} 589=-37.3^{\circ}(c=0.31, \mathrm{EtOH}) ;{ }^{1} \mathrm{H} \mathrm{NMR}\left(300 \mathrm{MHz}, \mathrm{CDCl}_{3}\right) \delta 5.91-5.78(\mathrm{~m}, 1 \mathrm{H}), 5.11$ $(\mathrm{dt}, J=17.10,1.10 \mathrm{~Hz}, 1 \mathrm{H}), 5.08(\mathrm{dt}, J=10.20,0.80 \mathrm{~Hz}, 1 \mathrm{H}), 3.94(\mathrm{dd}, J=10.45,3.85,1 \mathrm{H})$, 3.90-3.86 (m, 1 H), 3.72 (dd, $J=10.18,1.93 \mathrm{~Hz}, 1 \mathrm{H}), 2.97-2.84(\mathrm{~m}, 2 \mathrm{H}), 2.32-2.19(\mathrm{~m}$, $1 \mathrm{H}), 1.52(\mathrm{~s}, 9 \mathrm{H}), 0.87(\mathrm{~s}, 9 \mathrm{H}), 0.05(\mathrm{~s}, 3 \mathrm{H}) 0.03(\mathrm{~s}, 3 \mathrm{H}) ;{ }^{13} \mathrm{C} \mathrm{NMR}\left(75 \mathrm{MHz}, \mathrm{CDCl}_{3}\right) \delta$ 173.6, 149.7, 139.1, 114.8, 82.8, 64.4, 63.3, 38.1, 37.1, 28.0, 25.8, 18.2, 5.5.

tert-Butyl (2S,3R)-3-(But-1-en-2-yl)-2-(((tert-butyldimethylsilyl)oxy)methyl)-5oxopyrrolidine-1-carboxylate (6c).-2-Bromobut-1-ene (1.89 g, $14.05 \mathrm{mmol}, 2.3$ equiv) was dissolved in dry THF $(40 \mathrm{~mL})$. The solution was cooled to $-78{ }^{\circ} \mathrm{C}$. tertButyllithium (1.45 M in THF) (19.79 mL, $28.70 \mathrm{mmol}, 4.7$ equiv) was added dropwise, and the reaction was stirred for $30 \mathrm{~min}$ at $-78^{\circ} \mathrm{C}$. A suspension of $\mathrm{CuCN}$ (656 mg, $7.33 \mathrm{mmol}$, 1.2 equiv) in dry THF (10 mL) was added dropwise, and the reaction mixture was stirred at $-42{ }^{\circ} \mathrm{C}$ for $15 \mathrm{~min}$. The reaction mixture was cooled to $-78^{\circ} \mathrm{C}$, and a solution of $4(2.0 \mathrm{~g}$, $6.11 \mathrm{mmol}, 1$ equiv) in dry THF (25 mL) was added dropwise, followed by chlorotrimethylsilane $(1.78 \mathrm{~mL}, 14.05 \mathrm{mmol}, 2.3$ equiv). The reaction mixture was warmed to $-42{ }^{\circ} \mathrm{C}$ and stirred for $1 \mathrm{~h}$. The reaction mixture was quenched with sat. $\mathrm{NH}_{4} \mathrm{Cl}(40 \mathrm{~mL})$. Brine $(80 \mathrm{~mL})$ was added, and the product was extracted with EtOAc $(4 \times 80 \mathrm{~mL})$. The 
organic layers were combined, washed with brine $(60 \mathrm{~mL})$, and dried over $\mathrm{MgSO}_{4}$. The crude product was purified by DCVC $(0 \rightarrow 4 \%$ EtOAc in heptane $)$, which afforded the product as a colorless oil (1.43 g, $3.73 \mathrm{mmol}, 61 \%$ ). LCMS (ESI) $\mathrm{m} / z=384.3[\mathrm{M}+\mathrm{H}]^{+} ; R_{\mathrm{f}}$ $=0.52$ (3:1 heptane $/ \mathrm{EtOAc}) ;[a]^{25} 589=-45.4^{\circ}(c=0.41, \mathrm{EtOH}) ;{ }^{1} \mathrm{H} \mathrm{NMR}(400 \mathrm{MHz}$, $\left.\mathrm{CDCl}_{3}\right) \delta 4.82(\mathrm{t}, J=1.38 \mathrm{~Hz}, 1 \mathrm{H}), 4.81(\mathrm{~s}, 1 \mathrm{H}), 3.96(\mathrm{ddd}, J=4.20,2.40,1.50 \mathrm{~Hz}, 1 \mathrm{H})$, $3.90(\mathrm{dd}, J=10.30,4.30 \mathrm{~Hz}, 1 \mathrm{H}), 3.73(\mathrm{dd}, J=10.29,2.26 \mathrm{~Hz}, 1 \mathrm{H}), 2.93(\mathrm{dd}, J=17.30$, $9.54 \mathrm{~Hz}, 1 \mathrm{H}), 2.83(\mathrm{~d}, J=9.50 \mathrm{~Hz}, 1 \mathrm{H}), 2.34(\mathrm{dd}, J=17.32,1.51 \mathrm{~Hz}, 1 \mathrm{H}), 2.05(\operatorname{ttq}, J=$ 15.50, 15.50, 8.80, 8.80, 1.30, 1.30, $1.30 \mathrm{~Hz}, 2 \mathrm{H}), 1.54$ (s, 9H), 1.07 (t, $J=7.40 \mathrm{~Hz}, 3 \mathrm{H}$ ), 0.89 (s, 9H), 0.06 (s, 3H), 0.05 (s, 3H); $\left.{ }^{13} \mathrm{C} \mathrm{NMR} \mathrm{(100} \mathrm{MHz,} \mathrm{CDCl}_{3}\right) \delta 174.1,152.0,150.1$, $108.0,82.8,64.0,63.9,38.8,38.0,28.1,27.0,25.8,18.2,12.1,-5.5$.

\section{tert-Butyl (2S,3R)-2-(((tert-Butyldimethylsilyl)oxy)methyl)-5-oxo-3-(1-} phenylvinyl)pyrrolidine-1-carboxylate (6d).- $a$-Bromostyrene $(2.57 \mathrm{~g}, 14.05 \mathrm{mmol}$, 2.3 equiv) was dissolved in dry THF $(40 \mathrm{~mL})$. The solution was cooled to $-78{ }^{\circ} \mathrm{C}$. $t$ Butyllithium (1.45 M in THF) (19.79 mL, $28.70 \mathrm{mmol}$, 4.7 equiv) was added dropwise, and the reaction was stirred for $30 \mathrm{~min}$ at $-78^{\circ} \mathrm{C}$. A suspension of $\mathrm{CuCN}(656 \mathrm{mg}, 7.33 \mathrm{mmol}$, 1.2 equiv) in dry THF $(10 \mathrm{~mL})$ was added dropwise, and the reaction was stirred at $-42{ }^{\circ} \mathrm{C}$ for $15 \mathrm{~min}$. The reaction mixture was cooled to $-78{ }^{\circ} \mathrm{C}$, and a solution of $4(2.0 \mathrm{~g}, 6.11$ mmol, 1 equiv) in dry THF $(25 \mathrm{~mL})$ was added dropwise, followed by chlorotrimethylsilane (1.78 mL, $14.05 \mathrm{mmol}, 2.3$ equiv). The reaction mixture was warmed to $-42^{\circ} \mathrm{C}$ and stirred for $1 \mathrm{~h}$. The reaction mixture was quenched with sat. $\mathrm{NH}_{4} \mathrm{Cl}(40 \mathrm{~mL})$. Brine $(80 \mathrm{~mL})$ was added, and the product was extracted with EtOAc $(4 \times 80 \mathrm{~mL})$. The organic layers were combined, washed with brine $(60 \mathrm{~mL})$, and dried over $\mathrm{MgSO}_{4}$. The crude product was purified by DCVC $(0 \rightarrow 4 \%$ EtOAc in heptane), which yielded the product as a colorless oil (2.16 g, $5.01 \mathrm{mmol}, 82 \%)$. LCMS (ESI) $\mathrm{m} / z=432.3[\mathrm{M}+\mathrm{H}]^{+} ; R_{\mathrm{f}}=0.48$ (3:1 heptane/ EtOAc); ${ }^{1} \mathrm{H}$ NMR (400 MHz, $\left.\mathrm{CDCl}_{3}\right) \delta 7.41-7.27(\mathrm{~m}, 5 \mathrm{H}), 5.36(\mathrm{~s}, 1 \mathrm{H}), 5.11(\mathrm{~d}, \mathrm{~J}=1.0 \mathrm{~Hz}$, $1 \mathrm{H}), 4.10-4.06(\mathrm{~m}, 1 \mathrm{H}), 3.91(\mathrm{dd}, \mathrm{J}=10.5,4.5 \mathrm{~Hz}, 1 \mathrm{H}), 3.75(\mathrm{dd}, \mathrm{J}=10.5,2.4 \mathrm{~Hz}, 1 \mathrm{H})$, $3.42(\mathrm{dd}, \mathrm{J}=9.0,1.2 \mathrm{~Hz}, 1 \mathrm{H}), 3.05(\mathrm{dd}, \mathrm{J}=17.7,9.2 \mathrm{~Hz}, 1 \mathrm{H}), 2.46(\mathrm{dd}, \mathrm{J}=17.6,1.6 \mathrm{~Hz}$, 1H), $1.51(\mathrm{~s}, 9 \mathrm{H}), 0.89(\mathrm{~s}, 8 \mathrm{H}), 0.05(\mathrm{~s}, 3 \mathrm{H}), 0.05(\mathrm{~s}, 3 \mathrm{H}) ;{ }^{13} \mathrm{C} \mathrm{NMR}\left(100 \mathrm{MHz}, \mathrm{CDCl}_{3}\right) \delta$ $173.9,150.2,150.0,140.7,128.7,128.1,126.7,112.3,83.1,64.1,64.1,38.4,37.4,28.2$, $26.0,18.4,-5.4$.

(2S,3R)-tert-Butyl 2-(((tert-Butyldimethylsilyl)oxy)methyl)-3-(2hydroxyethyl)pyrrolidine-1-carboxylate (7a).-6a (600 mg, $1.69 \mathrm{mmol}, 1$ equiv) was dissolved in dry THF ( $25 \mathrm{~mL}$ ). $\mathrm{BH}_{3}$-THF complex (1 M in THF) (10.12 mL, $10.12 \mathrm{mmol}, 6$ equiv) was added dropwise, and the reaction was stirred for $4 \mathrm{~h}$ under reflux. The reaction was allowed to cool down to $\mathrm{rt}$, THF $(20 \mathrm{~mL})$ was added, and the reaction was cooled to $0{ }^{\circ} \mathrm{C} . \mathrm{H}_{2} \mathrm{O}(1.2 \mathrm{~mL})$ was added carefully, followed by dropwise addition of $2 \mathrm{M} \mathrm{NaOH}_{(\mathrm{aq} .)}$ (24 mL, $48 \mathrm{mmol}, 28.40$ equiv) and $\mathrm{H}_{2} \mathrm{O}_{2}$ in $\mathrm{H}_{2} \mathrm{O}(30 \% \mathrm{w} / \mathrm{w})(4.8 \mathrm{~mL}, 47.0 \mathrm{mmol}, 28$ equiv). The reaction was stirred vigorously for $1 \mathrm{~h}$ at $\mathrm{rt}$, it was quenched with sat. $\mathrm{NaHCO}_{3}$ solution $(42 \mathrm{~mL})$, and then it was stirred for an additional $30 \mathrm{~min}$. The product was extracted with $\mathrm{Et}_{2} \mathrm{O} / \mathrm{THF}$ 1:1 $(3 \times 50 \mathrm{~mL})$, and the combined organic layers were washed with brine $(120 \mathrm{~mL})$ and dried over $\mathrm{MgSO}_{4}$. The crude product was purified by DCVC $(0 \rightarrow 30 \%$ EtOAc in heptane), which afforded the product as a colorless oil (315 mg, $0.88 \mathrm{mmol}, 52 \%)$. LCMS (ESI) $m / z=260.3[\mathrm{M}+\mathrm{H}]^{+} ; R_{\mathrm{f}}=0.58(2: 1 \mathrm{EtOAc} /$ heptane $) ;[a]^{25}{ }_{589}=-37.7^{\circ}(c=$ 
0.26, EtOH); ${ }^{1} \mathrm{H}$ NMR $\left(300 \mathrm{MHz}, \mathrm{CDCl}_{3}\right) \delta 5.01(\mathrm{~d}, J=7.43 \mathrm{~Hz}, 1 \mathrm{H}), 3.83-3.50(\mathrm{~m}, 5 \mathrm{H})$, 3.25 (ddd, $J=11.00,8.66,6.74 \mathrm{~Hz}, 1 \mathrm{H}), 2.11-1.90(\mathrm{~m}, 2 \mathrm{H}), 1.90-1.71(\mathrm{~m}, 2 \mathrm{H}), 1.71-1.53$ (m, 1H), $1.49(\mathrm{~s}, 9 \mathrm{H}) ;{ }^{13} \mathrm{C} \mathrm{NMR}\left(75 \mathrm{MHz}, \mathrm{CDCl}_{3}\right) \delta 154.3,79.4,63.3,61.2,46.1,38.1$, $36.8,30.2,28.6,25.9,18.3,-3.5,-5.3$.

tert-Butyl (2S,3R)-2-(((tert-Butyldimethylsilyl)oxy)methyl)-3-((S)-1hydroxybutan-2-yl)pyrrolidine-1-carboxylate (7c-s1).-6c (1.85 g, $4.82 \mathrm{mmol}, 1$ equiv) was dissolved in dry THF (75 mL). $\mathrm{BH}_{3}$-THF complex ( $1 \mathrm{M}$ in THF) $(24.1 \mathrm{~mL}, 24.1$ mmol, 5 equiv) was added dropwise, and the reaction was stirred for $20 \mathrm{~h}$ at rt. The reaction was cooled to $0{ }^{\circ} \mathrm{C}$, and THF $(37 \mathrm{~mL})$ was added. $\mathrm{H}_{2} \mathrm{O}(3.7 \mathrm{~mL})$ was added carefully, followed by dropwise addition of $2 \mathrm{M} \mathrm{NaOH}\left(72.3 \mathrm{~mL}, 144.68 \mathrm{mmol}, 30\right.$ equiv) and $\mathrm{H}_{2} \mathrm{O}_{2}$ in $\mathrm{H}_{2} \mathrm{O}(30 \% \mathrm{w} / \mathrm{w})(13.72 \mathrm{~mL}, 135.04 \mathrm{mmol}, 28$ equiv). The reaction was stirred vigorously for $1 \mathrm{~h}$ at rt, it was quenched with sat. $\mathrm{NaHCO}_{3}$ solution $(150 \mathrm{~mL})$, and then it was stirred for an additional $1 \mathrm{~h}$. The product was extracted with EtOAc $(3 \times 150 \mathrm{~mL})$, and the combined organic layers were washed with brine $(200 \mathrm{~mL})$ and dried over $\mathrm{MgSO}_{4}$. The diastereomers were separated and purified by DCVC $(10 \rightarrow 22 \%$ EtOAc in heptane), which afforded the product as a colorless oil (515 mg, $1.33 \mathrm{mmol}, 28 \%$ ). LCMS (ESI) $\mathrm{m} / \mathrm{z}=388.3$ $[\mathrm{M}+\mathrm{H}]^{+} ; R_{\mathrm{f}}=0.61(2: 1 \mathrm{EtOAc} / \mathrm{heptane}) ;[a]^{25} 589=-32.3^{\circ}(c=1.035, \mathrm{EtOH}) ;{ }^{1} \mathrm{H} \mathrm{NMR}$ (400 MHz, $\left.\mathrm{CDCl}_{3}\right) \delta 3.71$ (br s, 2H), 3.68-3.49 (m, 3H), 3.48-3.39 (m, 1H), 3.26-3.15 (m, $1 \mathrm{H}), 2.46(\mathrm{br} \mathrm{s}, 1 \mathrm{H}), 2.05-1.94(\mathrm{~m}, 2 \mathrm{H}), 1.74-1.59(\mathrm{~m}, 1 \mathrm{H}), 1.45(\mathrm{~s}, 9 \mathrm{H}), 1.42-1.27(\mathrm{~m}$, 2H), 0.92 (t, $J=7.30 \mathrm{~Hz}, 4 \mathrm{H}), 0.89$ (s, 9H), 0.05 (br s, 6H); ${ }^{13} \mathrm{C} \mathrm{NMR} \mathrm{(100} \mathrm{MHz,} \mathrm{CDCl}_{3}$ ) (rotamers in brackets) $\delta 154.2,79.4$ [79.0], 64.4 [63.4], 63.3 [63.1], 60.7, [60.4], 46.6 [45.9], 44.9 [44.8], 41.7 [40.2], 28.5, 27.5 [26.6], 25.9, 21.0 [20.7], 18.3, 11.9 [11.7], -5.5.

\section{tert-Butyl (2S,3R)-2-(((tert-Butyldimethylsilyl)oxy)methyl)-3-((R)-1-} hydroxybutan-2-yl)pyrrolidine-1-carboxylate (7c-s2).-From the same reaction as 7c-s1 which afforded the product as a colorless oil (524 mg, $1.35 \mathrm{mmol}, 28 \%)$. LCMS (ESI) $\mathrm{m} / \mathrm{z}=388.3[\mathrm{M}+\mathrm{H}]^{+} ; R_{\mathrm{f}}=0.65(2: 1 \mathrm{EtOAc} / \mathrm{heptane}) ;[a]^{25} 589=-35.1^{\circ}(c=0.75, \mathrm{EtOH}) ;$ ${ }^{1} \mathrm{H}$ NMR $\left(400 \mathrm{MHz}, \mathrm{CDCl}_{3}\right) \delta 3.79(\mathrm{dd}, J=9.30,3.50 \mathrm{~Hz}, 1 \mathrm{H}), 3.76-3.66(\mathrm{~m}, 2 \mathrm{H}), 3.62$ (dd, $J=11.50,4.00 \mathrm{~Hz}, 1 \mathrm{H}), 3.59-3.50(\mathrm{~m}, 1 \mathrm{H}), 3.50-3.38(\mathrm{~m}, 1 \mathrm{H}), 3.19(\mathrm{dd}, J=17.60$, $7.30 \mathrm{~Hz}, 1 \mathrm{H}$ ), 2.30 (br s, 1H), 1.99 (dtd, $J=13.40,7.40,7.40,5.90 \mathrm{~Hz}, 1 \mathrm{H}), 1.71-1.59$ (m, $1 \mathrm{H}), 1.46(\mathrm{~s}, 9 \mathrm{H}), 1.44-1.36(\mathrm{~m}, 2 \mathrm{H}), 1.35-1.27(\mathrm{~m}, 1 \mathrm{H}), 0.93(\mathrm{t}, J=7.40 \mathrm{~Hz}, 3 \mathrm{H}), 0.90$ (s, $9 \mathrm{H}), 0.07(\mathrm{~s}, 6 \mathrm{H}) ;{ }^{13} \mathrm{C} \mathrm{NMR}\left(100 \mathrm{MHz}, \mathrm{CDCl}_{3}\right.$ ) (rotamers in brackets) $\delta 154.2,79.5$ [79.1], 64.8 [63.7], 62.5, 61.1 [61.0], 46.2 [45.5], 45.1 [44.9], 42.6 [41.0], 28.5, 27.9 [27.3], 25.9, $21.4[21.4], 18.3,11.7,-5.5$.

\section{tert-Butyl (2S,3R)-2-(((tert-Butyldimethylsilyl)oxy)methyl)-3-((S)-2-hydroxy-1-} phenylethyl)pyrrolidine-1-carboxylate (7d-s2).-6d (4.21 g, $9.75 \mathrm{mmol}, 1$ equiv) was dissolved in dry THF $(160 \mathrm{~mL})$. $\mathrm{BH}_{3}-\mathrm{THF}$ complex (1 M in THF) $(48.8 \mathrm{~mL}, 48.8 \mathrm{mmol}, 5$ equiv) was added dropwise, and the reaction was stirred for $20 \mathrm{~h}$ at rt. The reaction was cooled to $0{ }^{\circ} \mathrm{C}$, and THF $(55 \mathrm{~mL})$ was added. $\mathrm{H}_{2} \mathrm{O}(7.6 \mathrm{~mL})$ was added carefully, followed by dropwise addition of $2 \mathrm{M} \mathrm{NaOH}_{\text {(aq.) }}\left(146 \mathrm{~mL}, 292.61 \mathrm{mmol}, 30\right.$ equiv) and $\mathrm{H}_{2} \mathrm{O}_{2}$ in $\mathrm{H}_{2} \mathrm{O}$ $(30 \% \mathrm{w} / \mathrm{w})(27.9 \mathrm{~mL}, 273.10 \mathrm{mmol}, 28$ equiv). The reaction was stirred vigorously for $1 \mathrm{~h}$ at rt, it was quenched with sat. $\mathrm{NaHCO}_{3}$ solution $(320 \mathrm{~mL})$, and it was stirred for an additional hour. The product was extracted with EtOAc $(3 \times 150 \mathrm{~mL})$, and the combined organic layers 
were washed with brine $(200 \mathrm{~mL})$ and dried over $\mathrm{MgSO}_{4}$. The diastereomers were separated and purified by DCVC $(10 \rightarrow 26 \%$ EtOAc in heptane), which afforded the product as a colorless oil (723 mg, $1.66 \mathrm{mmol}, 17 \%)$. LCMS (ESI) $\mathrm{m} / z=436.3[\mathrm{M}+\mathrm{H}]^{+} ; R_{\mathrm{f}}=0.68(1: 1$ EtOAc/heptane); $[a]^{25}{ }_{589}=-35.1^{\circ}(c=0.75, \mathrm{EtOH}) ; 1 \mathrm{H} \mathrm{NMR}\left(400 \mathrm{MHz}, \mathrm{CDCl}_{3}\right) \delta$ 7.37-7.27 (m, 2H), 7.26-7.19 (m, 3H), 3.96-3.79 (m, 4H), 3.68-3.40 (m, 1H), 3.31 (dt, $J=$ $8.64,35.37 \mathrm{~Hz}, 1 \mathrm{H}), 3.22-3.09(\mathrm{~m}, 1 \mathrm{H}), 2.68(\mathrm{dt}, J=5.54,11.06 \mathrm{~Hz}, 1 \mathrm{H}), 2.65-2.54(\mathrm{~m}$, $1 \mathrm{H}), 2.18-1.91(\mathrm{~m}, 1 \mathrm{H}), 1.77$ (q, $J=7.06,7.50,14.04 \mathrm{~Hz}, 1 \mathrm{H}), 1.47$ (d, $J=12.55 \mathrm{~Hz}, 9 \mathrm{H})$, $1.39-1.30(\mathrm{~m}, 1 \mathrm{H}), 0.93(\mathrm{~s}, 9 \mathrm{H}), 0.10(\mathrm{~s}, 6 \mathrm{H}) .{ }^{13} \mathrm{C} \mathrm{NMR}\left(101 \mathrm{MHz}, \mathrm{CDCl}_{3}\right) \delta 154.5,128.9$, $128.8,128.6,127.1,62.2,51.2,28.7,26.1,25.9,21.2,18.5,14.3,14.2,-5.2$.

(2S,3R)-tert-Butyl 3-(2-Hydroxyethyl)-2-(hydroxymethyl)-pyrrolidine-1carboxylate (8a).-7a (440 mg, $1.23 \mathrm{mmol}, 1$ equiv) was dissolved in dry THF (12 mL), and TBAF (1 M in THF) (2.09 mL, $2.09 \mathrm{mmol}, 1.7$ equiv) was added dropwise. The reaction was stirred for $1 \mathrm{~h}$ at $\mathrm{rt}$. The reaction was quenched with sat. $\mathrm{NaHCO}_{3}(6 \mathrm{~mL})$, and $\mathrm{H}_{2} \mathrm{O}(6$ $\mathrm{mL})$ was added. The aqueous phase was extracted with EtOAc $(3 \times 30 \mathrm{~mL})$. The combined organic fractions were washed with brine $(100 \mathrm{~mL})$ and dried over $\mathrm{MgSO}_{4}$. The crude product was purified by DCVC (100\% EtOAc), which afforded the product as a colorless oil (253 mg, $1.03 \mathrm{mmol}, 84 \%$ ). LCMS (ESI) $\mathrm{m} / z=246.2[\mathrm{M}+\mathrm{H}]^{+} ; R_{\mathrm{f}}=0.21$ (100\% EtOAc); $[a]^{25}{ }_{589}=-38.4^{\circ}(c=0.19, \mathrm{EtOH}) ;{ }^{1} \mathrm{H}$ NMR $\left(300 \mathrm{MHz}, \mathrm{CDCl}_{3}\right) \delta 5.01(\mathrm{~d}, J=7.43 \mathrm{~Hz}$, $1 \mathrm{H}), 3.83-3.50(\mathrm{~m}, 5 \mathrm{H}), 3.25$ (ddd, $J=11.00,8.66,6.74 \mathrm{~Hz}, 1 \mathrm{H}), 2.11-1.90(\mathrm{~m}, 2 \mathrm{H})$, $1.90-1.71(\mathrm{~m}, 2 \mathrm{H}), 1.71-1.53(\mathrm{~m}, 1 \mathrm{H}), 1.49(\mathrm{~s}, 9 \mathrm{H}) ;{ }^{13} \mathrm{C} \mathrm{NMR}\left(100 \mathrm{MHz}, \mathrm{CDCl}_{3}\right) \delta 156.8$, $80.3,66.7,65.6,60.9,46.5,38.2,36.1,30.2,28.4$

tert-Butyl (2S,3R)-3-((S)-1-Hydroxybutan-2-yl)-2-(hydroxymethyl)pyrrolidine-1carboxylate (8c-s1).-7c-s1 (533 mg, $1.38 \mathrm{mmol}, 1$ equiv) was dissolved in dry THF (15 $\mathrm{mL}$ ), and TBAF ( $1 \mathrm{M}$ in THF) ( $2.52 \mathrm{~mL}, 2.34 \mathrm{mmol}, 1.7$ equiv) was added dropwise. The reaction was stirred for $1 \mathrm{~h}$ at $\mathrm{rt}$. The reaction was quenched with sat. $\mathrm{NaHCO}_{3}(8 \mathrm{~mL})$, and $\mathrm{H}_{2} \mathrm{O}(8 \mathrm{~mL})$ was added. The aqueous phase was extracted with EtOAc $(3 \times 40 \mathrm{~mL})$, and the combined organic fractions were washed with brine $(75 \mathrm{~mL})$ and dried over $\mathrm{MgSO}_{4}$. The crude product was purified by DCVC $(80 \rightarrow 94 \%$ EtOAc in heptane), which yielded the product as a colorless oil (303 $\mathrm{mg}, 1.11 \mathrm{mmol}, 80 \%$ ). LCMS (ESI) $\mathrm{m} / z=274.2[\mathrm{M}+\mathrm{H}]^{+}$; $R_{\mathrm{f}}=0.30$ (2:1 EtOAc/heptane); $[a]^{25} 589=-93.0^{\circ}(c=0.115, \mathrm{EtOH}) ;{ }^{1} \mathrm{H} \mathrm{NMR}(400 \mathrm{MHz}$, $\left.\mathrm{CDCl}_{3}\right) \delta 4.82(\mathrm{br} \mathrm{s}, 1 \mathrm{H}) 3.89-3.76(\mathrm{~m}, 1 \mathrm{H}) 3.72-3.51(\mathrm{~m}, 5 \mathrm{H}) 3.19$ (ddd, $J=11.00,8.50$, $7.03 \mathrm{~Hz}, 1 \mathrm{H}) 2.12(\mathrm{br} \mathrm{s}, 1 \mathrm{H}) 2.02-1.81(\mathrm{~m}, 2 \mathrm{H}) 1.65(\mathrm{ddd}, J=16.60,12.30,8.30 \mathrm{~Hz}, 1 \mathrm{H})$ $1.54-1.33(\mathrm{~m}, 12 \mathrm{H}) 0.94(\mathrm{t}, J=7.50 \mathrm{~Hz}, 3 \mathrm{H}) ;{ }^{13} \mathrm{C} \mathrm{NMR}\left(100 \mathrm{MHz}, \mathrm{CDCl}_{3}\right) \delta 156.8,80.3$, $67.6,63.0,62.5,46.4,44.1,42.3,28.5,27.4,22.2,11.8$.

tert-Butyl (2S,3R)-3-((R)-1-Hydroxybutan-2-yl)-2-(hydroxymethyl)pyrrolidine-1carboxylate (8c-s2).-7c-s2 (575.7 mg, $1.49 \mathrm{mmol}, 1$ equiv) was dissolved in dry THF $(15 \mathrm{~mL})$, and TBAF (1 M in THF) (2.52 mL, $2.52 \mathrm{mmol}, 1.7$ equiv) was added dropwise. The reaction was stirred for $1 \mathrm{~h}$ at rt. The reaction was quenched with sat. $\mathrm{NaHCO}_{3}(8 \mathrm{~mL})$, and $\mathrm{H}_{2} \mathrm{O}(8 \mathrm{~mL})$ was added. The aqueous phase was extracted with EtOAc $(3 \times 40 \mathrm{~mL})$. The combined organic fractions were washed with brine $(75 \mathrm{~mL})$ and dried over $\mathrm{MgSO}_{4}$. The crude product was purified by DCVC $(84 \rightarrow 92 \%$ EtOAc in heptane), which afforded the product as a colorless oil (328 $\mathrm{mg}, 1.20 \mathrm{mmol}, 81 \%$ ). LCMS (ESI) $\mathrm{m} / z=274.2[\mathrm{M}+\mathrm{H}]^{+}$; 
$R_{\mathrm{f}}=0.42(100 \% \mathrm{EtOAc}) ;[a]^{25}{ }_{589}=-26.2^{\circ}(c=0.625, \mathrm{EtOH}) ;{ }^{1} \mathrm{H} \mathrm{NMR}\left(400 \mathrm{MHz}, \mathrm{CDCl}_{3}\right)$ $\delta 4.82$ (br s, 1H), 3.82-3.52 (m, 6H), 3.17 (ddd, $J=11.04,9.41,6.65 \mathrm{~Hz}, 1 \mathrm{H}), 2.18-1.96$ $(\mathrm{m}, 2 \mathrm{H}), 1.96-1.68(\mathrm{~m}, 2 \mathrm{H}), 1.66-1.51(\mathrm{~m}, 1 \mathrm{H}), 1.47(\mathrm{~s}, 9 \mathrm{H}), 1.45-1.39(\mathrm{~m}, 1 \mathrm{H}), 1.38-1.24$ $(\mathrm{m}, 1 \mathrm{H}), 0.95(t, J=7.28 \mathrm{~Hz}, 3 \mathrm{H}) ;{ }^{13} \mathrm{C}$ NMR $\left(100 \mathrm{MHz}, \mathrm{CDCl}_{3}\right) \delta 156.6,80.2,67.2,63.0$, $62.8,46.4,44.3,42.2,28.4,27.3,20.5,11.9$.

\section{tert-Butyl (2S,3R)-3-((R)-2-Hydroxy-1-phenylethyl)-2-} (hydroxymethyl)pyrrolidine-1-carboxylate (8d-s1).-The compound 8d-s1 was obtained as a side-product from the synthesis of $\mathbf{7 d - s} \mathbf{2}$. After isolation of $\mathbf{7 d - s} \mathbf{2}$ by DCVC, the remaining fractions were combined and submitted to preparative HPLC, which afforded 8d-s1 as a colorless oil (157 mg, $0.49 \mathrm{mmol}, 5 \%)$. LCMS (ESI) $\mathrm{m} / \mathrm{Z}=322.2[\mathrm{M}+\mathrm{H}]^{+} ;{ }^{1} \mathrm{H}$ NMR (400 MHz, $\left.\mathrm{CDCl}_{3}\right) \delta 7.35-7.24(\mathrm{~m}, 3 \mathrm{H}), 7.21-7.13(\mathrm{~m}, 2 \mathrm{H}), 3.92-3.75(\mathrm{~m}, 2 \mathrm{H})$, 3.75-3.65 (m, 1H), 3.42-3.09 (m, 4H), 2.84-2.67 (m, 1H), 2.30-2.15 (m, 1H), 2.15-1.96 $(\mathrm{m}, 1 \mathrm{H}), 1.74(\mathrm{dp}, J=7.4,13.9 \mathrm{~Hz}, 1 \mathrm{H}), 1.40(\mathrm{~s}, 9 \mathrm{H}) ;{ }^{13} \mathrm{C} \mathrm{NMR}\left(101 \mathrm{MHz}, \mathrm{CDCl}_{3}\right) \delta$ 156.6, 140.6, 129.0, 128.5, 127.5, 80.4, 66.3, 64.9, 62.9, 51.4, 46.2, 43.0, 29.5, 28.5.

\section{tert-Butyl (2S, 3R)-3-((S)-2-Hydroxy-1-phenylethyl)-2-} (hydroxymethyl)pyrrolidine-1-carboxylate (8d-s2).-7d-s2 (700 mg, $1.61 \mathrm{mmol}, 1$ equiv) was dissolved in dry THF (20 mL), and TBAF (1 M in THF) $(2.73 \mathrm{~mL}, 2.72 \mathrm{mmol}$, 1.7 equiv) was added dropwise. The reaction was stirred for $1 \mathrm{~h}$ at $\mathrm{rt}$. The reaction was quenched with sat. $\mathrm{NaHCO}_{3}(10 \mathrm{~mL})$, and $\mathrm{H}_{2} \mathrm{O}(8 \mathrm{~mL})$ was added. The aqueous phase was extracted with EtOAc $(3 \times 50 \mathrm{~mL})$. The combined organic fractions were washed with brine $(100 \mathrm{~mL})$ and dried over $\mathrm{MgSO}_{4}$. The crude product was purified by DCVC $(54 \rightarrow 70 \%$ EtOAc in heptane), which afforded the product as a colorless oil (290 mg, $0.90 \mathrm{mmol}, 56 \%)$. LCMS (ESI) $\mathrm{m} / z=322.2[\mathrm{M}+\mathrm{H}]^{+} ; R_{\mathrm{f}}=0.26\left(1: 1\right.$ EtOAc/heptane); ${ }^{1} \mathrm{H}$ NMR $(400 \mathrm{MHz}$, $\left.\mathrm{CDCl}_{3}\right) \delta 7.35-7.29(\mathrm{~m}, 2 \mathrm{H}), 7.27-7.19(\mathrm{~m}, 3 \mathrm{H}), 3.96-3.83(\mathrm{~m}, 3 \mathrm{H}), 3.79-3.67(\mathrm{~m}, 2 \mathrm{H})$, 3.37 (br. s, $1 \mathrm{H}$ ), 3.14 (dt, $J=7.2,11$. Hz, 1H), 2.74 (br. s, 1H), 2.32 (br. s, 1H), 1.70 (dq, $J=$ $6.8,13.0 \mathrm{~Hz}, 1 \mathrm{H}), 1.45$ (s, 9H), 1.36 (dq, $J=7.2,14.2 \mathrm{~Hz}, 1 \mathrm{H}) ;{ }^{13} \mathrm{C} \mathrm{NMR}(101 \mathrm{MHz}$, $\left.\mathrm{CDCl}_{3}\right) \delta 156.5,141.0,128.8,128.7,127.1,80.4,66.7,65.6,63.4,51.0,45.8,42.8,28.4$, 14.3.

(2S,3R)-1-(tert-Butoxycarbonyl)-3-(carboxymethyl)pyrrolidine-2-carboxylic Acid (9a).-8a (275 mg, $1.12 \mathrm{mmol}, 1.0$ equiv) was dissolved in EtOAc (9.3 mL), and $\mathrm{MeCN}(9.3 \mathrm{~mL})$ was added. $\mathrm{NaIO}_{4}\left(1960 \mathrm{mg}, 9.19 \mathrm{mmol}, 8.2\right.$ equiv) was suspended in $\mathrm{H}_{2} \mathrm{O}$ ( $8.5 \mathrm{~mL}$ ), followed by addition of $\mathrm{RuCl}_{3} \cdot \mathrm{H}_{2} \mathrm{O}$ ( $4.65 \mathrm{mg}, 0.02 \mathrm{mmol}, 0.02$ equiv). The aqueous phase was transferred to the organic phase, and $\mathrm{H}_{2} \mathrm{O}(4 \mathrm{~mL})$ was added. The reaction was vigorously stirred for $4 \mathrm{~h}$ at rt. The reaction mixture was filtered through Celite, and the residue was washed with EtOAc $(30 \mathrm{~mL})$. The layers were separated, and the aqueous phase was extracted with EtOAc $(3 \times 30 \mathrm{~mL})$. The organic fractions were combined, washed with brine $(75 \mathrm{~mL})$, and dried over $\mathrm{MgSO}_{4}$. The crude product was purified by DCVC $(10 \rightarrow 50 \%$ EtOAc in heptane $\% \mathrm{AcOH})$. All fractions were combined and evaporated. The residue was dissolved in a minimum volume of warm EtOAc (approximately $1.5 \mathrm{~mL}$ ). Heptane (approximately $7 \mathrm{~mL}$ ) was added until the solution stayed turbid, and the mixture was placed at $5{ }^{\circ} \mathrm{C}$ overnight, which afforded a crystalline white solid (228 mg, $0.83 \mathrm{mmol}, 75 \%)$; LCMS (ESI) $\mathrm{m} / \mathrm{z}=274.1[\mathrm{M}+\mathrm{H}]^{+} ;{ }^{1} \mathrm{H} \mathrm{NMR}(300 \mathrm{MHz}$, 
$\left.\mathrm{CDCl}_{3}\right) \delta 10.21$ (br. s, 2H), $4.01(\mathrm{dd}, J=50.90,6.30 \mathrm{~Hz}, 1 \mathrm{H}), 3.71-3.39(\mathrm{~m}, 2 \mathrm{H}), 2.92-2.64$ $(\mathrm{m}, 2 \mathrm{H}), 2.51(\mathrm{dt}, J=15.75,7.67 \mathrm{~Hz}, 1 \mathrm{H}), 2.24(\mathrm{dq}, J=11.86,6.04 \mathrm{~Hz}, 1 \mathrm{H}), 1.78-1.59(\mathrm{~m}$, $1 \mathrm{H}), 1.47(\mathrm{~d}, J=15.68 \mathrm{~Hz}, 9 \mathrm{H}) ;{ }^{13} \mathrm{C}$ NMR $\left(100 \mathrm{MHz}, \mathrm{CDCl}_{3}\right) \delta 176.2,153.8,80.8,64.1$, $45.9,40.7,38.9,37.3,30.3,28.2$.

(2S,3R)-1-(tert-Butoxycarbonyl)-3-((S)-1-carboxypropyl)-pyrrolidine-2carboxylic Acid (9c-s1).-8c-s1 (325 mg, 1.19 mmol, 1.0 equiv) was dissolved in EtOAc $(10.0 \mathrm{~mL})$, and $\mathrm{MeCN}(10.0 \mathrm{~mL})$ was added. $\mathrm{NaIO}_{4}(2085 \mathrm{mg}, 9.75 \mathrm{mmol}, 8.2$ equiv) was suspended in $\mathrm{H}_{2} \mathrm{O}(9.0 \mathrm{~mL})$, followed by the addition of $\mathrm{RuCl}_{3} \cdot \mathrm{H}_{2} \mathrm{O}(4.93 \mathrm{mg}, 0.02 \mathrm{mmol}$, 0.02 equiv). The aqueous phase was transferred to the organic phase, and $\mathrm{H}_{2} \mathrm{O}(4.3 \mathrm{~mL})$ was added. The reaction was vigorously stirred for $7 \mathrm{~h}$ at $\mathrm{rt}$. The reaction mixture was filtered through Celite, and the residue was washed with EtOAc $(35 \mathrm{~mL})$. The layers were separated, and the aqueous phase was extracted with EtOAc $(3 \times 25 \mathrm{~mL})$. The organic fractions were combined, washed with brine $(75 \mathrm{~mL})$, and dried over $\mathrm{MgSO}_{4}$. The crude product was purified by DCVC ( $34 \rightarrow 50 \%$ EtOAc in heptane $+1 \% \mathrm{AcOH}$ ), which afforded the product as a white solid $(110 \mathrm{mg})$. The impure fractions were combined and together crystallized in minimum volume of warm EtOAc (approximately $1 \mathrm{~mL}$ ). Heptane (approximately $6 \mathrm{~mL}$ ) was added until the solution stayed turbid, and the mixture was placed at $5{ }^{\circ} \mathrm{C}$ and was left overnight, which afforded additional product as a crystalline white solid $(27 \mathrm{mg})$. This was combined with the already obtained product (138 mg, $0.46 \mathrm{mmol} 38 \%$ ). LCMS (ESI) $\mathrm{m} / \mathrm{z}=$ $302.1[\mathrm{M}+\mathrm{H}]^{+}$; mp: $133.7-135.3^{\circ} \mathrm{C}$ (decomposition); $[a]^{25}{ }_{589}=+5.1^{\circ}(c=0.33, \mathrm{EtOH})$; ${ }^{1} \mathrm{H} \mathrm{NMR}\left(400 \mathrm{MHz}, \mathrm{CDCl}_{3}\right.$ ) (rotamers in brackets) $\delta 11.21$ (br s, $\left.2 \mathrm{H}\right), 4.22[4.08]$ (d, $J=$ $5.27 \mathrm{~Hz}, 1 \mathrm{H}), 3.66-3.37(\mathrm{~m}, 2 \mathrm{H}), 2.71-2.54(\mathrm{~m}, 1 \mathrm{H}), 2.53-2.37(\mathrm{~m}, 1 \mathrm{H}), 2.17-2.06(\mathrm{~m}$, $1 \mathrm{H}), 1.85-1.68(\mathrm{~m}, 3 \mathrm{H}), 1.47$ [1.42] (s, 9H), $0.98(\mathrm{t}, J=7.28 \mathrm{~Hz}, 3 \mathrm{H}) ;{ }^{13} \mathrm{C} \mathrm{NMR}(100 \mathrm{MHz}$, $\mathrm{CDCl}_{3}$ ) (rotamers in brackets) $\delta 179.5$ [179.4], 178.6 [175.8], 155.7 [153.8], 81.4 [80.9], 62.0, 49.3 [49.2], 45.9 [45.7], 45.3 [44.0], 28.4, 28.2, 23.8 [23.4], 11.8 [11.7].

\section{(2S,3R)-1-(tert-Butoxycarbonyl)-3-((R)-1-carboxypropyl)-pyrrolidine-2-}

carboxylic Acid (9c-s2).-8c-s2 (325 mg, 1.19 mmol, 1.0 equiv) was dissolved in EtOAc $(10.0 \mathrm{~mL})$, and $\mathrm{MeCN}(10.0 \mathrm{~mL})$ was added. $\mathrm{NaIO}_{4}(2085 \mathrm{mg}, 9.75 \mathrm{mmol}, 8.2$ equiv) was suspended in $\mathrm{H}_{2} \mathrm{O}\left(9.0 \mathrm{~mL}\right.$ ), followed by the addition of $\mathrm{RuCl}_{3} \cdot \mathrm{H}_{2} \mathrm{O}(4.93 \mathrm{mg}, 0.02 \mathrm{mmol}$, 0.02 equiv). The aqueous phase was transferred to the organic phase, and $\mathrm{H}_{2} \mathrm{O}(4.3 \mathrm{~mL}$ ) was added. The reaction was vigorously stirred for $7 \mathrm{~h}$ at $\mathrm{rt}$. The reaction mixture was filtered through Celite, and the residue was washed with EtOAc $(35 \mathrm{~mL})$. The layers were separated, and the aqueous phase was extracted with EtOAc $(3 \times 25 \mathrm{~mL})$. The organic fractions were combined, washed with brine $(75 \mathrm{~mL})$, and dried over $\mathrm{MgSO}_{4}$. The crude product was purified by DCVC $(34 \rightarrow 50 \%$ EtOAc in heptane $+1 \% \mathrm{AcOH})$, which afforded the product as a white solid $(110 \mathrm{mg}, 31 \%)$. The impure fractions were combined and together crystallized in minimum volume of warm EtOAc (approximately $1 \mathrm{~mL}$ ). Heptane (approximately $6 \mathrm{~mL}$ ) was added until the solution stayed turbid, and the mixture was placed at $5{ }^{\circ} \mathrm{C}$ and was left overnight, which afforded the product as a white solid $(27 \mathrm{mg})$. This was combined with the already obtained product (138 mg, $0.46 \mathrm{mmol}, 38 \%)$. LCMS (ESI) $\mathrm{m} / \mathrm{z}=302.1[\mathrm{M}+\mathrm{H}]^{+} ; \mathrm{mp}: 128.0-129.4{ }^{\circ} \mathrm{C}$ (decomposition); $[a]^{25}{ }_{589}=-3.0^{\circ}(c=0.32$, $\mathrm{EtOH}) ; 1 \mathrm{H} \mathrm{NMR}\left(400 \mathrm{MHz}, \mathrm{CDCl}_{3}\right.$ ) (rotamers in brackets) $\delta 9.21$ (br s, 2H), 4.14 [3.93] (d, $J=7.53 \mathrm{~Hz}, 1 \mathrm{H}), 3.70-3.62[3.59-3.51](\mathrm{m}, 1 \mathrm{H}), 3.47-3.33(\mathrm{~m}, 1 \mathrm{H}), 2.74-2.59(\mathrm{~m}, 1 \mathrm{H})$, 
2.42-2.29 (m, 1H), 2.18-2.06 (m, 1H), 1.79-1.55 (m, 3H), 1.45 [1.41] (s, 9H) 0.97 (t, $J=$ $7.28 \mathrm{~Hz}, 3 \mathrm{H}) ;{ }^{13} \mathrm{C} \mathrm{NMR}\left(100 \mathrm{MHz}, \mathrm{CDCl}_{3}\right.$ ) (rotamers in brackets) $\delta 179.7$ [179.4], 178.0 [176.1], 155.0 [153.7], 81.1 [81.0], 63.7 [63.2], 50.2, 46.0 [45.8], 45.5 [44.5], 28.4, 28.2, 23.6 [23.4], 11.5 [11.4].

(2S,3R)-1-(tert-Butoxycarbonyl)-3-((R)-Carboxy(phenyl)methyl)-pyrrolidine-2carboxylic Acid (9d-s1).-8d-s1 (130 mg, $0.40 \mathrm{mmol}, 1.0$ equiv) was dissolved in EtOAc (3.4 mL), and MeCN (3.4 mL) was added. $\mathrm{NaIO}_{4}$ (709 mg, $3.32 \mathrm{mmol}, 8.2$ equiv) was suspended in $\mathrm{H}_{2} \mathrm{O}(3.0 \mathrm{~mL})$, followed by the addition of $\mathrm{RuCl}_{3} \cdot \mathrm{H}_{2} \mathrm{O}(1.68 \mathrm{mg}, 0.02$ mmol, 0.01 equiv). The aqueous phase was transferred to the organic phase, and $\mathrm{H}_{2} \mathrm{O}$ (1.5 $\mathrm{mL}$ ) was added. The reaction was vigorously stirred for $4 \mathrm{~h}$ at $\mathrm{rt}$. The reaction mixture was filtered through Celite, and the residue was washed with EtOAc $(10 \mathrm{~mL})$. The layers were separated, and the aqueous phase was extracted with EtOAc $(3 \times 10 \mathrm{~mL})$. The organic fractions were combined, washed with brine $(25 \mathrm{~mL})$, and dried over $\mathrm{MgSO}_{4}$. The crude product was purified by DCVC $(40 \rightarrow 55 \%$ EtOAc in heptane $+1 \% \mathrm{AcOH})$, which afforded the product as a white solid. The product was crystallized in minimum volume of warm $\mathrm{POH}$ (approximately $4 \mathrm{~mL}$ ). $\mathrm{H}_{2} \mathrm{O}$ (approximately $1 \mathrm{~mL}$ ) was added until the solution stayed turbid, and the mixture was placed at $\mathrm{rt}$ and was left overnight, which afforded the product as a crystalline white solid (32 $\mathrm{mg}, 0.09 \mathrm{mmol}, 23 \%$ ). LCMS (ESI) $\mathrm{m} / z=350.2[\mathrm{M}$ $+\mathrm{H}]^{+} ;{ }_{1}^{1} \mathrm{H}$ NMR (400 MHz, acetone) $\delta 7.43-7.38(\mathrm{~m}, 2 \mathrm{H}), 7.38-7.32(\mathrm{~m}, 2 \mathrm{H}), 7.32-7.27$ (m, $1 \mathrm{H}), 3.86(\mathrm{dd}, J=2.3,36.8 \mathrm{~Hz}, 1 \mathrm{H}), 3.60(\mathrm{dd}, J=6.6,11.2 \mathrm{~Hz}, 1 \mathrm{H}), 3.57-3.47(\mathrm{~m}, 2 \mathrm{H})$, 3.10 (ddd, $J=3.0,6.6,10.9 \mathrm{~Hz}, 1 \mathrm{H}), 2.29-2.13(\mathrm{~m}, 1 \mathrm{H}), 1.93-1.79(\mathrm{~m}, 1 \mathrm{H}), 1.37$ (d, $J=$ $43.6 \mathrm{~Hz}, 9 \mathrm{H})$.

(2S,3R)-1-(tert-Butoxycarbonyl)-3-((S)-carboxy(phenyl)methyl)-pyrrolidine-2carboxylic Acid (9d-s2).-8d-s2 (290 $\mathrm{mg}, 0.90 \mathrm{mmol}, 1.0$ equiv) was dissolved in EtOAc (7.6 mL), and $\mathrm{MeCN}(7.6 \mathrm{~mL})$ was added. $\mathrm{NaIO}_{4}(1583 \mathrm{mg}, 7.40 \mathrm{mmol}, 8.2$ equiv) was suspended in $\mathrm{H}_{2} \mathrm{O}(6.8 \mathrm{~mL})$, followed by the addition of $\mathrm{RuCl}_{3} \cdot \mathrm{H}_{2} \mathrm{O}(3.74 \mathrm{mg}, 0.02$ mmol, 0.02 equiv). The aqueous phase was transferred to the organic phase, and $\mathrm{H}_{2} \mathrm{O}$ (3.3 $\mathrm{mL}$ ) was added. The reaction was vigorously stirred for $4 \mathrm{~h}$ at $\mathrm{rt}$. The reaction mixture was filtered through Celite, and the residue was washed with EtOAc $(20 \mathrm{~mL})$. The layers were separated, and the aqueous phase was extracted with EtOAc $(3 \times 15 \mathrm{~mL})$. The organic fractions were combined, washed with brine $(50 \mathrm{~mL})$, and dried over $\mathrm{MgSO}_{4}$. The crude product was purified by DCVC $(40 \rightarrow 55 \%$ EtOAc in heptane $+1 \% \mathrm{AcOH})$, which afforded the product as a white solid (129 $\mathrm{mg}, 0.37 \mathrm{mmol}, 41 \%$ ). LCMS (ESI) $\mathrm{m} / z=350.2$ $[\mathrm{M}+\mathrm{H}]^{+} ; 1 \mathrm{H}$ NMR (400 MHz, acetone) $\delta 11.13$ (br. s, 2H)7.47-7.41 (m, 2H), 7.41-7.35 (m, 2H), 7.35-7.29 (m, 1H), $4.11(\mathrm{dd}, J=3.6,28.2 \mathrm{~Hz}, 1 \mathrm{H}), 3.68(\mathrm{dd}, J=4.0,10.6 \mathrm{~Hz}, 1 \mathrm{H})$, $3.49-3.32(\mathrm{~m}, 2 \mathrm{H}), 3.14-3.03(\mathrm{~m}, 1 \mathrm{H}), 1.85$ (ddq, $J=7.5,12.7,25.3 \mathrm{~Hz}, 1 \mathrm{H}), 1.45-1.36(\mathrm{~m}$, $10 \mathrm{H})$.

(2S,3R)-3-(Carboxymethyl)pyrrolidine-2-carboxylic Acid Hydrochloride (3a).9a (205 mg, $0.75 \mathrm{mmol}, 1$ equiv) was dissolved in DCM (25 mL), and TFA ( $25 \mathrm{~mL})$ was added dropwise. The reaction was stirred for $2 \mathrm{~h}$. The solvents were removed under reduced pressure. The crude was dissolved in $1 \mathrm{M} \mathrm{HCl}_{(\mathrm{aq} .)}(3 \times 30 \mathrm{~mL})$, and the solvent was evaporated. The crude was purified by preparative HPLC. The combined fractions were 
evaporated and redissolved in $1 \mathrm{M} \mathrm{HCl}_{(\mathrm{aq} .)}(3 \times 30 \mathrm{~mL})$, and the solvent was evaporated. The final compound was freeze-dried, which afforded the product as a hygroscopic solid (21 $\mathrm{mg}, 0.10 \mathrm{mmol}, 13 \%)$. LCMS (ESI) $\mathrm{m} / z=174.1[\mathrm{M}+\mathrm{H}]^{+} ;[a]^{25}{ }_{589}=+18.3^{\circ}(c=0.61$, $\left.\mathrm{H}_{2} \mathrm{O}\right) ;{ }^{1} \mathrm{H}$ NMR $\left(300 \mathrm{MHz}, \mathrm{D}_{2} \mathrm{O}\right) \delta 3.81(\mathrm{~d}, J=7.70 \mathrm{~Hz}, 1 \mathrm{H}), 3.50-3.34(\mathrm{~m}, 2 \mathrm{H}), 2.85(\mathrm{dd}, J$ $=15.70,4.70 \mathrm{~Hz}, 1 \mathrm{H}), 2.79-2.64(\mathrm{~m}, 1 \mathrm{H}), 2.54(\mathrm{dd}, J=15.70,8.80 \mathrm{~Hz}, 1 \mathrm{H}), 2.38-2.25(\mathrm{~m}$, $1 \mathrm{H}), 1.81(\mathrm{dq}, J=13.34,8.30 \mathrm{~Hz}, 1 \mathrm{H}) ;{ }^{13} \mathrm{C}$ NMR $\left(100 \mathrm{MHz}, \mathrm{D}_{2} \mathrm{O}\right) \delta 177.1,174.0,65.4$, $45.5,39.9,38.1,30.5$.

(2S,3R)-3-((S)-1-Carboxypropyl)pyrrolidine-2-carboxylic Acid Hydrochloride (3c-s1).-9c-s1 (105 mg, $0.34 \mathrm{mmol}, 1$ equiv) was dissolved in DCM $(6.8 \mathrm{~mL})$, and the solution was cooled to $0{ }^{\circ} \mathrm{C}$. TFA $(6.8 \mathrm{~mL})$ was added dropwise, and the reaction was allowed to warm to $\mathrm{rt}$ and stirred for $2 \mathrm{~h}$. The solvents were removed under reduced pressure. The crude was purified by preparative HPLC. The purified compound was dissolved in $1 \mathrm{M} \mathrm{HCl}$ in $\mathrm{H}_{2} \mathrm{O}(3 \times 30 \mathrm{~mL})$, and solvent was evaporated. The final compound was freeze-dried, which afforded the product as a white solid (38 $\mathrm{mg}, 0.16 \mathrm{mmol}, 47 \%)$. LCMS (ESI) $\mathrm{m} / z=202.1[\mathrm{M}+\mathrm{H}]^{+}$; mp: $184.1-188.7^{\circ} \mathrm{C}$ (decomposition); $[a]^{25}{ }_{589}=$ $+18.3^{\circ}\left(c=0.57, \mathrm{H}_{2} \mathrm{O}\right) ;{ }^{1} \mathrm{H}$ NMR $\left(300 \mathrm{MHz}, \mathrm{D}_{2} \mathrm{O}\right) \delta 4.31(\mathrm{~d}, J=7.28 \mathrm{~Hz}, 1 \mathrm{H}), 3.50(\mathrm{ddd}, J$ $=11.92,7.40,4.77 \mathrm{~Hz}, 1 \mathrm{H}), 3.40(\mathrm{ddd}, J=11.50,8.80,7.00 \mathrm{~Hz}, 1 \mathrm{H}$ ), 2.82 (quin, $J=7.65$ $\mathrm{Hz}, 1 \mathrm{H}), 2.69$ (dd, $J=14.30,7.50 \mathrm{~Hz}, 1 \mathrm{H}), 2.34-2.24(\mathrm{~m}, 1 \mathrm{H}), 1.93(\mathrm{dq}, J=13.55,8.28 \mathrm{~Hz}$, $1 \mathrm{H}), 1.78-1.68(\mathrm{~m}, 2 \mathrm{H}), 0.95(\mathrm{t}, J=7.40 \mathrm{~Hz}, 3 \mathrm{H}) ;{ }^{13} \mathrm{C} \mathrm{NMR}\left(100 \mathrm{MHz}, \mathrm{D}_{2} \mathrm{O}\right) \delta 178.5$, $171.9,62.0,49.3,46.2,44.0,28.0,24.2,11.6$.

(2S,3R)-3-((R)-1-Carboxypropyl)pyrrolidine-2-carboxylic Acid Hydrochloride (3c-s2).—9c-s2 (89 mg, $0.29 \mathrm{mmol}, 1$ equiv) was dissolved in DCM $(5.8 \mathrm{~mL})$, and the solution was cooled to $0{ }^{\circ} \mathrm{C}$. TFA $(5.8 \mathrm{~mL})$ was added dropwise, and the reaction was allowed to warm to $\mathrm{rt}$ and stirred for $2 \mathrm{~h}$. The solvents were removed under reduced pressure. The crude was purified by preparative HPLC. The combined fractions were evaporated and redissolved in $1 \mathrm{M} \mathrm{HCl}(3 \times 30 \mathrm{~mL})$, and the solvent was evaporated. The final compound was freeze-dried, which afforded the product as a white solid (27 mg, 0.11 mmol, 39\%). LCMS (ESI) $\mathrm{m} / z=202.1[\mathrm{M}+\mathrm{H}]^{+}$; mp: 68.7-71.2 ${ }^{\circ} \mathrm{C}$ (decomposition); $[a]^{25}{ }_{589}=+12.9^{\circ}\left(c=0.23, \mathrm{H}_{2} \mathrm{O}\right) ;{ }^{1} \mathrm{H}$ NMR $\left(300 \mathrm{MHz}, \mathrm{D}_{2} \mathrm{O}\right) \delta 4.24(\mathrm{~d}, J=7.28 \mathrm{~Hz}, 1 \mathrm{H})$, 3.51 (ddd, $J=11.73,7.84,4.02 \mathrm{~Hz}, 1 \mathrm{H}), 3.39$ (ddd, $J=11.54,9.91,7.15 \mathrm{~Hz}, 1 \mathrm{H}$ ), 2.82 (quin, $J=8.09 \mathrm{~Hz}, 1 \mathrm{H}), 2.57$ (td, $J=9.16,4.27 \mathrm{~Hz}, 1 \mathrm{H}), 2.42-2.28(\mathrm{~m}, 1 \mathrm{H}), 1.90$ (dtd, $J=$ $13.50,9.00,9.00,8.20 \mathrm{~Hz}, 1 \mathrm{H}), 1.80-1.56(\mathrm{~m}, 2 \mathrm{H}), 0.94(\mathrm{t}, J=7.40 \mathrm{~Hz}, 3 \mathrm{H}) ;{ }^{13} \mathrm{C}$ NMR (100 MHz, $\left.\mathrm{D}_{2} \mathrm{O}\right) \delta 179.0,171.8,62.6,49.9,46.1,44.3,28.6,23.5,11.3$.

\section{(2S,3R)-3-((R)-Carboxy(phenyl)methyl)pyrrolidine-2-carboxylic Acid}

Hydrochloride (3d-s1).-9d-s1 (25 mg, 0.07 mmol, 1 equiv) was dissolved in DCM (1.4 $\mathrm{mL})$, and the solution was cooled to $0{ }^{\circ} \mathrm{C}$. TFA $(1.4 \mathrm{~mL})$ was added dropwise, and the reaction was allowed to warm to $\mathrm{rt}$ and stirred for $2 \mathrm{~h}$. The solvents were removed under reduced pressure. The crude was purified by preparative HPLC. The combined fractions were evaporated and redissolved in $1 \mathrm{M} \mathrm{HCl}(3 \times 30 \mathrm{~mL})$, and the solvent was evaporated. The final compound was freeze-dried, which afforded the product as a white solid (12 $\mathrm{mg}$, $0.04 \mathrm{mmol}, 60 \%)$. LCMS (ESI) $\mathrm{m} / z=250.1[\mathrm{M}+\mathrm{H}]^{+} ;{ }^{1} \mathrm{H} \mathrm{NMR}\left(600 \mathrm{MHz}, \mathrm{D}_{2} \mathrm{O}\right) \delta$ $7.49-7.42(\mathrm{~m}, 5 \mathrm{H}), 3.96(\mathrm{~d}, J=5.4 \mathrm{~Hz}, 1 \mathrm{H}), 3.88(\mathrm{~d}, J=10.1 \mathrm{~Hz}, 1 \mathrm{H}), 3.53(\mathrm{td}, J=2.8,7.3$ 
$\mathrm{Hz}, 2 \mathrm{H}), 3.34$ (ddt, $J=5.8,7.92,10.5 \mathrm{~Hz}, 1 \mathrm{H}), 2.36(\mathrm{dq}, J=7.6,14.9 \mathrm{~Hz}, 1 \mathrm{H}), 2.08$ (dq, $J=$ $7.1,13.6 \mathrm{~Hz}, 1 \mathrm{H}) ;{ }^{13} \mathrm{C}$ NMR $\left(151 \mathrm{MHz}, \mathrm{D}_{2} \mathrm{O}\right) \delta 175.6,170.8,135.7,129.2,128.8,128.5$, $61.4,53.4,45.3,44.9,28.3$.

(2S,3R)-3-((S)-Carboxy(phenyl)methyl)pyrrolidine-2-carboxylic Acid Hydrochloride (3d-s2).-9d-s2 (25 mg, 0.07 mmol, 1 equiv) was dissolved in DCM (1.4 $\mathrm{mL})$, and the solution was cooled to $0{ }^{\circ} \mathrm{C}$. TFA $(1.4 \mathrm{~mL})$ was added dropwise, and the reaction was allowed to warm to $\mathrm{rt}$ and stirred for $2 \mathrm{~h}$. The solvents were removed under reduced pressure. The crude was purified by preparative HPLC. The combined fractions were evaporated and redissolved in $1 \mathrm{M} \mathrm{HCl}(3 \times 30 \mathrm{~mL})$, and the solvent was evaporated. The final compound was freeze-dried, which afforded the product as a white solid (10 $\mathrm{mg}$, $0.035 \mathrm{mmol}, 50 \%)$. LCMS (ESI) $\mathrm{m} / z=250.1[\mathrm{M}+\mathrm{H}]^{+} ;{ }^{1} \mathrm{H}$ NMR $\left(600 \mathrm{MHz}, \mathrm{D}_{2} \mathrm{O}\right) \delta$ 7.48-7.44 (m, 2H), 7.44-7.40 (m, 3H), $4.18(\mathrm{~d}, J=7.4 \mathrm{~Hz}, 1 \mathrm{H}), 3.93(\mathrm{~d}, J=9.3 \mathrm{~Hz}, 1 \mathrm{H})$, $3.41-3.36$ (m, 2H), 3.32 (p, $J=7.8 \mathrm{~Hz}, 1 \mathrm{H}), 2.03$ (dq, $J=6.8,13.5 \mathrm{~Hz}, 1 \mathrm{H}), 1.69$ (dq, $J=$ 8.4, $13.7 \mathrm{~Hz}, 1 \mathrm{H}) .{ }^{13} \mathrm{C} \mathrm{NMR}\left(151 \mathrm{MHz}, \mathrm{D}_{2} \mathrm{O}\right) \delta 175.9,171.2,135.8,129.2,128.7,128.4$, $62.8,52.9,44.7,44.1,27.4$.

trans-1-Benzyl 2-Methyl 3-(1,3-Dimethoxy-1,3-dioxopropan-2-yl)pyrrolidine-1,2dicarboxylate (12a).-The title compound was prepared according to general procedure I, starting from $10(2.0 \mathrm{~g}, 7.65 \mathrm{mmol})$ and dimethyl malonate $(2.53 \mathrm{~g}, 2.19 \mathrm{~mL}, 19.14 \mathrm{mmol})$, which afforded the title compound as a colorless oil (2.98 g, $7.57 \mathrm{mmol}, 99 \%)$. LCMS (ESI) $\mathrm{m} / \mathrm{z}=394.1[\mathrm{M}+\mathrm{H}]^{+} ; R_{\mathrm{f}}=0.41\left(1: 1\right.$ heptane/EtOAc) $;{ }^{1} \mathrm{H} \mathrm{NMR}\left(600 \mathrm{MHz}, \mathrm{CDCl}_{3}\right) \delta$ $7.38-7.28(\mathrm{~m}, 5 \mathrm{H}), 5.18(\mathrm{dd}, J=12.4,15.5 \mathrm{~Hz}, 1 \mathrm{H}), 5.05(\mathrm{dd}, J=12.4,56.3 \mathrm{~Hz}, 1 \mathrm{H}), 4.24$ (dd, $J=4.8,25.0 \mathrm{~Hz}, 1 \mathrm{H}), 3.77-3.73(\mathrm{~m}, 7.5 \mathrm{H}), 3.69-3.63(\mathrm{~m}, 1 \mathrm{H}), 3.60-3.58(\mathrm{~m}, 1 \mathrm{H}), 3.57$ (s, $1.5 \mathrm{H}), 3.51$ (dd, $J=1.4,8.9 \mathrm{~Hz}, 1 \mathrm{H}), 3.05-2.97(\mathrm{~m}, 1 \mathrm{H}), 2.20$ (tdd, $J=6.4,10.2,12.9$ $\mathrm{Hz}, 1 \mathrm{H}), 1.78(\mathrm{dp}, J=7.0,21.1 \mathrm{~Hz}, 1 \mathrm{H}) ;{ }^{13} \mathrm{C} \mathrm{NMR}\left(151 \mathrm{MHz}, \mathrm{CDCl}_{3}\right)$ (rotamers) $\delta 172.1$, 172.0, 168.0, 168.0, 167.9, 167.9, 154.7, 154.1, 136.5, 136.4, 128.5, 128.4, 128.06, 128.04, $128.00,127.96,127.90,67.24,67.18,62.5,62.1,53.8,53.7,52.85,52.81,52.79,52.5,52.3$, 45.6, 45.1, 43.3, 42.3, 28.2, 27.6 .

trans-1-Benzyl 2-Methyl 3-(1-Ethoxy-2-(ethoxycarbonyl)-1-oxopentan-2yl)pyrrolidine-1,2-dicarboxylate (12e).-The title compound was prepared according to general procedure I, starting from $10(200 \mathrm{mg}, 0.77 \mathrm{mmol})$ and diethyl 2-propylmalonate (387 mg, $0.39 \mathrm{~mL}, 1.91 \mathrm{mmol}$ ), which afforded the title compound as a colorless oil (146 $\mathrm{mg}, 0.31 \mathrm{mmol}, 41 \%)$. LCMS (ESI) $\mathrm{m} / z=464.2[\mathrm{M}+\mathrm{H}]^{+} ; R_{\mathrm{f}}=0.31(2: 1$ heptane/EtOAc); ${ }^{1} \mathrm{H}$ NMR $\left(400 \mathrm{MHz}, \mathrm{CDCl}_{3}\right) \delta 7.39-7.27(\mathrm{~m}, 6 \mathrm{H}), 5.24-4.96(\mathrm{~m}, 2 \mathrm{H}), 4.55$ (dd, J= 3.6, $18.8 \mathrm{~Hz}, 1 \mathrm{H}), 4.26-3.94(\mathrm{~m}, 4 \mathrm{H}), 3.77(\mathrm{~s}, 1.5 \mathrm{H}), 3.58$ (s, $1.5 \mathrm{H}), 3.51$ (ddd, $J=6.4,8.8,10.5$ $\mathrm{Hz}, 2 \mathrm{H}), 3.06-2.93(\mathrm{~m}, 1 \mathrm{H}), 2.30-2.18(\mathrm{~m}, 1 \mathrm{H}), 2.06-1.87$ (m, 3H), 1.28-1.12 (m, 8H), $0.91(\mathrm{t}, J=7.2 \mathrm{~Hz}, 3 \mathrm{H}) ;{ }^{13} \mathrm{C}$ NMR $\left(101 \mathrm{MHz}, \mathrm{CDCl}_{3}\right)$ (rotamers) $\delta 173.4,173.3,170.7$, $170.62,170.57,170.5,154.6,154.2,136.8,136.7,128.7,128.5,128.2,128.1,128.0,127.9$, 67.2, 61.7, 61.6, 61.4, 60.9, 59.9, 59.8, 52.5, 52.3, 46.9, 46.0, 45.7, 45.4, 36.4, 26.5, 25.8, $17.74,17.72,14.5,14.12,14.07,14.05,13.99$.

trans-1-Benzyl 2-Methyl 3-(1-Ethoxy-2-(ethoxycarbonyl)-3-methyl-1oxobutan-2-yl)pyrrolidine-1,2-dicarboxylate (12f).-The title compound was 
prepared according to general procedure I, starting from $10(200 \mathrm{mg}, 0.77 \mathrm{mmol})$ and diethyl 2-isopropylmalonate $(387 \mathrm{mg}, 0.39 \mathrm{~mL}, 1.91 \mathrm{mmol})$, which afforded the title compound as a colorless oil (125 mg, $0.27 \mathrm{mmol}, 35 \%)$. LCMS (ESI) $\mathrm{m} / z=464.2[\mathrm{M}+\mathrm{H}]^{+} ; R_{\mathrm{f}}=0.32(2: 1$ heptane/EtOAc); ${ }^{1} \mathrm{H}$ NMR (400 MHz, $\left.\mathrm{CDCl}_{3}\right) \delta 7.37-7.27(\mathrm{~m}, 5 \mathrm{H}), 5.18(\mathrm{dd}, J=5.9,12.5$ $\mathrm{Hz}, 1 \mathrm{H}), 5.02(\mathrm{dd}, J=12.4,14.2 \mathrm{~Hz}, 1 \mathrm{H}), 4.51(\mathrm{dd}, J=3.4,19.3 \mathrm{~Hz}, 1 \mathrm{H}), 4.26-3.95$ (m, $4 \mathrm{H}), 3.76(\mathrm{~s}, 1.5 \mathrm{H}), 3.58(\mathrm{~s}, 1.5 \mathrm{H}), 3.55-3.38(\mathrm{~m}, 2 \mathrm{H}), 3.25-3.12(\mathrm{~m}, 1 \mathrm{H}), 2.54(\mathrm{dp}, J=6.6$, $10.0 \mathrm{~Hz}, 1 \mathrm{H}), 2.31-2.17(\mathrm{~m}, 1 \mathrm{H}), 2.07-1.90(\mathrm{~m}, 1 \mathrm{H}), 1.31-1.10(\mathrm{~m}, 6 \mathrm{H}), 1.03-0.91(\mathrm{~m}$, $6 \mathrm{H}) .{ }^{13} \mathrm{C} \mathrm{NMR}\left(101 \mathrm{MHz}, \mathrm{CDCl}_{3}\right)$ (rotamers) $\delta 172.9,169.8,169.60,169.57,169.5,154.6$, $154.2,136.8,136.7,128.55,128.49,128.23,128.19,128.12,128.05,67.2,67.1,64.3,64.2$, $61.5,61.5,61.4,61.3,60.8,46.8,46.0,45.7,45.3,31.9,31.8,26.8,26.1,18.9,18.7,18.5$, $18.4514 .3,14.2,14.1,14.0$.

trans-1-Benzyl 2-Methyl 3-(2-Benzyl-1,3-diethoxy-1,3-dioxopropan-2yl)pyrrolidine-1,2-dicarboxylate (12g).-The title compound was prepared according to general procedure I ( $5 \mathrm{~h}$ reaction time), starting from $10(180 \mathrm{mg}, 0.69 \mathrm{mmol})$ and diethyl benzylmalonate $(431 \mathrm{mg}, 0.41 \mathrm{~mL}, 1.72 \mathrm{mmol})$, which afforded the title compound as a colorless oil (210 mg, $0.41 \mathrm{mmol}, 60 \%)$. LCMS (ESI) $\mathrm{m} / \mathrm{z}=512.2[\mathrm{M}+\mathrm{H}]^{+} ; R_{\mathrm{f}}=0.10(8: 2$ heptane/EtOAc); ${ }^{1} \mathrm{H}$ NMR $\left(400 \mathrm{MHz}, \mathrm{CDCl}_{3}\right) \delta 7.37-7.28(\mathrm{~m}, 5 \mathrm{H}), 7.25-7.18(\mathrm{~m}, 3 \mathrm{H})$, 7.12-7.07 (m, 2H), 5.20 (d, $J=12.3 \mathrm{~Hz}, 1 \mathrm{H}), 5.01(\mathrm{~d}, J=12.9 \mathrm{~Hz}, 1 \mathrm{H}), 4.67$ (br d, $J=21.1$ $\mathrm{Hz}, 1 \mathrm{H}), 4.20-3.79$ (m, 4H), 3.73 (s, 1.5H), 3.57 (s, 1.5H), 3.56-3.41 (m, 2H), $3.32(\mathrm{~s}, 2 \mathrm{H})$, $2.94-2.83(\mathrm{~m}, 1 \mathrm{H}), 2.34-2.11(\mathrm{~m}, 2 \mathrm{H}), 1.17(\mathrm{t}, J=7.2 \mathrm{~Hz}, 3 \mathrm{H}), 1.08(\mathrm{t}, J=7.2 \mathrm{~Hz}, 3 \mathrm{H}) ;{ }^{13} \mathrm{C}$ NMR (101 MHz, $\mathrm{CDCl}_{3}$ ) (rotamers) $\delta 173.2,173.1,170.3,170.2,170.13,170.10,154.5$, 154.2, 136.7, 136.6, 135.4, 130.1, 128.6, 128.54, 128.49, 128.3, 128.2, 128.1, 127.4, 67.2, $61.94,61.89,61.8,61.7,61.4,61.3,61.2,52.5,52.3,46.7,45.9,45.5,45.2,40.0,26.2,25.5$, $14.0,13.9,13.83,13.79$.

trans-1-Benzyl 2-Methyl 3-(1-Ethoxy-2-(ethoxycarbonyl)-1-oxo-4phenylbutan-2-yl)pyrrolidine-1,2-dicarboxylate (12h).-The title compound was prepared according to general procedure I, starting from $\mathbf{1 0}(200 \mathrm{mg}, 0.77 \mathrm{mmol})$ and diethyl 2-phenethylmalonate (506 mg, $1.91 \mathrm{mmol}$ ), which afforded the title compound as a colorless oil (242 mg, $0.46 \mathrm{mmol}, 60 \%$ ). LCMS (ESI) $\mathrm{m} / z=526.3[\mathrm{M}+\mathrm{H}]^{+} ; R_{\mathrm{f}}=0.39$ (2:1 heptane/ EtOAc); 1H NMR (600 MHz, $\left.\mathrm{CDCl}_{3}\right) \delta 7.36-7.26(\mathrm{~m}, 7 \mathrm{H}), 7.22-7.18(\mathrm{~m}, 1 \mathrm{H}), 7.18-7.14$ (m, 2H), 5.23-5.15 (m, 1H), $5.02(\mathrm{dd}, J=12.4,29.2 \mathrm{~Hz}, 1 \mathrm{H}), 4.60(\mathrm{dd}, J=3.5,33.1 \mathrm{~Hz}$, $1 \mathrm{H}), 4.25-4.16(\mathrm{~m}, 2 \mathrm{H}), 4.16-4.00(\mathrm{~m}, 2 \mathrm{H}), 3.77(\mathrm{~s}, 1.5 \mathrm{H}), 3.59(\mathrm{~s}, 1.5 \mathrm{H}), 3.58-3.45(\mathrm{~m}$, $2 \mathrm{H}$ ), 3.09 (ddq, $J=3.8,8.3,12.3 \mathrm{~Hz}, 1 \mathrm{H}), 2.63-2.54(\mathrm{~m}, 1 \mathrm{H}), 2.50-2.43(\mathrm{~m}, 1 \mathrm{H}), 2.32-2.20$ (m, 3H), 2.13-1.99 (m, 1H), 1.28-1.18 (m, 6H); ${ }^{13} \mathrm{C} \mathrm{NMR}\left(151 \mathrm{MHz}, \mathrm{CDCl}_{3}\right.$ ) (rotamers) $\delta$ 173.3, 173.2, 172.7, 170.5, 170.4, 170.32, 170.30, 170.27, 170.25, 170.22, 170.18, 154.59, $154.57,154.23,154.18,141.18,141.15,141.11,136.8,136.71,136.66,128.67,128.65$, $128.62,128.57,128.52,128.51,128.46,128.45,128.20,128.16,128.13,128.10,128.08$, $128.06,126.37,126.35,67.22,67.18,67.16,61.90,61.88,61.86,61.83,61.80,61.78,61.6$, $61.5,61.44,61.41,61.0,60.9,59.9,59.81,59.80,52.6,52.4,47.22,47.14,46.05,46.01$, $45.98,45.4,36.5,36.3,30.89,30.87,26.7,26.6,26.0,25.9,14.3,14.16,14.14,14.12,14.10$, 14.08 . 
trans-1-Benzyl 2-Methyl 3-(2-Fluoro-1,3-dimethoxy-1,3-dioxopropan-2yl)pyrrolidine-1,2-dicarboxylate (12i). -The title compound was prepared according to general procedure I, starting from $\mathbf{1 0}(200 \mathrm{mg}, 0.77 \mathrm{mmol})$ and dimethyl 2-fluoromalonate (287 mg, $1.91 \mathrm{mmol}$ ), which afforded the title compound as a colorless oil (198 mg, 0.48 mmol, 63\%). LCMS (ESI) $m / z=412.1[\mathrm{M}+\mathrm{H}]^{+} ; R_{\mathrm{f}}=0.32\left(2: 1\right.$ heptane/EtOAc); ${ }^{1} \mathrm{H}$ NMR $\left(600 \mathrm{MHz}, \mathrm{CDCl}_{3}\right) \delta 7.37-7.27(\mathrm{~m}, 5 \mathrm{H}), 5.18(\mathrm{dd}, J=12.3,34.5 \mathrm{~Hz}, 1 \mathrm{H}), 5.03(\mathrm{dd}, J=$ $12.4,67.1 \mathrm{~Hz}, 1 \mathrm{H}), 4.37(\mathrm{dd}, J=5.5,40.4 \mathrm{~Hz}, 1 \mathrm{H}), 3.84-3.80(\mathrm{~m}, 6 \mathrm{H}), 3.81-3.72(\mathrm{~m}, 1 \mathrm{H})$, $3.74(\mathrm{~s}, 1.5 \mathrm{H}), 3.57-3.52(\mathrm{~m}, 1 \mathrm{H}), 3.51(\mathrm{~s}, 1.5 \mathrm{H}), 3.39-3.26(\mathrm{~m}, 1 \mathrm{H}), 2.22-2.08(\mathrm{~m}, 1 \mathrm{H})$, 2.03-1.90 (m, 1H); ${ }^{13} \mathrm{C}$ NMR $\left(151 \mathrm{MHz}, \mathrm{CDCl}_{3}\right)$ (rotamers) $\delta 172.1,165.5,165.4,165.33$, $165.31,165.27,165.23,165.16,165.1,154.5,153.9,136.5,136.4,128.6,128.5,128.2$, $128.14,128.07,128.0,95.4,95.1,94.1,93.7,67.4,67.3,59.52,59.50,58.85,58.83,53.84$, $53.81,53.7,52.7,52.4,48.3,48.1,47.1,46.9,46.2,45.8,32.0,26.03,26.01,25.3,25.2$, $22.8,14.3,14.2$.

\section{trans-1-Benzyl 2-Methyl 3-(1,2,3-Trimethoxy-1,3-dioxopropan-2-} yl)pyrrolidine-1,2-dicarboxylate (12j).-The title compound was prepared according to general procedure I ( $24 \mathrm{~h}$ reaction time), starting from $10(135 \mathrm{mg}, 0.52 \mathrm{mmol})$ and dimethyl methoxymalonate $(209 \mathrm{mg}, 0.18 \mathrm{~mL}, 1.29 \mathrm{mmol})$, which afforded the title compound as a colorless oil (149 mg, $0.35 \mathrm{mmol}, 68 \%)$. LCMS (ESI) $\mathrm{m} / z=424.2[\mathrm{M}+\mathrm{H}]^{+} ; R_{\mathrm{f}}=0.40(1: 1$ heptane/EtOAc); ${ }^{1} \mathrm{H}$ NMR (400 MHz, $\mathrm{CDCl}_{3}$ ) (rotamers) $\delta 7.38-7.27(\mathrm{~m}, 5 \mathrm{H}), 5.18(\mathrm{~d}, J=$ $12.5 \mathrm{~Hz}, 1 \mathrm{H}), 5.05(\mathrm{~d}, J=12.5 \mathrm{~Hz}, 1 \mathrm{H}), 4.61$ (br d, $J=23.3,1 \mathrm{H}), 3.77-3.71(4 \mathrm{~s}, 7.5 \mathrm{H})$, 3.61-3.45 (m, 2H), 3.57 (s, 1.5H), 3.48 (br s, 3H), 3.17-3.09 (m, 1H), 2.17-2.05 (m, 2H); ${ }^{13} \mathrm{C}$ NMR $\left(101 \mathrm{MHz}, \mathrm{CDCl}_{3}\right.$ ) (rotamers) $\delta 172.93,172.91,168.3,168.14,168.09,154.6$, 154.2, 136.7, 128.50, 128.47, 128.1, 128.0, 85.3, 85.2, 67.24, 67.21, 60.3, 59.7, 55.4, 53.0, $52.9,52.2,52.80,52.6,52.4,48.9,47.8,46.2,45.7,29.8,26.0,25.2$.

\section{trans-1-Benzyl 2-Methyl 3-(2-((tert-Butoxycarbonyl)amino)-1,3-diethoxy-1,3-} dioxopropan-2-yl)pyrrolidine-1,2-dicarboxylate (12k).-The title compound was prepared according to general procedure I, starting from $10(200 \mathrm{mg}, 0.77 \mathrm{mmol})$ and diethyl 2-((tert-butoxycarbonyl)amino)malonate $(527 \mathrm{mg}, 1.91 \mathrm{mmol})$, which afforded the title compound as a colorless oil (347 mg, $0.65 \mathrm{mmol}, 84 \%$ ). LCMS (ESI) $\mathrm{m} / z=537.2[\mathrm{M}+\mathrm{H}]$ ${ }^{+} ; R_{\mathrm{f}}=0.28\left(2: 1\right.$ heptane/EtOAc); ${ }^{1} \mathrm{H}$ NMR $\left(400 \mathrm{MHz}, \mathrm{CDCl}_{3}\right) \delta 7.35-7.27(\mathrm{~m}, 5 \mathrm{H}), 5.99$ (d, $J=6.17 \mathrm{~Hz}, 1 \mathrm{H}), 5.18(\mathrm{dd}, J=12.3,23.3 \mathrm{~Hz}, 1 \mathrm{H}), 5.00(\mathrm{dd}, J=12.5,47.7 \mathrm{~Hz}, 1 \mathrm{H}), 4.58$ (dd, $J=2.77,22.91 \mathrm{~Hz}, 1 \mathrm{H}), 4.33-4.14(\mathrm{~m}, 3 \mathrm{H}), 4.14-3.99(\mathrm{~m}, 1 \mathrm{H}), 3.73(\mathrm{~s}, 1.5 \mathrm{H}), 3.56(\mathrm{~s}$, 1.5H), 3.59-3.49 (m, 2H), 3.44-3.34 (m, 1H), 2.32-2.18 (m, 1H), 2.12-2.03 (m, 1H), 1.40 (s, 9H), 1.22 (dt, $J=7.10,15.46 \mathrm{~Hz}, 6 \mathrm{H}) ;{ }^{13} \mathrm{C} \mathrm{NMR}\left(101 \mathrm{MHz}, \mathrm{CDCl}_{3}\right.$ ) (rotamers) $\delta 172.8$, 172.7, 167.5, 167.4, 167.3, 167.1, 154.6, 154.3, 154.2, 136.7, 136.7, 128.54, 128.47, 128.08, $128.03,128.00,80.9,80.8,67.2,67.13,67.07,63.1,62.9,62.8,60.9,60.5,52.5,52.3,48.4$, 47.3, 46.3, 45.6, 31.0, 28.23, 28.20, 26.1, 25.2, 14.04, 14.00, 13.90, 13.86.

trans-Triethyl 1-(1-((Benzyloxy)carbonyl)-2-(methoxycarbonyl)-pyrrolidin-3yl)ethane-1,1,2-tricarboxylate (12l).-The title compound was prepared according to general procedure I, starting from $\mathbf{1 0}(200 \mathrm{mg}, 0.77 \mathrm{mmol})$ and triethylethane-1,1,2tricarboxylate $(471 \mathrm{mg}, 0.44 \mathrm{~mL}, 1.91 \mathrm{mmol})$, which afforded the title compound as a colorless oil (285 mg, $0.56 \mathrm{mmol}, 73 \%)$. LCMS (ESI) $\mathrm{m} / \mathrm{z}=508.2[\mathrm{M}+\mathrm{H}]^{+} ; \mathrm{R}_{\mathrm{f}}=0.23(2: 1$ 
heptane/EtOAc); ${ }^{1} \mathrm{H}$ NMR (400 MHz, $\mathrm{CDCl}_{3}$ ) $\delta 7.37-7.27$ (m, 5H), 5.18 (dd, $J=12.41$, $15.72 \mathrm{~Hz}, 1 \mathrm{H}), 5.03(\mathrm{dd}, J=12.44,30.17 \mathrm{~Hz}, 1 \mathrm{H}), 4.60$ (dd, $J=4.21,10.41 \mathrm{~Hz}, 1 \mathrm{H})$, 4.26-4.14 (m, 3H), 4.14-4.03 (m, 3H), $3.74(\mathrm{~s}, 1.5 \mathrm{H}), 3.67-3.59(\mathrm{~m}, 1 \mathrm{H}), 3.55(\mathrm{~s}, 1.5 \mathrm{H})$, 3.54-3.46 (m, 1H), 3.19-3.10 (m, 1H), $3.02(\mathrm{~d}, J=7.95 \mathrm{~Hz}, 2 \mathrm{H}), 2.29-2.17(\mathrm{~m}, 1 \mathrm{H})$, $2.08-1.88(\mathrm{~m}, 1 \mathrm{H}), 1.29-1.13(\mathrm{~m}, 9 \mathrm{H}) ;{ }^{13} \mathrm{C} \mathrm{NMR}\left(101 \mathrm{MHz}, \mathrm{CDCl}_{3}\right) \delta 173,0,170.10$, 170.08, 169.4, 169.3, 154.6, 154.1, 136.7, 136.6, 128.6, 128.5, 128.14, 128.09, 67.2, 62.19, $62.16,61.4,61.0,60.8,57.5,57.49,52.5,52.3,47.4,46.3,46.2,45.6,38.5,38.3,27.1,26.4$, $14.2,14.00,13.98,13.93,13.91$.

trans-1-Benzyl 2-Methyl 3-(4-Cyano-1-ethoxy-2-(ethoxycarbonyl)-1-oxobutan-2yl)pyrrolidine-1,2-dicarboxylate (12m).-The title compound was prepared according to general procedure I, starting from $10(200 \mathrm{mg}, 0.77 \mathrm{mmol})$ and diethyl 2-(2cyanoethyl)malonate ( $408 \mathrm{mg}, 0.38 \mathrm{~mL}, 1.91 \mathrm{mmol})$, which afforded the title compound as a colorless oil (354 mg, $0.74 \mathrm{mmol}$, 97\%). LCMS (ESI) $\mathrm{m} / z=475.2[\mathrm{M}+\mathrm{H}]^{+} ; \mathrm{R}_{\mathrm{f}}=0.39(2: 1$ heptane/EtOAc); ${ }^{1} \mathrm{H}$ NMR (600 MHz, $\left.\mathrm{CDCl}_{3}\right) \delta 7.37-7.28(\mathrm{~m}, 5 \mathrm{H}), 5.19(\mathrm{dd}, J=12.3,16.8$ $\mathrm{Hz}, 1 \mathrm{H}), 5.03$ (dd, $J=12.4,33.4 \mathrm{~Hz}, 1 \mathrm{H}), 4.49$ (dd, $J=3.8,36.7 \mathrm{~Hz}, 1 \mathrm{H}), 4.26-4.05$ (m, $4 \mathrm{H}), 3.77(\mathrm{~s}, 1.5 \mathrm{H}), 3.58(\mathrm{~s}, 1.5 \mathrm{H}), 3.64-3.48(\mathrm{~m}, 2 \mathrm{H}), 2.97-2.89(\mathrm{~m}, 1 \mathrm{H}), 2.54-2.46(\mathrm{~m}$, $1 \mathrm{H}), 2.46-2.39(\mathrm{~m}, 1 \mathrm{H}), 2.33-2.26(\mathrm{~m}, 2 \mathrm{H}), 2.25-2.15(\mathrm{~m}, 1 \mathrm{H}), 2.04-1.92(\mathrm{~m}, 1 \mathrm{H})$, $1.27-1.19(\mathrm{~m}, 6 \mathrm{H}) ;{ }^{13} \mathrm{C} \mathrm{NMR}\left(151 \mathrm{MHz}, \mathrm{CDCl}_{3}\right)$ (rotamers) $\delta 172.81,172.78,169.2$, $169.1,169.04,169.03,154.5,154.0,136.55,136.47,128.60,128.57,128.24,128.21,128.1$, $118.9,67.37,67.36,62.50,62.47,62.4,61.2,60.7,59.1,59.0,52.7,52.5,48.0,46.8,46.0$, $45.4,30.2,30.1,26.8,26.2,14.01,13.99,13.9,13.4$.

trans-3-(Carboxymethyl)pyrrolidine-2-carboxylic Acid Hydrochloride (3a).-The title compound was prepared according to general procedure II, starting from 12a (1.50 g, $4.13 \mathrm{mmol}$ ) and stirred for 5 days, which afforded the title compound as a white solid (753 $\mathrm{mg}, 3.59 \mathrm{mmol}, 87 \%)$. LCMS (ESI) $\mathrm{m} / z=174.1[\mathrm{M}+\mathrm{H}]^{+} ;{ }^{1} \mathrm{H}$ NMR $(600 \mathrm{MHz}, \mathrm{D} 2 \mathrm{O}) \delta$ $4.15(\mathrm{~d}, J=8.46 \mathrm{~Hz}, 1 \mathrm{H}), 3.51$ (ddd, $J=4.48,8.29,11.84 \mathrm{~Hz}, 1 \mathrm{H}), 3.43$ (ddd, $J=7.34,9.03$, $11.80 \mathrm{~Hz}, 1 \mathrm{H}), 2.91-2.81(\mathrm{~m}, 2 \mathrm{H}), 2.72-2.65(\mathrm{~m}, 1 \mathrm{H}), 2.39$ (dtd, $J=4.43,7.27,13.26 \mathrm{~Hz}$, $1 \mathrm{H}), 1.87$ (dq, $J=8.74,13.48 \mathrm{~Hz}, 1 \mathrm{H}) ;{ }^{13} \mathrm{C}$ NMR $\left(151 \mathrm{MHz}, \mathrm{D}_{2} \mathrm{O}\right) \delta 175.4,171.0,62.9$, $45.2,38.5,36.2,29.7$.

trans-3-(1-Carboxybutyl)pyrrolidine-2-carboxylic Acid Hydrochloride (3e).-The title compound was prepared according to general procedure II, starting from 12e (140 mg, $0.30 \mathrm{mmol}$ ) and stirred for 6 days. The diastereomers could not be separated on preparative HPLC, which afforded a mixture of the trans-diastereomers $\mathbf{3 e}$ as a white solid $(21 \mathrm{mg}, 0.08$ mmol, 28\%). d.r. 63:37; LCMS (ESI) $\mathrm{m} / z=216.1[\mathrm{M}+\mathrm{H}]^{+} ;{ }^{1} \mathrm{H} \mathrm{NMR}\left(600 \mathrm{MHz}, \mathrm{D}_{2} \mathrm{O}\right)$ (minor trans-diastereomer in brackets) $\delta 4.21(\mathrm{~d}, J=6.8 \mathrm{~Hz}, 1 \mathrm{H}),[4.16(\mathrm{~d}, J=7.34 \mathrm{~Hz}$, $1 \mathrm{H})], 3.45-3.37(\mathrm{~m}, 1 \mathrm{H}),[3.45-3.37(\mathrm{~m}, 1 \mathrm{H})], 3.35-3.26(\mathrm{~m}, 1 \mathrm{H}),[3.35-3.26(\mathrm{~m}, 1 \mathrm{H})]$, 2.76-2.65 (m, 2H), [2.76-2.65 (m, 1H)], [2.71-2.65 (m, 1H)], [2.26 (dtd, $J=3.92,7.35$, $14.31 \mathrm{~Hz}, 1 \mathrm{H})], 2.23-2.16(\mathrm{~m}, 1 \mathrm{H}),[1.90-1.77(\mathrm{~m}, 1 \mathrm{H})], 1.90-1.77(\mathrm{~m}, 1 \mathrm{H}), 1.62(\mathrm{tdd}, J=$ 5.1, 9.7, $14.0 \mathrm{~Hz}, 1 \mathrm{H}),[1.58-1.51(\mathrm{~m}, 2 \mathrm{H})], 1.58-1.51(\mathrm{~m}, 1 \mathrm{H}),[1.34-1.17(\mathrm{~m}, 2 \mathrm{H})]$, $1.34-1.17(\mathrm{~m}, 2 \mathrm{H}),[0.82(\mathrm{t}, J=7.33 \mathrm{~Hz}, 3 \mathrm{H})], 0.82(\mathrm{t}, J=7.4 \mathrm{~Hz}, 3 \mathrm{H}) ;{ }^{13} \mathrm{C}$ NMR $(151$ $\mathrm{MHz}, \mathrm{D}_{2} \mathrm{O}$ ) (minor trans-diastereomer in brackets) $\delta$ [178.5], 178.0, 171.4, [171.3], [61.9], 
61.6, [47.6], 46.8, 45.6, [45.5], [43.9], 43.6, 32.3, [31.6], [28.0], 27.3, 19.9, [19.8], [13.1], 13.0.

trans-3-(1-Carboxy-2-methylpropyl)pyrrolidine-2-carboxylic Acid Hydrochloride (3f).-The title compound was prepared according to general procedure II, starting from $12 \mathrm{f}(120 \mathrm{mg}, 0.25 \mathrm{mmol})$ and stirred for 8 days. The diastereomers could not be separated on preparative HPLC, which afforded a mixture of the trans-diastereomers $\mathbf{3 f}$ as a white solid (27 mg, $0.11 \mathrm{mmol}, 43 \%$ ). d.r. 67:33; LCMS (ESI) $\mathrm{m} / \mathrm{z}=216.1[\mathrm{M}+\mathrm{H}]^{+} ;{ }^{1} \mathrm{H}$ NMR (600 MHz, $\left.\mathrm{D}_{2} \mathrm{O}\right)$ (minor trans-diastereomer in brackets) $\delta[4.25(\mathrm{~d}, J=7.2 \mathrm{~Hz}, 1 \mathrm{H})]$, $4.17(\mathrm{~d}, J=8.2 \mathrm{~Hz}, 1 \mathrm{H}),[3.56-3.44(\mathrm{~m}, 1 \mathrm{H})], 3.56-3.44(\mathrm{~m}, 1 \mathrm{H}),[3.44-3.36(\mathrm{~m}, 1 \mathrm{H})]$, 3.44-3.36 (m, 1H), [2.97-2.86 (m, 1H)], 2.97-2.86 (m, 1H), $2.61(\mathrm{t}, J=7.3 \mathrm{~Hz}, 1 \mathrm{H}),[2.49$ $(\mathrm{dd}, J=56.0,8.8 \mathrm{~Hz}, 1 \mathrm{H})],[2.37(\mathrm{dtd}, J=4.1,7.3,13.6 \mathrm{~Hz}, 1 \mathrm{H})], 2.34-2.25(\mathrm{~m}, 1 \mathrm{H})$, [2.09-2.00 (m, 1H)], 2.09-2.00 (m, 2H), [1.94-1.84 (m, 1H)], $0.99(\mathrm{dd}, J=6.7,24.9 \mathrm{~Hz}$, $6 \mathrm{H}),[0.98(\mathrm{dd}, J=6.9,51.2 \mathrm{~Hz}, 6 \mathrm{H})] ;{ }^{13} \mathrm{C}$ NMR $\left(151 \mathrm{MHz}, \mathrm{D}_{2} \mathrm{O}\right)$ (minor transdiastereomer in brackets) $\delta$ [177.2], 177.1, [171.3], 171.1, [62.2], 61.6, [53.6], 53.1, 45.5, [45.2], [42.2], 41.5, 30.2, [28.4], [28.1], 26.7, [20.5], 19.8, 19.1, [17.3].

trans-3-(1-Carboxy-2-phenylethyl)pyrrolidine-2-carboxylic Acid Hydrochloride $(\mathbf{3 g})$.- The title compound was prepared according to general procedure II, starting from $12 \mathrm{~g}$ (184 $\mathrm{mg}, 0.36 \mathrm{mmol})$ and stirred for 7 days. The diastereomers could not be separated on preparative HPLC, which afforded a mixture of the trans-diastereomers $\mathbf{3 g}$ as a white solid (24 mg, $0.080 \mathrm{mmol}, 22 \%$ ). d.r. 58:42; LCMS (ESI) $\mathrm{m} / z=264.1[\mathrm{M}+\mathrm{H}]^{+1} \mathrm{H} \mathrm{NMR}$ (400 MHz, $\left.\mathrm{D}_{2} \mathrm{O}\right) \delta 7.43-7.38(\mathrm{~m}, 2 \mathrm{H}), 7.36-7.31(\mathrm{~m}, 3 \mathrm{H}), 4.34(\mathrm{~d}, J=7.5 \mathrm{~Hz}, 1 \mathrm{H})$, $3.60-3.37(\mathrm{~m}, 2 \mathrm{H}), 3.22-2.93(\mathrm{~m}, 3 \mathrm{H}), 2.83(\mathrm{p}, J=7.6 \mathrm{~Hz}, 1 \mathrm{H}), 2.49-2.29(2 \mathrm{~m}, 1 \mathrm{H})$, 2.10-1.96 (m, 1H); ${ }^{13} \mathrm{C}$ NMR $\left(151 \mathrm{MHz}, \mathrm{D}_{2} \mathrm{O}\right) \delta 178.4,178.2,173.9,173.6,139.44$, $139.41,129.72,129.69,129.65,129.61,127.7,127.6,64.0,63.9,51.1,50.4,46.0,45.9$, $45.0,44.8,37.3,36.4,28.8,28.1$.

\section{trans-3-(1-Carboxy-3-phenylpropyl)pyrrolidine-2-carboxylic Acid}

Hydrochloride (3h).-The title compound was prepared according to general procedure II, starting from $12 \mathbf{h}$ ( $225 \mathrm{mg}, 0.43 \mathrm{mmol})$ and stirred for 5 days. The diastereomers could not be separated on preparative HPLC, which afforded a mixture of the trans-diastereomers 3h as a white solid (48 mg, $0.15 \mathrm{mmol}, 36 \%$ ). LCMS (ESI) $\mathrm{m} / z=278.1[\mathrm{M}+\mathrm{H}]^{+} ;{ }^{1} \mathrm{H}$ NMR $\left(600 \mathrm{MHz}, \mathrm{D}_{2} \mathrm{O}\right) \delta 7.39(\mathrm{t}, J=7.5 \mathrm{~Hz}, 2 \mathrm{H}), 7.33-7.28(\mathrm{~m}, 3 \mathrm{H}), 4.21(\mathrm{~d}, J=7.5 \mathrm{~Hz}, 1 \mathrm{H})$, $3.50-3.44(\mathrm{~m}, 1 \mathrm{H}), 3.42-3.33(\mathrm{~m}, 1 \mathrm{H}), 2.86-2.72(\mathrm{~m}, 3 \mathrm{H}), 2.72-2.60(\mathrm{~m}, 1 \mathrm{H}), 2.34-2.24$ $(\mathrm{m}, 1 \mathrm{H}), 2.13-1.83(\mathrm{~m}, 3 \mathrm{H}) ;{ }^{13} \mathrm{C}$ NMR $\left(151 \mathrm{MHz}, \mathrm{D}_{2} \mathrm{O}\right) \delta 178.0,171.2,141.4,128.7$, 128.6, 126.3, 61.7, 47.1, 45.4, 43.7, 32.6, 31.1, 28.0.

\section{trans-3-(Carboxyfluoromethyl)pyrrolidine-2-carboxylic Acid Hydrochloride (3i-} d1).-The title compound was prepared according to general procedure II, starting from 12i (150 mg, $0.36 \mathrm{mmol})$ and stirred for 4 days. The diastereomers were separated on preparative HPLC, which afforded the trans-diastereomer 3i-d1 as a white solid (4 $\mathrm{mg}, 0.02$ mmol, 5\%). d.r. 95:5; LCMS (ESI) $\mathrm{m} / z=192.1[\mathrm{M}+\mathrm{H}]^{+} ;{ }^{1} \mathrm{H}$ NMR $\left(600 \mathrm{MHz}, \mathrm{D}_{2} \mathrm{O}\right) \delta 5.29$ (dd, $J=2.8,47.5 \mathrm{~Hz}, 1 \mathrm{H}), 4.41(\mathrm{~d}, J=6.6 \mathrm{~Hz}, 1 \mathrm{H}), 3.50$ (ddd, $J=5.4,7.7,12.6 \mathrm{~Hz}, 1 \mathrm{H})$, $3.41(\mathrm{dt}, J=7.9,11.5 \mathrm{~Hz}, 1 \mathrm{H}), 3.26(\mathrm{dqd}, J=2.7,8.9,31.7 \mathrm{~Hz}, 1 \mathrm{H}), 2.43(\mathrm{dtd}, J=5.5,7.5$, 
$13.8 \mathrm{~Hz}, 1 \mathrm{H}), 2.14(\mathrm{dq}, J=7.9,13.7 \mathrm{~Hz}, 1 \mathrm{H}) ;{ }^{13} \mathrm{C} \mathrm{NMR}\left(151 \mathrm{MHz}, \mathrm{D}_{2} \mathrm{O}\right) \delta 171.8,171.6$, $170.5,88.8,87.6,58.3,58.2,45.9,43.8,43.7,27.12,27.10$.

And trans-diastereomer 3i-d2 as a white solid (35 mg, $0.15 \mathrm{mmol}$, 43\%). d.r. 1:99; LCMS (ESI) $\mathrm{m} / z=192.1[\mathrm{M}+\mathrm{H}]^{+} ;{ }^{1} \mathrm{H}$ NMR $\left(600 \mathrm{MHz}, \mathrm{D}_{2} \mathrm{O}\right) \delta 5.41(\mathrm{dd}, J=2.6,49.0 \mathrm{~Hz}, 1 \mathrm{H})$, 4.41 (d, $J=7.9 \mathrm{~Hz}, 1 \mathrm{H}), 3.53$ (ddd, $J=5.2,8.2,11.7 \mathrm{~Hz}, 1 \mathrm{H}), 3.46(\mathrm{dt}, J=8.0,11.7 \mathrm{~Hz}$, $1 \mathrm{H}), 3.21(\mathrm{dqd}, J=2.7,8.2,31.9 \mathrm{~Hz}, 1 \mathrm{H}), 2.21(\mathrm{dtd}, J=5.1,7.8,13.2 \mathrm{~Hz}, 1 \mathrm{H}), 2.10(\mathrm{dq}, J=$ $8.3,13.6 \mathrm{~Hz}, 1 \mathrm{H}) ;{ }^{13} \mathrm{C} \mathrm{NMR}\left(151 \mathrm{MHz}, \mathrm{D}_{2} \mathrm{O}\right) \delta 172.5,172.4,171.1,88.5,87.3,60.22$, $60.19,45.6,44.1,44.0,23.82,23.80$.

trans-3-(Carboxy(methoxy)methyl)pyrrolidine-2-carboxylic Acid Hydrochloride (3j-d1).-The title compound was prepared according to general procedure II, starting from $\mathbf{1 2 j}$ ( $189 \mathrm{mg}, 0.45 \mathrm{mmol}$ ) and stirred for 5 days. One diastereomer was purified on preparative HPLC, which afforded the trans-diastereomer $\mathbf{3 j}$-d1 as a white solid $(6 \mathbf{m g}$, $0.025 \mathrm{mmol}, 6 \%$ ). d.r. 1:99; LCMS (ESI) $\mathrm{m} / z=204.1[\mathrm{M}+\mathrm{H}]^{+} ;{ }^{1} \mathrm{H}$ NMR $\left(600 \mathrm{MHz}, \mathrm{D}_{2} \mathrm{O}\right)$ $\delta 4.41(\mathrm{~d}, J=5.7 \mathrm{~Hz}, 1 \mathrm{H}), 4.12(\mathrm{~d}, J=3.5 \mathrm{~Hz}, 1 \mathrm{H}), 3.55-3.50(\mathrm{~m}, 1 \mathrm{H}), 3.48(\mathrm{~s}, 3 \mathrm{H})$, 3.46-3.35 (m, 1H), 3.14-3.09 (m, 1H), 2.40-2.33 (m, 1H), 2.13-2.06 (m, 1H); ${ }^{13} \mathrm{C}$ NMR $\left(151 \mathrm{MHz}, \mathrm{D}_{2} \mathrm{O}\right) \delta 175.6,172.1,80.7,60.3,59.6,46.8,45.4,28.3$.

trans-3-(Amino(carboxy)methyl)pyrrolidine-2-carboxylic Acid Dihydrochloride (3k).-The title compound was prepared according to general procedure II, starting from 12k (300 mg, $0.59 \mathrm{mmol}$ ) and stirred for 5 days. The diastereomers could not be separated on preparative HPLC, which afforded a mixture of the trans-diastereomers $3 \mathbf{k}$ as a white solid (57 mg, $0.22 \mathrm{mmol}, 37 \%$ ). d.r. 50:50; LCMS (ESI) $\mathrm{m} / z=189.1[\mathrm{M}+\mathrm{H}]^{+} ;{ }^{1} \mathrm{H} \mathrm{NMR}$ $\left(600 \mathrm{MHz}, \mathrm{D}_{2} \mathrm{O}\right)$ (two diastereomers) $\delta 4.53(\mathrm{~d}, J=9.2 \mathrm{~Hz}, 1 \mathrm{H}), 4.32(\mathrm{~d}, J=5.7 \mathrm{~Hz}, 1 \mathrm{H})$, $4.30-4.24$ (m, 1H), 3.48 (tdd, $J=3.6,7.9,12.0 \mathrm{~Hz}, 1 \mathrm{H}), 3.38-3.29$ (m, 1H), 2.99 (qd, $J=$ $4.8,8.9 \mathrm{~Hz}, 1 \mathrm{H}), 2.95-2.85(\mathrm{~m}, 1 \mathrm{H}), 2.42-2.30(\mathrm{~m}, 1 \mathrm{H}), 2.24-2.15(\mathrm{~m}, 1 \mathrm{H}), 1.98-1.88(\mathrm{~m}$, $1 \mathrm{H}) ;{ }^{13} \mathrm{C}$ NMR $\left(151 \mathrm{MHz}, \mathrm{D}_{2} \mathrm{O}\right.$ ) (two diastereomers) $\delta 170.79,170.75,169.9,169.8,61.8$, 60.5, 54.1, 53.6, 45.3, 44.9, 42.1, 41.6, 27.8, 27.0.

trans-2-(2-Carboxypyrrolidin-3-yl)succinic Acid Hydrochloride (3l).-The title compound was prepared according to general procedure II, starting from 121 (275 $\mathrm{mg}, 0.54$ $\mathrm{mmol}$ ) and stirred for 9 days. The diastereomers could not be separated on preparative HPLC, which afforded a mixture of the trans-diastereomers $\mathbf{3 l}$ as a white solid (48 $\mathrm{mg}, 0.18$ mmol, 33\%). d.r. 63:37; LCMS (ESI) $\mathrm{m} / z=232.1[\mathrm{M}+\mathrm{H}]^{+} ; 1 \mathrm{H} \mathrm{NMR}\left(400 \mathrm{MHz}, \mathrm{D}_{2} \mathrm{O}\right)$ (minor trans-diastereomer in brackets) $\delta 4.36(\mathrm{~d}, J=8.5 \mathrm{~Hz}, 1 \mathrm{H}),[4.33(\mathrm{~d}, J=7.4 \mathrm{~Hz}, 1 \mathrm{H})]$, 3.49-3.39 (m, 1H), [3.49-3.39 (m, 1H)], 3.35-3.25 (m, 1H), [3.35-3.25 (m, 1H)], 3.22 (ddd, $J=4.6,5.6,10.1 \mathrm{~Hz}, 1 \mathrm{H}),[3.02(\mathrm{ddd}, J=4.8,7.4,9.7 \mathrm{~Hz}, 1 \mathrm{H})], 2.86-2.62(\mathrm{~m}, 3 \mathrm{H})$, [2.86-2.62 (m, 3H)], 2.31-2.19 (m, 1H), [2.31-2.19 (m, 1H)], 1.90-1.76 (m, 1H), [1.90-1.76 (m, 1H)]; ${ }^{13} \mathrm{C} \mathrm{NMR}\left(151 \mathrm{MHz}, \mathrm{D}_{2} \mathrm{O}\right)$ (minor trans-diastereomer in brackets) $\delta$ [176.7], 176.0, 175.53, [175.51], 171.0, [170.9], 61.2, [61.0], 45.6, [45.5], [43.2], 43.0, [42.8], 42.2, 34.6, [33.7], [28.1], 27.1.

trans-2-(2-Carboxypyrrolidin-3-yl)pentanedioic Acid Hydrochloride (3m).-The title compound was prepared according to general procedure II, starting from 12m $(300 \mathrm{mg}$, $0.63 \mathrm{mmol}$ ) and stirred for 9 days. The diastereomers could not be separated on preparative 
HPLC, which afforded a mixture of the trans-diastereomers $\mathbf{3 m}$ as a white solid (52 $\mathrm{mg}, 0.18$ mmol, 29\%). d.r. 67:33; LCMS (ESI) $\mathrm{m} / z=246.1[\mathrm{M}+\mathrm{H}]^{+} ;{ }^{1} \mathrm{H} \mathrm{NMR}\left(600 \mathrm{MHz}, \mathrm{D}_{2} \mathrm{O}\right)$ (minor trans-diastereomer in brackets) $\delta 4.33(\mathrm{~d}, J=6.9 \mathrm{~Hz}, 1 \mathrm{H}),[4.28(\mathrm{~d}, J=7.4 \mathrm{~Hz}, 1 \mathrm{H})]$, 3.56-3.48 (m, 1H), [3.56-3.48 (m, 1H)], 3.45-3.36 (m, 1H), [3.45-3.36 (m, $1 \mathrm{H})]$, 2.90-2.80 (m, 2H), [2.90-2.80 (m, 1H)], [2.72-2.69 (m, 1H)], 2.58-2.43 (m, 2H), [2.58-2.43 (m, 2H)], [2.40-2.35 (m, 1H)], $2.32(\mathrm{dtd}, J=4.5,7.3,13.8 \mathrm{~Hz}, 1 \mathrm{H}), 2.08-1.89$ $(\mathrm{m}, 3 \mathrm{H}),[2.08-1.89(\mathrm{~m}, 3 \mathrm{H})] ;{ }^{13} \mathrm{C}$ NMR $\left(151 \mathrm{MHz}, \mathrm{D}_{2} \mathrm{O}\right)$ (minor trans-diastereomer in brackets) $\delta$ [177.4], 177.33, [177.27], 176.9, 171.6, [171.4], [61.9], 61.7, [46.6], 46.1, 45.5, [45.4], [43.7], 43.6, 31.34, [31.29], [27.8], 27.3, 25.2, [24.4].

\section{trans-1-Benzyl 2-Methyl 3-(3-(Ethoxycarbonyl)-2-oxotetrahydrofuran-3-} yl)pyrrolidine-1,2-dicarboxylate (12n).-The title compound was prepared according to general procedure I, starting from $\mathbf{1 0}(200 \mathrm{mg}, 0.77 \mathrm{mmol})$ and ethyl 2oxotetrahydrofuran-3-carboxylate $(303 \mathrm{mg}, 1.91 \mathrm{mmol})$, which afforded the title compound as a colorless oil (228 mg, $0.54 \mathrm{mmol}, 71 \%$ ). LCMS (ESI) $\mathrm{m} / z=420.2[\mathrm{M}+\mathrm{H}]^{+} ; R_{\mathrm{f}}=0.25$ (1:1 heptane/EtOAc); ${ }^{1} \mathrm{H}$ NMR (400 MHz, $\left.\mathrm{CDCl}_{3}\right) \delta 7.38-7.27(\mathrm{~m}, 5 \mathrm{H}), 5.27-4.93(\mathrm{~m}$, $2 \mathrm{H}), 4.44-4.11(\mathrm{~m}, 5 \mathrm{H}), 3.75(\mathrm{~d}, J=5.95 \mathrm{~Hz}, 1.5 \mathrm{H}), 3.72-3.64(\mathrm{~m}, 1 \mathrm{H}), 3.64-3.55(\mathrm{~m}, 1 \mathrm{H})$, $3.53(\mathrm{~d}, J=4.05 \mathrm{~Hz}, 1.5 \mathrm{H}), 3.32(\mathrm{td}, J=5.79,7.84 \mathrm{~Hz}, 0.5 \mathrm{H}), 3.15$ (dtd, $J=5.42,7.66$, $13.28 \mathrm{~Hz}, 0.5 \mathrm{H}$ ), 2.74 (dqd, $J=2.21,6.87,14.18 \mathrm{~Hz}, 1 \mathrm{H}), 2.37-2.17(\mathrm{~m}, 2 \mathrm{H}), 1.89-1.71(\mathrm{~m}$, $1 \mathrm{H}), 1.33-1.21(\mathrm{~m}, 3 \mathrm{H}) ;{ }^{13} \mathrm{C}$ NMR $\left(101 \mathrm{MHz}, \mathrm{CDCl}_{3}\right.$ ) (rotamers) $\delta$ 173.0, 172.93, 172.87, 172.6, 172.3, 172.2, 168.3, 168.2, 168.11, 168.07, 154.7, 154.6, 154.0, 136.5, 136.35, $136.31,128.60,128.56,128.54,128.21,128.15,128.08,128.05,67.5,67.4,66.5,66.4,66.1$, 63.03, 62.97, 62.9, 61.6, 61.22, 61.19, 60.7, 56.89, 56.87, 56.77, 56.69, 52.66, 52.5, 52.4, $52.3,46.9,46.6,46.3,46.1,46.0,45.9,45.7,45.5,31.0,29.8,29.8,28.71,28.66,27.7,27.1$, 26.9, 26.3, 14.1, 14.0.

\section{Disodium trans-3-(1-Carboxylato-3-hydroxypropyl)pyrrolidine-2-carboxylate}

(3n).-The title compound was prepared according to general procedure II, starting from 12n (200 mg, $0.48 \mathrm{mmol})$ and stirred for 4 days. The diastereomers could not be separated on preparative HPLC, but afforded a mixture of the trans-diastereomers of the corresponding lactone $\cdot \mathrm{HCl}$ salt 13 , which was submitted to 3 equiv of $0.5 \mathrm{M} \mathrm{NaOH}(\mathrm{aq}$.) and afforded a mixture of the trans-diastereomers $\mathbf{3 n}$ as a white solid $(52 \mathrm{mg}, 0.20 \mathrm{mmol}, 42 \%)$. d.r. 53:47; $1 \mathrm{H} \mathrm{NMR}\left(600 \mathrm{MHz}, \mathrm{D}_{2} \mathrm{O}\right)$ (minor trans-diastereomer in brackets) $\delta[4.05(\mathrm{~d}, J=5.2 \mathrm{~Hz}$, $1 \mathrm{H})$ ], $3.98(\mathrm{~d}, J=4.6 \mathrm{~Hz}, 1 \mathrm{H}),[3.74-3.64(\mathrm{~m}, 2 \mathrm{H})], 3.65-3.55(\mathrm{~m}, 2 \mathrm{H}),[3.49-3.38(\mathrm{~m}$, $2 \mathrm{H})], 3.49-3.38(\mathrm{~m}, 2 \mathrm{H}),[2.73(\mathrm{p}, J=6.3 \mathrm{~Hz}, 1 \mathrm{H})],[2.62-2.55(\mathrm{~m}, 1 \mathrm{H})], 2.53$ (ddd, $J=3.7$, 6.6, $10.7 \mathrm{~Hz}, 1 \mathrm{H}), 2.41(\mathrm{td}, J=3.8,10.4 \mathrm{~Hz}, 1 \mathrm{H}),[2.19-2.09(\mathrm{~m}, 1 \mathrm{H})], 2.19-2.09(\mathrm{~m}, 1 \mathrm{H})$, [2.01-1.91 (m, 1H)], 2.01-1.91 (m, 2H), [1.91-1.82 (m, 1H)], 1.91-1.82 (m, 1H), $[1.82-1.74(\mathrm{~m}, 1 \mathrm{H})] ;{ }^{13} \mathrm{C}$ NMR $\left(151 \mathrm{MHz}, \mathrm{D}_{2} \mathrm{O}\right)$ (minor trans-diastereomer in brackets) $\delta$ [181.9], 181.7, [174.5], 174.4, [64.1], 63.4, [60.2], 60.1, 48.8, [46.9], 45.4, [45.10], 45.08, [45.0], 33.9, [31.8], [28.2], 27.0.

\section{trans-1-Benzyl 2-Methyl 3-(1-Ethoxy-2-(ethoxycarbonyl)-1-oxopent-4-en-2-} yl)pyrrolidine-1,2-dicarboxylate (14).-The title compound was prepared according to general procedure I ( $3 \mathrm{~h}$ reaction time), starting from $10(270 \mathrm{mg}, 1.03 \mathrm{mmol})$ and diethyl allylmalonate (517 mg, $0.54 \mathrm{~mL}, 2.58 \mathrm{mmol}$ ), which afforded the title compound as a 
colorless oil (444 mg, $0.96 \mathrm{mmol}, 93 \%)$. LCMS (ESI) $\mathrm{m} / \mathrm{z}=462.2[\mathrm{M}+\mathrm{H}]^{+} ; \mathrm{R}_{\mathrm{f}}=0.18(7: 3$ heptane/EtOAc); ${ }^{1} \mathrm{H}$ NMR (400 MHz, $\mathrm{CDCl}_{3}$ ) (rotamers) $\delta 7.38-7.28(\mathrm{~m}, 5 \mathrm{H}), 5.71-5.57$ $(\mathrm{m}, 1 \mathrm{H}), 5.19(\mathrm{~d}, J=12.3 \mathrm{~Hz}, 1 \mathrm{H}), 5.15-5.07(\mathrm{~m}, 2 \mathrm{H}), 5.01(\mathrm{~d}, J=12.5 \mathrm{~Hz}, 1 \mathrm{H}), 4.58(\mathrm{br} \mathrm{d}$, $J=16.2 \mathrm{~Hz}, 1 \mathrm{H}), 4.21-3.93(\mathrm{~m}, 4 \mathrm{H}), 3.77(\mathrm{~s}, 1.5 \mathrm{H}), 3.59(\mathrm{~s}, 1.5 \mathrm{H}), 3.57-3.45(\mathrm{~m}, 2 \mathrm{H})$, $3.02-2.92(\mathrm{~m}, 1 \mathrm{H}), 2.74(\mathrm{br} \mathrm{d}, J=6.1 \mathrm{~Hz}, 2 \mathrm{H}), 2.28-2.14(\mathrm{~m}, 1 \mathrm{H}), 2.09-1.94(\mathrm{~m}, 1 \mathrm{H}), 1.21$ (t, $J=7.2 \mathrm{~Hz}, 3 \mathrm{H}), 1.17(\mathrm{t}, J=7.3 \mathrm{~Hz}, 3 \mathrm{H}) ;{ }^{13} \mathrm{C} \mathrm{NMR}\left(101 \mathrm{MHz}, \mathrm{CDCl}_{3}\right)$ (rotamers) $\delta$ 173.3, 173.2, 170.1, 170.0, 169.9, 154.5, 154.2, 136.7, 136.6, 131.9, 128.6, 128.5, 128.2, $128.14,128.11,128.08,119.8,67.2,61.8,61.5,61.0,59.8,52.5,52.3,46.7,46.0,45.6,45.4$, 38.6, 26.3, 25.6, 14.13, 14.11, 14.01, 13.98 .

\section{trans-1-Benzyl 2-Methyl 3-(1-Ethoxy-2-(ethoxycarbonyl)-5-hydroxy-1- oxopentan-2-yl)pyrrolidine-1,2-dicarboxylate (120).-To a solution of trans-} enantiomers 14 (410 mg, $0.89 \mathrm{mmol}, 1$ equiv) in anhydrous THF $(9 \mathrm{~mL})$ at $0{ }^{\circ} \mathrm{C}, 1 \mathrm{M}$ borane tetrahydrofuran complex solution $(1.3 \mathrm{~mL}, 1.33 \mathrm{mmol}, 1.5$ equiv) was added and the resulting solution was stirred at this temperature for $2 \mathrm{~h}$. Then, water ( $80 \mu \mathrm{L}, 4.44 \mathrm{mmol}, 5$ equiv), $4 \mathrm{M}$ aq $\mathrm{NaOH}$ ( $933 \mu \mathrm{L}, 3.73 \mathrm{mmol}, 4.2$ equiv), and $30 \%$ aq peroxide solution (483 $\mu \mathrm{L}, 4.26 \mathrm{mmol}, 4.8$ equiv) were added to the previous mixture, which was stirred at $0{ }^{\circ} \mathrm{C}$ for an additional hour. After that, the reaction mixture was diluted with EtOAc $(60 \mathrm{~mL})$ and water $(60 \mathrm{~mL})$. The aqueous layer was extracted with EtOAc $(3 \times 60 \mathrm{~mL})$, and the collected organic layers were washed with brine $(60 \mathrm{~mL})$, dried over $\mathrm{MgSO}_{4}$, and filtered. The solvent of the filtrate was removed under reduced pressure to give a residue that was purified by flash chromatography (silica gel, heptane/ EtOAc 1:1, isocratic) to afford the desired mixture of trans-enantiomers as a colorless oil (211 $\mathrm{mg}, 0.44 \mathrm{mmol}, 50 \%$ ). LCMS (ESI) $\mathrm{m} / z$ $=480.2[\mathrm{M}+\mathrm{H}]^{+} ; \mathrm{R}_{\mathrm{f}}=0.10\left(1: 1\right.$ heptane/EtOAc); ${ }^{1} \mathrm{H} \mathrm{NMR}\left(400 \mathrm{MHz}, \mathrm{CDCl}_{3}\right)$ (rotamers) $\delta 7.37-7.27(\mathrm{~m}, 5 \mathrm{H}), 5.19(\mathrm{~d}, J=12.7 \mathrm{~Hz}, 1 \mathrm{H}), 5.02(\mathrm{~d}, J=12.4 \mathrm{~Hz}, 1 \mathrm{H}), 4.56$ (br d, $J=$ $19.0 \mathrm{~Hz}, 1 \mathrm{H}), 4.23-3.96(\mathrm{~m}, 4 \mathrm{H}), 3.76(\mathrm{~s}, 1.5 \mathrm{H}), 3.62(\mathrm{t}, J=6.2 \mathrm{~Hz}, 2 \mathrm{H}), 3.58(\mathrm{~s}, 1.5 \mathrm{H})$, 3.55-3.44 (m, 2H), 3.05-2.95 (m, 1H), 2.29-2.15 (m, 1H), $2.05(\mathrm{t}, J=8.2 \mathrm{~Hz}, 2 \mathrm{H})$, 2.03-1.95 (m, 1H), 1.52-1.42 (m, 2H), 1.26-1.16 (m, 6H); ${ }^{13} \mathrm{C}$ NMR (101 MHz, CDCl 3 ) (rotamers) $\delta 173.31,173.27,170.5,170.44,170.42,170.3,154.5,154.2,136.7,136.6,129.1$, $128.51,128.47,128.3,128.15,128.13,128.10,127,99,125.4,67.2,62.5,61.8,61.8,61.4$, $60.9,59.51,59.50,52.6,52.3,47.1,46.0,45.4,30.7,30.6,27.6,26.5,25.8,14.1,14.03$, 14.00 .

trans-3-(1-Carboxy-4-hydroxybutyl)pyrrolidine-2-carboxylic Acid Hydrochloride (30).-The title compound was prepared according to general procedure II, starting from $120(119 \mathrm{mg}, 0.25 \mathrm{mmol})$ and stirred for 3 days. The diastereomers could not be separated on preparative HPLC, which afforded a mixture of the trans-diastereomers 30 as a white solid (19 mg, $0.071 \mathrm{mmol}, 29 \%$ ). d.r. 56:44; LCMS (ESI) $\mathrm{m} / z=250.1[\mathrm{M}+\mathrm{H}]$ ${ }^{+},{ }_{1} \mathrm{H}_{\mathrm{NMR}}\left(600 \mathrm{MHz}, \mathrm{D}_{2} \mathrm{O}\right)$ (two diastereomers) $\delta 4.33-4.20(2 \mathrm{~m}, 1 \mathrm{H}), 3.71-3.61(\mathrm{~m}, 2 \mathrm{H})$, $3.54-3.48(\mathrm{~m}, 1 \mathrm{H}), 3.44-3.38(\mathrm{~m}, 1 \mathrm{H}), 2.88-2.68(2 \mathrm{~m}, 2 \mathrm{H}), 2.40-2.28(\mathrm{~m}, 1 \mathrm{H}), 1.98-1.90$ $(\mathrm{m}, 1 \mathrm{H}), 1.90-1.76(\mathrm{~m}, 4 \mathrm{H}) ;{ }^{13} \mathrm{C} \mathrm{NMR}\left(151 \mathrm{MHz}, \mathrm{D}_{2} \mathrm{O}\right)$ (two diastereomers) $\delta 178.6$, 178.1, 172.4, 172.1, 62.7, 62.5, 47.6, 47.0, 46.1, 46.0, 45.5, 44.4, 44.3, 30.2, 30.1, 28.5, $28.2,28.0,27.4$. 
trans-1-Benzyl 2-Methyl 3-(1-Methoxy-2-(methoxycarbonyl)-1-oxopent-4-yn-2yl)pyrrolidine-1,2-dicarboxylate (15).-The title compound was prepared according to general procedure I, starting from $10(180 \mathrm{mg}, 0.69 \mathrm{mmol})$ and dimethyl propargylmalonate (293 mg, $0.28 \mathrm{~mL} 1.72 \mathrm{mmol}$ ), which afforded the title compound as a colorless oil (264 $\mathrm{mg}, 0.61 \mathrm{mmol}, 89 \%$ ). LCMS (ESI) $\mathrm{m} / z=432.2[\mathrm{M}+\mathrm{H}]^{+} ; \mathrm{R}_{\mathrm{f}}=0.17$ (7:3 heptane/EtOAc); ${ }^{1} \mathrm{H}$ NMR $\left(400 \mathrm{MHz}, \mathrm{CDCl}_{3}\right.$ ) (rotamers) $\delta 7.39-7.27(\mathrm{~m}, 5 \mathrm{H}), 5.18(\mathrm{~d}, J=12.5 \mathrm{~Hz}, 1 \mathrm{H})$, 5.05 (d, $J=12.0 \mathrm{~Hz}, 1 \mathrm{H}), 4.58-4.49$ (br d, $J=11.4 \mathrm{~Hz}, 1 \mathrm{H}), 3.78(\mathrm{~s}, 1.5 \mathrm{H}), 3.74(\mathrm{~s}, 1.5 \mathrm{H})$, $3.72(\mathrm{~s}, 1.5 \mathrm{H}), 3.66(\mathrm{~s}, 1.5 \mathrm{H}), 3.63(\mathrm{~s}, 1.5 \mathrm{H}), 3.61(\mathrm{~s}, 1.5 \mathrm{H}), 3.60-3.49(\mathrm{~m}, 2 \mathrm{H}), 3.32-3.23$ (m, 1H), 3.01-2.86 (m, 2H), 2.37-2.23 (m, 1H), 2.10-1.94 (m, 2H); ${ }^{13} \mathrm{C}$ NMR (151 MHz, $\mathrm{CDCl}_{3}$ ) (rotamers) $\delta 173.0,172.9,169.7,169.63,169.61,169.5,154.6,154.2,136.65$, $136.63,128.60,128.5,128.21,128.18,78.10,78.07,72.4,67.34,67.30,61.3,60.8,58.9$, $53.2,53.1,53.0,52.7,52.5,46.5,46.0,45.5,45.4,26.6,25.9,24.34,24.32$.

trans-1-Benzyl 2-Methyl 3-(2-((1H-1,2,3-Triazol-4-yl)methyl)-1,3-dimethoxy-1,3dioxopropan-2-yl)pyrrolidine-1,2-dicarboxylate (12p).-In a $9 \mathrm{~mL}$ vessel, a solution of 15 (391 mg, $0.91 \mathrm{mmol}$ ), copper(I) iodide (17 mg, $0.091 \mathrm{mmol})$, and azidotrimethylsilane $(95 \%, 380 \mu \mathrm{L}, 2.72 \mathrm{mmol})$ in DMF.MeOH 1:1 $(5 \mathrm{~mL})$ was prepared under argon atmosphere. The vessel was sealed with a septum, heated to reflux, and stirred overnight. Next day, the reaction mixture was allowed to reach $\mathrm{rt}$ and then diluted with water $(50 \mathrm{~mL})$ and EtOAc $(50 \mathrm{~mL})$. The aqueous layer was extracted with EtOAc $(3 \times 50 \mathrm{~mL})$, and the collected organic layers were washed with water $(3 \times 50 \mathrm{~mL})$, dried over $\mathrm{MgSO}_{4}$, and filtered. After that, the solvent of the filtrate was removed under reduced pressure to give a brown oil that was purified by flash chromatography (silica gel, heptane/EtOAc 1:1 to 2:8, gradient) to afford the desired mixture of trans-enantiomers as a white solid (307 mg, 0.65 mmol, 71\%). LCMS (ESI) $\mathrm{m} / z=475.2[\mathrm{M}+\mathrm{H}]^{+} ;{ }^{1} \mathrm{H} \mathrm{NMR}$ (400 MHz, $\mathrm{CDCl}_{3}$ ) (rotamers) $\delta$ $7.48(\mathrm{~s}, 1 \mathrm{H}), 7.39-7.26(\mathrm{~m}, 5 \mathrm{H}), 5.19(\mathrm{~d}, J=12.5 \mathrm{~Hz}, 1 \mathrm{H}), 5.04(\mathrm{br} \mathrm{t}, J=11.9 \mathrm{~Hz}, 1 \mathrm{H}), 4.61$ (br d, $J=25.0,1 \mathrm{H}), 3.74-3.72(2 \mathrm{~s}, 1.5 \mathrm{H}), 3.69(\mathrm{~s}, 1.5 \mathrm{H}), 3.66(\mathrm{~s}, 1.5 \mathrm{H}), 3.63(\mathrm{~s}, 1.5 \mathrm{H}), 3.60$ $(\mathrm{s}, 1.5 \mathrm{H}), 3.56(\mathrm{~s}, 1.5 \mathrm{H}), 3.55-3.38(\mathrm{~m}, 4 \mathrm{H}), 3.01-2.91(\mathrm{~m}, 1 \mathrm{H}), 2.32-2.18(\mathrm{~m}, 1 \mathrm{H})$, 2.17-2.01 (m, 1H); ${ }^{13} \mathrm{C} \mathrm{NMR} \mathrm{(101} \mathrm{MHz,} \mathrm{CDCl}_{3}$ ) (rotamers) $\delta 173.2,173.1,170.4,170.3$, 170.1, 154.8, 154.4, 140.8, 136.6, 132.1, 128.72, 128.70, 128.34, 128.29, 128.26, 67.5, 61.6, 61.1, 60.3, 60.2, 53.2, 53.14, 53.10, 53.0, 52.8, 52.6, 47.0, 46.0, 45.9, 45.4, 30.03, 30.00, 26.7, 25.9.

trans-3-(1-Carboxy-2-(1H-1,2,3-triazol-4-yl)ethyl)pyrrolidine-2-carboxylic Acid Hydrochloride (3p).-The title compound was prepared according to general procedure II, starting from 12p ( $289 \mathrm{mg}, 0.61 \mathrm{mmol})$ and stirred for 3 days. The two epsilon diastereomers were separated on preparative HPLC. For the trans-diastereomer 3p-d1: as a white solid (18 mg, $0.06 \mathrm{mmol}, 10 \%)$. d.r. 99:1; LCMS (ESI) $\mathrm{m} / \mathrm{z}=255.1[\mathrm{M}+\mathrm{H}]^{+} ;{ }^{1} \mathrm{H}$ NMR (600 MHz, $\left.\mathrm{D}_{2} \mathrm{O}\right) \delta 8.02(\mathrm{br} \mathrm{s}, 1 \mathrm{H}), 4.49(\mathrm{br} \mathrm{d}, J=8.1 \mathrm{~Hz}, 1 \mathrm{H}), 3.56-3.50(\mathrm{~m}, 1 \mathrm{H})$, 3.43-3.36 (m, 1H), 3.34-3.28 (m, 2H), 3.22-3.15 (m, 1H), 2.87-2.80 (m, 1H), 2.37-2.31 $(\mathrm{m}, 1 \mathrm{H}), 2.00-1.92(\mathrm{~m}, 1 \mathrm{H}) ;{ }^{13} \mathrm{C}$ NMR $\left(151 \mathrm{MHz}, \mathrm{D}_{2} \mathrm{O}\right) \delta 176.1,171.6,141.9,127.3,62.0$, 46.8, 46.3, 43.7, 27.6, 25.5. For the trans-diastereomer 3p-d2: as a white solid (8 mg, 0.03 mmol, 5\%). d.r. 10:90; LCMS (ESI) $\mathrm{m} / z=255.1[\mathrm{M}+\mathrm{H}]^{+} ;{ }^{1} \mathrm{H}$ NMR $\left(400 \mathrm{MHz}, \mathrm{D}_{2} \mathrm{O}\right) \delta$ 7.92 (br s, $1 \mathrm{H}$ ), 4.39 (br d, $J=7.4 \mathrm{~Hz}, 1 \mathrm{H}), 3.64-3.53(\mathrm{~m}, 1 \mathrm{H}), 3.49-3.42(\mathrm{~m}, 1 \mathrm{H})$, 3.26-3.19 (m, 2H), 3.15-3.07 (m, 1H), 2.98-2.88 (m, 1H), 2.51-2.41 (m, 1H), 2.11-2.00 
$(\mathrm{m}, 1 \mathrm{H}) ;{ }^{13} \mathrm{C}$ NMR $\left(151 \mathrm{MHz}, \mathrm{D}_{2} \mathrm{O}\right) \delta 177.1,171.9,142.2,127.4,62.3,48.3,46.1,44.0$, 28.8, 25.2. In addition, a mixture of the trans-diastereomers $\mathbf{3 p - d 1 / 3 p - d 2}$ was isolated as a white solid (113 mg, $0.39 \mathrm{mmol}, 64 \%$ ). LCMS (ESI) $\mathrm{m} / z=255.1[\mathrm{M}+\mathrm{H}]^{+}$.

trans-1-Benzyl 2-Methyl 3-(2-(Cyanomethyl)-1,3-dimethoxy-1,3-dioxopropan-2yl)pyrrolidine-1,2-dicarboxylate (16).-To a solution of 12a $(5.23 \mathrm{~g}, 13.3 \mathrm{mmol}, 1$ equiv) in THF $(150 \mathrm{~mL})$ was added $\mathrm{NaH}\left(532 \mathrm{mg}, 13.3 \mathrm{mmol}, 1\right.$ equiv) at $0{ }^{\circ} \mathrm{C}$, and the reaction mixture was stirred for $15 \mathrm{~min}$. Then bromoacetonitrile $(7.92 \mathrm{~g}, 66.6 \mathrm{mmol}, 5$ equiv) was added, and the mixture was stirred at $50{ }^{\circ} \mathrm{C}$ for $23 \mathrm{~h}$. The reaction was quenched with $\mathrm{NH}_{4} \mathrm{Cl}(100 \mathrm{~mL})$. The mixture was concentrated under reduced pressure, and following purified by DCVC $(0 \rightarrow 50 \%$ EtOAc in heptane $)$, to afford the title compound as a colorless oil (4.80 g, $11.11 \mathrm{mmol}, 84 \%)$. LCMS (ESI) $\mathrm{m} / z=433.2[\mathrm{M}+\mathrm{H}]^{+} ; R_{\mathrm{f}}=0.27$ (2:1 heptane/ EtOAc); 1H NMR (600 MHz, $\left.\mathrm{CDCl}_{3}\right) \delta 7.37-7.29(\mathrm{~m}, 5 \mathrm{H}), 5.19(\mathrm{dd}, J=12.4,19.0 \mathrm{~Hz}$, $1 \mathrm{H}), 5.05(\mathrm{dd}, J=12.3,41.0 \mathrm{~Hz}, 1 \mathrm{H}), 4.46(\mathrm{dd}, J=4.4,25.1 \mathrm{~Hz}, 1 \mathrm{H}), 3.80-3.73(\mathrm{~m}, 6 \mathrm{H})$, $3.72(\mathrm{~s}, 1.5 \mathrm{H}), 3.71-3.61(\mathrm{~m}, 1 \mathrm{H}), 3.60(\mathrm{~s}, 1.5 \mathrm{H}), 3.53(\mathrm{dt}, J=7.8,10.8 \mathrm{~Hz}, 1 \mathrm{H}), 3.20-3.14$ (m, $1 \mathrm{H}), 3.12-2.97(\mathrm{~m}, 2 \mathrm{H}), 2.35-2.23(\mathrm{~m}, 1 \mathrm{H}), 2.04(\mathrm{ddt}, J=7.4,14.5,47.9 \mathrm{~Hz}, 1 \mathrm{H}) ;{ }^{13} \mathrm{C}$ NMR $\left(151 \mathrm{MHz}, \mathrm{CDCl}_{3}\right.$ ) (rotamers) $\delta 172.3,172.2,168.3,168.2,168.13,168.08,154.6$, 154.0, 136.5, 136.4, 128.64, 128.61, 128.34, 128.29, 128.25, 128.21, 115.9, 115.8, 67.5, $67.4,60.6,60.5,57.54,57.50,53.8,53.72,53.68,52.9,52.7,47.3,46.2,46.0,45.5,27.0$, $26.3,22.92,22.90,21.2$.

trans-1-Benzyl 2-Methyl 3-(2-((2H-Tetrazol-5-yl)methyl)-1,3-dimethoxy-1,3dioxopropan-2-yl)pyrrolidine-1,2-dicarboxylate (17-s1 and 17-s2).-To a vial with a solution of $\mathbf{1 6}(1.31 \mathrm{~g}, 3.03 \mathrm{mmol}, 1$ equiv) in dry toluene $(17.5 \mathrm{~mL})$ were added sodium azide (1.77 g, $27.3 \mathrm{mmol}, 9$ equiv) and triethylammonium chloride $(3.76 \mathrm{~g}, 27.3 \mathrm{mmol}, 9$ equiv) under $\mathrm{N}_{2}$ atmosphere. The vial was capped and stirred for $19 \mathrm{~h}$ at $115^{\circ} \mathrm{C}$ using a sand bath. The reaction mixture was quenched using sat. $\mathrm{Na}_{2} \mathrm{CO}_{3}(0.30 \mathrm{~mL})$ with $\mathrm{H}_{2} \mathrm{O}(15 \mathrm{~mL})$ added in addition. The separated aqueous phase was acidified using $1 \mathrm{M} \mathrm{HCl}$ to about $\mathrm{pH} 2$ and extracted with EtOAc $(3 \times 20 \mathrm{~mL})$. The combined organic phases were concentrated in vacuo and purified using preperative HPLC to give the racemic product $(0.796 \mathrm{mg}, 55 \%)$. The enantiomers were obtained using a ChiralPak AD $(250 \times 20 \mathrm{~mm}, 10 \mu \mathrm{m})$ column (isocratic elution: 70:30:0.1 $n$-heptane/EtOH/TFA, $20 \mathrm{~mL} / \mathrm{min}$ ) after four injections of the racemic mixture. The fractions of first eluting enantiomer were pooled, concentrated in vacuo, and freeze-dried to afford pure enantiomer 17-s1 as a clear oil $(419 \mathrm{mg}, 0.88 \mathrm{mmol}$, 29\%). LCMS (ESI) $\mathrm{m} / z=476.2[\mathrm{M}+\mathrm{H}]{ }^{+} ;{ }^{1} \mathrm{H}$ NMR $\left(600 \mathrm{MHz}, \mathrm{CDCl}_{3}\right) \delta 7.40-7.27(\mathrm{~m}$, $5 \mathrm{H}), 5.21(\mathrm{dd}, J=19.2,12.3 \mathrm{~Hz}, 1 \mathrm{H}), 5.07$ (dd, $J=53.9,12.3 \mathrm{~Hz}, 1 \mathrm{H}), 4.59$ (dd, $J=33.4$, $3.7 \mathrm{~Hz}, 1 \mathrm{H}), 3.74-3.65(\mathrm{~m}, 8 \mathrm{H}), 3.64-3.61(\mathrm{~m}, 2 \mathrm{H}), 3.60-3.54(\mathrm{~m}, 2 \mathrm{H}), 3.54-3.46(\mathrm{~m}, 1 \mathrm{H})$, $3.10-2.99(\mathrm{~m}, 1 \mathrm{H}), 2.38-2.22(\mathrm{~m}, 1 \mathrm{H}), 2.18-1.98(\mathrm{~m}, 1 \mathrm{H}) ;{ }^{13} \mathrm{C} \mathrm{NMR}\left(151 \mathrm{MHz}, \mathrm{CDCl}_{3}\right)$ (rotamers) $\delta 173.2,173.1,173.0,172.93,172.92,169.6,169.54,169.51,169.4,155.1,154.4$, $136.13,136.09,136.06,128.7,128.6,128.44,128.42,128.2,128.1,67.9,67.7,61.2,60.91$, 60.87, 59.7, 59.6, 59.63, 59.61, 53.6, 53.55, 53.53, 53.47, 53.12, 53.11, 52.9, 47.53, 47.50, $46.48,46.46,46.0,45.5,28.2,27.2,26.2$. The fractions of the second eluting enantiomer were pooled, concentrated in vacuo, and freeze-dried to afford the pure enantiomer 17-s2 as a clear oil (370 mg, $0.78 \mathrm{mmol}, 26 \%)$. LCMS (ESI) $\mathrm{m} / z=476.2[\mathrm{M}+\mathrm{H}]^{+} ;{ }^{1} \mathrm{H}$ NMR $(600$ $\left.\mathrm{MHz}, \mathrm{CDCl}_{3}\right) \delta 7.38-7.27(\mathrm{~m}, 5 \mathrm{H}), 5.20(\mathrm{dd}, J=17.4,12.4 \mathrm{~Hz}, 1 \mathrm{H}), 5.06(\mathrm{dd}, J=52.2,12.4$ 
$\mathrm{Hz}, 1 \mathrm{H}), 4.60(\mathrm{dd}, J=29.6,3.8 \mathrm{~Hz}, 1 \mathrm{H}), 3.72-3.64(\mathrm{~m}, 7 \mathrm{H}), 3.64-3.58(\mathrm{~m}, 3 \mathrm{H}), 3.56(\mathrm{~s}$, $2 \mathrm{H}), 3.53-3.46(\mathrm{~m}, 1 \mathrm{H}), 3.10-3.00(\mathrm{~m}, 1 \mathrm{H}), 2.29(\mathrm{~m}, 1 \mathrm{H}), 2.18-1.96(\mathrm{~m}, 1 \mathrm{H}) ;{ }^{13} \mathrm{C} \mathrm{NMR}$ $\left(151 \mathrm{MHz}, \mathrm{CDCl}_{3}\right)$ (rotamers) $\delta 173.1,172.9,169.6,169.5,169.4,154.9,154.3,136.23$, $136.22,128.65,128.61,128.33,128.29,128.14,128.10,67.7,67.6,61.3,60.9,59.53,59.49$, $53.52,53.50,53.4,53.0,52.8,47.4,46.4,45.9,45.5,28.4,28.3,27.1,26.1,25.3$.

trans-Dimethyl 2-((2H-Tetrazol-5-yl)methyl)-2-(2(methoxycarbonyl)pyrrolidin-3-yl)malonate (18-s1).-To a round-bottomed flask with a three-way valve connected were added 17-s1 (419 mg, $0.88 \mathrm{mmol}, 1$ equiv) and 10 $\mathrm{mol} \% \mathrm{Pd} / \mathrm{C}$ ( $9.3 \mathrm{mg}, 0.1$ equiv). The flask was evacuated and refilled with nitrogen three times, and $\mathrm{MeOH}(5 \mathrm{~mL})$ was added. The flask was evacuated and refilled once with nitrogen and three times with hydrogen. The reaction was stirred for 1 day at rt. The reaction flask was evacuated and refilled with nitrogen three times. The reaction mixture was filtered over a pad of Celite with $\mathrm{MeOH}(25 \mathrm{~mL})$ under a flow of nitrogen. The catalyst was washed with water and disposed, while the $\mathrm{MeOH}$ solution was concentrated in vacuo to give the crude of the desired enantiomer 18-s1 as a clear oil (313 $\mathrm{mg}, 0.92 \mathrm{mmol})$. The crude product was used in next reaction without further purification. LCMS (ESI) $\mathrm{m} / z=342.1[\mathrm{M}+\mathrm{H}]^{+}$.

\section{trans-Dimethyl 2-((2H-Tetrazol-5-)methyl)-2-(2-(methoxycarbonyl)pyrrolidin-3-}

yl)malonate (18-s2).-To a round-bottomed flask with a three-way valve connected were added 17-s2 ( $370 \mathrm{mg}, 0.78 \mathrm{mmol}, 1$ equiv) and $10 \mathrm{~mol} \% \mathrm{Pd} / \mathrm{C}$ ( $8.2 \mathrm{mg}, 0.1$ equiv). The flask was evacuated and refilled with nitrogen three times, and $\mathrm{MeOH}(4 \mathrm{~mL})$ was added. The flask was evacuated and refilled once with nitrogen and three times with hydrogen. The reaction was stirred for 1 day at $\mathrm{rt}$. The reaction flask was evacuated and refilled with nitrogen three times. The reaction mixture was filtered over a pad of Celite with $\mathrm{MeOH}(25$ $\mathrm{mL}$ ) under a flow of nitrogen. The catalyst was washed with water and disposed, while the $\mathrm{MeOH}$ solution was concentrated in vacuo to give the crude of the desired enantiomer 18-s2 as a clear oil (267 mg, $0.78 \mathrm{mmol})$. Product used in next reaction without further purification. LCMS (ESI) $\mathrm{m} / z=342.1[\mathrm{M}+\mathrm{H}]^{+}$.

trans-3-(1-Carboxy-2-(2H-tetrazol-5-yl)ethyl)pyrrolidine-2-carboxylic Acid (3qs1 and 3q-s2).-A stirring solution of crude 18-s1 (301 mg, $0.88 \mathrm{mmol}, 1$ equiv) in excess $6 \mathrm{M} \mathrm{HCl}$ was stirred under reflux for 4 days, under an argon atmosphere. The acidic solution was concentrated in vacuo, and the crude mixture of diastereomers was resolved using a chiral Chirobiotic T column $(500 \times 10 \mathrm{~mm})$ (Astec) (isocratic $20 \% \mathrm{~B}$; solvent $\mathrm{A}: \mathrm{NH}_{4} \mathrm{OAc}$ $(15 \mathrm{mM})+\mathrm{AcOH}$ to $\mathrm{pH} 4$; solvent $\mathrm{B}$ : $\mathrm{EtOH}, 5 \mathrm{~mL} / \mathrm{min}$ ) to afford 3q-s1 (contains 2.5 equiv of $\mathrm{AcONH}_{4}$ ) (the first eluting diastereomer) as semisolid (hygroscopic), after removal of the solvent in vacuo ( $181 \mathrm{mg}, 0.40 \mathrm{mmol}, 46 \%$ over two steps). d.r. 96:4; LCMS (ESI) $\mathrm{m} / z$ $256.1[\mathrm{M}+\mathrm{H}]^{+} ;[a]^{25} 589=-20.6^{\circ}(c=0.369,0.1 \mathrm{M} \mathrm{HCl}) ; 1 \mathrm{H} \mathrm{NMR}\left(600 \mathrm{MHz}, \mathrm{D}_{2} \mathrm{O}\right) \delta$ $4.17(\mathrm{~d}, J=5.7 \mathrm{~Hz}, 1 \mathrm{H}), 3.45(\mathrm{dt}, J=12.9,6.6 \mathrm{~Hz}, 1 \mathrm{H}), 3.42-3.36(\mathrm{~m}, 1 \mathrm{H}), 3.28$ (d, $J=8.2$ $\mathrm{Hz}, 2 \mathrm{H}), 2.91(\mathrm{q}, J=7.9 \mathrm{~Hz}, 1 \mathrm{H}), 2.60(\mathrm{p}, J=7.3 \mathrm{~Hz}, 1 \mathrm{H}), 2.20(\mathrm{dt}, J=13.9,7.0 \mathrm{~Hz}, 1 \mathrm{H})$, $1.91(\mathrm{dt}, J=14.5,7.2 \mathrm{~Hz}, 1 \mathrm{H}) ;{ }^{13} \mathrm{C} \mathrm{NMR}\left(151 \mathrm{MHz}, \mathrm{D}_{2} \mathrm{O}\right) \delta 179.1,173.8,157.3,63.8,50.2$, 45.2, 44.7, 27.7, 25.9. The second eluting diastereomer, 3q-s2 (contains 0.14 of equiv $\mathrm{AcONH}_{4}$ ), was obtained as a white solid after removal of the solvent in vacuo (41 $\mathrm{mg}, 0.15$ mmol, $18 \%$ over two steps). d.r. 4:96; LCMS (ESI) $\mathrm{m} / z 256.1[\mathrm{M}+\mathrm{H}]^{+} ;[a]^{25}{ }_{589}=-28.6^{\circ}$ 
$(c=0.273,0.1 \mathrm{M} \mathrm{HCl}) ; 1 \mathrm{H} \mathrm{NMR}\left(600 \mathrm{MHz}, \mathrm{D}_{2} \mathrm{O}\right) \delta 4.08(\mathrm{~d}, J=4.9 \mathrm{~Hz}, 1 \mathrm{H}), 3.43(\mathrm{t}, J=$ $7.5 \mathrm{~Hz}, 2 \mathrm{H}), 3.25(\mathrm{dd}, J=15.0,9.6 \mathrm{~Hz}, 1 \mathrm{H}), 3.06$ (dd, $J=14.9,5.0 \mathrm{~Hz}, 1 \mathrm{H}), 2.93$ (ddd, $J=$ 9.6, 6.9, $5.0 \mathrm{~Hz}, 1 \mathrm{H}), 2.87-2.79(\mathrm{~m}, 1 \mathrm{H}), 2.14(\mathrm{dt}, J=14.8,7.5 \mathrm{~Hz}, 1 \mathrm{H}), 1.96(\mathrm{dt}, J=13.6$, $7.0 \mathrm{~Hz}, 1 \mathrm{H}) ;{ }^{13} \mathrm{C}$ NMR $\left(151 \mathrm{MHz}, \mathrm{D}_{2} \mathrm{O}\right) \delta 180.4,173.8,160.6,63.4,49.3,45.0,44.9,26.9$, 25.2 .

trans-3-(1-Carboxy-2-(1H-tetrazol-5-yl)ethyl)pyrrolidine-2-carboxylic Acid Hydrochloride (3q-s3-4).-A stirring solution of crude 18-s2 (265 mg, $0.78 \mathrm{mmol}, 1$ equiv) in excess $6 \mathrm{M} \mathrm{HCl}_{(\mathrm{aq} .)}$ was stirred under reflux for 4 days, under argon. The acidic solution was concentrated in vacuo to afford a mixture of the trans-diastereomers $\mathbf{3 q}-\mathbf{s} \mathbf{3} / \mathbf{3 q}$ s4 as a white solid (226 mg, $0.77 \mathrm{mmol}, 99 \%$ ). d.r. 2:1. LCMS (ESI) $\mathrm{m} / z 256.1[\mathrm{M}+\mathrm{H}]^{+}$; ${ }^{1} \mathrm{H}$ NMR $\left(600 \mathrm{MHz}, \mathrm{D}_{2} \mathrm{O}\right)$ (two diastereomers) $\delta 4.48(\mathrm{dd}, J=38.3,7.9 \mathrm{~Hz}, 1 \mathrm{H}), 3.64-3.24$ (m, 5H), 3.01-2.81 (m, 1H), 2.49-2.29 (m, 1H), 2.10-1.90 (m, 1H); ${ }^{13} \mathrm{C}$ NMR (151 MHz, $\mathrm{D}_{2} \mathrm{O}$ ) (two diastereomers) $\delta 175.5,174.9,171.1,171.0,154.6,154.5,61.4,61.2,45.54$, $45.51,45.4,44.5,43.2,43.1,28.2,26.9,24.0,23.3$.

\section{Pharmacological Characterization.}

Ligand binding affinities for native AMPA, KA, and NMDA receptors in rat cortical synaptosomes were determined as previously described using $\left[{ }^{3} \mathrm{H}\right]-\mathrm{AMPA},\left[{ }^{3} \mathrm{H}\right]-\mathrm{KA}$, and $\left[{ }^{3} \mathrm{H}\right]$-CGP 39653 , respectively. ${ }^{40} \mathrm{CPM}$ values were fitted by nonlinear regression using GraphPad Prism 7.0 (GraphPad Software, San Diego, CA). Ligand affinities at recombinant rat homomeric GluK1-3 were determined as previously described ${ }^{21,52}$ using $\left[{ }^{3} \mathrm{H}\right]-\mathrm{KA}$ and the newly developed radioligand $\left[{ }^{3} \mathrm{H}\right]-\mathrm{NF} 608$ for GluK1 $1{ }^{69}$ Competition curves $(n \geq 3)$ were conducted in triplicate at 12-16 ligand concentrations. Data were analyzed using GraphPad Prism v6 (GraphPad Software, San Diego, CA) to determine ligand affinity ( $K_{\mathrm{i}}$ one site equation) and Hill slope (four-parameter logistic equation) values. The inhibitory concentrations of the compounds were determined at human EAAT1, EAAT2, and EAAT3 stably expressed in HEK293 cells in a conventional $\left[{ }^{3} \mathrm{H}\right]$-D-Asp uptake assay essentially as described previously. ${ }^{70}$ The cell lines were cultured at $37{ }^{\circ} \mathrm{C}$ in a humidified $5 \% \mathrm{CO}_{2}$ atmosphere in Dulbecco's modified Eagle's medium Glutamax-I supplemented with 5\% dialyzed fetal bovine serum, $100 \mathrm{U} / \mathrm{mL}$ penicillin, $100 \mu \mathrm{g} / \mathrm{mL}$ streptomycin, and $1 \mathrm{mg} / \mathrm{mL}$ G-418. The day before the assay, cells were split into poly-D-lysinecoated white 96-well plates. At 16-24 h later, the culture medium was aspirated and cells were washed twice with $100 \mu \mathrm{L}$ of assay buffer (Hank's buffered saline solution supplemented with $20 \mathrm{mM}$ HEPES, $1 \mathrm{mM} \mathrm{CaCl}_{2}$ and $1 \mathrm{mM} \mathrm{MgCl}_{2}, \mathrm{pH}$ 7.4). Then $50 \mu \mathrm{L}$ of assay buffer supplemented with 100 $\mathrm{nM}\left[{ }^{3} \mathrm{H}\right]$-D-Asp (PerkinElmer, Boston, MA) and various concentrations of test compounds were added to the wells, and the plate was incubated at $37{ }^{\circ} \mathrm{C}$ for $3 \mathrm{~min}$. Nonspecific $\left[{ }^{3} \mathrm{H}\right]-\mathrm{D}-$ Asp uptake/binding in the cells was determined in the presence of $3 \mathrm{mM}$ (S)-Glu. The assay mixtures were quickly removed from the wells, and the wells were washed with $2 \times 100 \mu \mathrm{L}$ ice-cold assay buffer, after which $150 \mu \mathrm{L}$ of Microscint-20 scintillation fluid (PerkinElmer, Boston, MA) was added to each well. Then the plate was shaken for at least $1 \mathrm{~h}$ and counted in a TopCounter (PerkinElmer, Boston, MA). The experiments were performed in duplicate at least three times for each compound. Functional characterization at cloned GluN1/ GluN2A-D receptors was done using rat cDNAs for GluN1-1a (GenBank U08261; hereafter GluN1), GluN2A (D13211), GluN2B (U11419), GluN2C (M91563), and GluN2D (L31611) 
were provided by S. Heinemann (Salk Institute), S. Nakanishi (Osaka Bioscience Institute), and P. Seeburg (University of Heidelberg). The cDNA encoding rat GluN2B was modified by removing a T7 RNA polymerase termination site located in the C-terminal domain, without changing the amino acid sequence. ${ }^{71}$ DNA constructs were first linearized by restriction enzymes and then used as templates for in vitro cRNA transcription. The cRNA encoding GluN1 was coinjected with different GluN2 subunit cRNA at a volume of $50 \mathrm{~nL}$ (0.5-5 ng) into Xenopus oocytes (purchased from Rob Weymouth at Xenopus 1, Dexter, MI). The injected oocytes were incubated at $17{ }^{\circ} \mathrm{C}$ for at least 2 days before recording in modified Barth's solution containing (in $\mathrm{mM}$ ) $88 \mathrm{NaCl}, 1.0 \mathrm{KCl}, 15 \mathrm{HEPES}, 2.4 \mathrm{NaHCO}_{3}$, $0.41 \mathrm{CaCl}_{2}, 0.82 \mathrm{MgSO}_{4}$, and $0.3 \mathrm{Ca}\left(\mathrm{NO}_{3}\right)_{2}(\mathrm{pH} 7.5$; osmolarity $0.22 \mathrm{Osm} / \mathrm{kg}$ ) supplemented with $0.1 \mathrm{U} / \mathrm{L}$ penicillin and $0.1 \mathrm{mg} / \mathrm{L}$ streptomycin. Two-electrode voltageclamp recordings were performed essentially as previously described. ${ }^{71}$ Briefly, a gravitydriven perfusion system was used with extracellular recording solution containing (in $\mathrm{mM}$ ) $90 \mathrm{NaCl}, 1 \mathrm{KCl}, 10 \mathrm{HEPES}, 0.5 \mathrm{BaCl}_{2}$, and $0.01 \mathrm{EDTA}$ (pH 7.4; osmolarity $0.20 \mathrm{Osm} / \mathrm{kg}$ ) at a flow rate of $5 \mathrm{~mL} / \mathrm{min}$. Oocytes expressing GluN1/2A or GluN1/2B were injected with 50 $\mathrm{nL}$ or $30 \mathrm{~nL}$ of $50 \mathrm{mM}$ BAPTA at least $10 \mathrm{~min}$ before recording to prevent activitydependent increases in response amplitude. ${ }^{72,73}$ For antagonist concentration-inhibition experiments, $100 \mu \mathrm{M}$ glycine and $1 \mu \mathrm{M}$ glutamate were coapplied to elicit current response followed by increasing concentrations of compound to inhibit current the response.

Concentration-response data were analyzed using GraphPad Prism (GraphPad Software). Antagonist concentration-inhibition data were fitted to

$I=I_{\min }+\left(I_{\max }-I_{\text {min }}\right) /\left(1+10^{\left(\left(\log [A]-\log \left[C_{50}\right) n H\right)\right)}\right.$, where $I_{\min }$ is the minimum current in response to the agonist plus a saturating concentration of antagonist. For some combinations of antagonist and NMDA receptor subtype, $I_{\min }$ was constrained to be 0 . For graphical presentation, the data from individual oocytes were normalized to the current response to glutamate plus glycine in the same recording and averaged. Antagonist binding affinities were estimated using published glutamate $\mathrm{EC}_{50}$ values for GluN1/2A-D, ${ }^{74} \mathrm{IC}_{50}$ values for individual oocytes, the agonist concentration $[A]$, and the Cheng-Prusoff relationship: $K_{\mathrm{i}}=$ $\mathrm{IC}_{50} /\left(1+[A] / \mathrm{EC}_{50}\right)$.

\section{Supplementary Material}

Refer to Web version on PubMed Central for supplementary material.

\section{ACKNOWLEDGMENTS}

The technical assistance of Niels Vissing Holst and Anders Kadziola, Department of Chemistry, University of Copenhagen, with collecting X-ray data and data reduction is gratefully acknowledged.

Funding

This work was financially supported by the Lundbeck Foundation (grant given to L.B.) and NIH (GM103546 and NS097536 grants given to K.B.H.).

\section{ABBREVIATIONS}
AMPA
$a$-amino-3-hydroxy-5-methyl-4-isoxazolepropionic acid 


$\begin{array}{ll}\text { CPAA } & (2 S, 3 R) \text {-2-carboxy-3-pyrrolidine acetic acid } \\ \text { DCVC } & \text { dry column vacuum chromatography } \\ \text { DHK } & \text { dihydrokainic acid } \\ \text { EAATs } & \text { excitatory amino acid transporters } \\ \text { Glu } & (S) \text {-glutamic acid } \\ \text { GluK1-3 } & \text { Kainate receptor subunits } 1-3 \\ \text { iGluRs } & \text { ionotropic Glu receptors } \\ \text { KA } & \text { kainic acid } \\ \text { NMDA } & N \text {-methyl-D-aspartate } \\ \text { SAR } & \text { structure-activity relationship }\end{array}$

\section{REFERENCES}

(1). Reiner A, and Levitz J (2018) Glutamatergic Signaling in the Central Nervous System: Ionotropic and Metabotropic Receptors in Concert. Neuron 98, 1080-1098. [PubMed: 29953871]

(2). Traynelis SF, et al. (2010) Glutamate Receptor Ion Channels: Structure, Regulation, and Function. Pharmacol. Rev 62, 405-496. [PubMed: 20716669]

(3). Gan Q, Salussolia CL, and Wollmuth LP (2015) Assembly of AMPA receptors: mechanisms and regulation. J. Physiol 593, 39-48. [PubMed: 25556786]

(4). Zhu S, and Gouaux E (2017) Structure and symmetry inform gating principles of ionotropic glutamate receptors. Neuropharmacology 112, 11-15. [PubMed: 27663701]

(5). Hansen KB, et al. (2018) Structure, function, and allosteric modulation of NMDA receptors. J. Gen. Physiol 150, 1081-1105. [PubMed: 30037851]

(6). Greger IH, Watson JF, and Cull-Candy SG (2017) Structural and Functional Architecture of AMPA-Type Glutamate Receptors and Their Auxiliary Proteins. Neuron 94, 713-730. [PubMed: 28521126]

(7). Chen PE, and Wyllie D. J. a. (2006) Pharmacological insights obtained from structure-function studies of ionotropic glutamate receptors. Br. J. Pharmacol 147, 839-853. [PubMed: 16474411]

(8). Lee C-H, et al. (2014) NMDA receptor structures reveal subunit arrangement and pore architecture. Nature 511, 191-197. [PubMed: 25008524]

(9). Karakas E, and Furukawa H (2014) Crystal structure of a heterotetrameric NMDA receptor ion channel. Science 344, 992-997. [PubMed: 24876489]

(10). Sobolevsky AI, Rosconi MP, and Gouaux E (2009) X-ray structure, symmetry and mechanism of an AMPA-subtype glutamate receptor. Nature 462, 745-756. [PubMed: 19946266]

(11). Farooqui AA, Ong WY, Lu X-R, Halliwell B, and Horrocks LA (2001) Neurochemical consequences of kainate-induced toxicity in brain: involvement of arachidonic acid release and prevention of toxicity by phospholipase A2 inhibitors. Brain Res. Rev 38, 61-78. [PubMed: 11750927]

(12). Ko S, Zhao M-G, Toyoda H, Qiu C-S, and Zhuo M (2005) Altered Behavioral Responses to Noxious Stimuli and Fear in Glutamate Receptor 5 (GluR5)- or GluR6-Deficient Mice. J. Neurosci 25, 977-984. [PubMed: 15673679]

(13). Pitt D, Werner P, and Raine CS (2000) Glutamate excitotoxicity in a model of multiple sclerosis. Nat. Med 6, 67-70. [PubMed: 10613826]

(14). Matute C (2011) Therapeutic potential of kainate receptors. CNS Neurosci. Ther 17, 661-9. [PubMed: 21129167] 
(15). Lerma J, and Marques JM (2013) Kainate receptors in health and disease. Neuron 80, 292-311. [PubMed: 24139035]

(16). Meador-Woodruff JH, Davis KL, and Haroutunian V (2001) Abnormal kainate receptor expression in prefrontal cortex in schizophrenia. Neuropsychopharmacology 24, 545-52. [PubMed: 11282254]

(17). Contractor A, Mulle C, and Swanson GT (2011) Kainate receptors coming of age: milestones of two decades of research. Trends Neurosci 34, 154-163. [PubMed: 21256604]

(18). Jamain S, et al. (2002) Linkage and association of the glutamate receptor 6 gene with autism. Mol. Psychiatry 7, 302-310. [PubMed: 11920157]

(19). Woo TU, et al. (2007) Differential alterations of kainate receptor subunits in inhibitory interneurons in the anterior cingulate cortex in schizophrenia and bipolar disorder. Schizophr. Res 96, 46-61. [PubMed: 17698324]

(20). Xu J, et al. (2017) Complete Disruption of the Kainate Receptor Gene Family Results in Corticostriatal Dysfunction in Mice. Cell Rep 18, 1848-1857. [PubMed: 28228252]

(21). Frydenvang K, et al. (2010) Biostructural and Pharmacological Studies of Bicyclic Analogues of the 3-Isoxazolol Glutamate Receptor Agonist Ibotenic Acid. J. Med. Chem 53, 8354-8361. [PubMed: 21067182]

(22). Madsen U, et al. (1996) N-Methyl-d-aspartic Acid Receptor Agonists: Resolution, Absolute Stereochemistry, and Pharmacology of the Enantiomers of 2-Amino-2-(3-hydroxy-5-methyl-4isoxazolyl)-acetic Acid. J. Med. Chem 39, 183-190. [PubMed: 8568805]

(23). Conti P, et al. (1999) Synthesis and Enantiopharmacology of New AMPA-Kainate Receptor Agonists. J. Med. Chem 42, 4099-4107. [PubMed: 10514280]

(24). Sagot E, et al. (2008) Chemo-Enzymatic Synthesis of a Series of 2,4-Syn -Functionalized (S)Glutamate Analogues: New Insight into the Structure-Activity Relation of Ionotropic Glutamate Receptor Subtypes 5, 6, and 7. J. Med. Chem 51, 4093-4103. [PubMed: 18578478]

(25). Bunch L, and Krogsgaard-Larsen P (2009) Subtype selective kainic acid receptor agonists: Discovery and approaches to rational design. Med. Res. Rev 29, 3-28. [PubMed: 18623169]

(26). Rasmussen JL, Storgaard M, Pickering DS, and Bunch L (2011) Rational Design, Synthesis and Pharmacological Evaluation of the (2R)- and (2S)-Stereoisomers of 3-(2-Carboxypyrrolidinyl)-2methyl Acetic Acid as Ligands for the Ionotropic Glutamate Receptors. ChemMedChem 6, 498504. [PubMed: 21268287]

(27). Bunch L, Nielsen B, Jensen AA, and Bräuner-Osborne H (2006) Rational Design and Enantioselective Synthesis of (1R,4S,5R,6S)-3-Azabicyclo[3.3.0]octane-4,6-dicarboxylic Acid A Novel Inhibitor at Human Glutamate Transporter Subtypes 1, 2, and 3. J. Med. Chem 49, 172 178. [PubMed: 16392801]

(28). Møllerud S, et al. (2017) Structure and Affinity of Two Bicyclic Glutamate Analogues at AMPA and Kainate Receptors. ACS Chem. Neurosci 8, 2056-2064. [PubMed: 28691798]

(29). Stensbøl TB, et al. (1999) Resolution, absolute stereo-chemistry and molecular pharmacology of the enantiomers of ATPA. Eur. J. Pharmacol 380, 153-162. [PubMed: 10513575]

(30). Clausen RP, et al. (2009) The Glutamate Receptor GluR5 Agonist (S)-2-Amino-3-(3hydroxy-7,8-dihydro-6H-cyclohepta[d]-isoxazol-4-yl)propionic Acid and the 8-Methyl Analogue: Synthesis, Molecular Pharmacology, and Biostructural Characterization. J. Med. Chem 52, 4911-4922. [PubMed: 19588945]

(31). Lash LL, et al. (2007) Novel Analogs and Stereoisomers of the Marine Toxin Neodysiherbaine with Specificity for Kainate Receptors. J. Pharmacol. Exp. Ther 324, 484-496. [PubMed: 18032572]

(32). Shoji M, et al. (2006) Total Synthesis and Biological Evaluation of Neodysiherbaine A and Analogues. J. Org. Chem 71, 5208-5220. [PubMed: 16808508]

(33). Butini S, et al. (2008) 1H-Cyclopentapyrimidine-2,4(1H,3H)-dione-Related Ionotropic Glutamate Receptors Ligands. Structure-Activity Relationships and Identification of Potent and Selective iGluR5Modulators. J. Med. Chem 51, 6614-6618. [PubMed: 18811139]

(34). Zhou LM, et al. (1997) (2S,4R)-4-methylglutamic acid (SYM 2081): a selective, high-affinity ligand for kainate receptors. J. Pharmacol. Exp. Ther 280, 422-7. [PubMed: 8996224] 
(35). Gu Z-Q, et al. (1995) Synthesis, Resolution, and Biological Evaluation of the Four Stereoisomers of 4-Methylglutamic Acid: Selective Probes of Kainate Receptors. J. Med. Chem 38, 2518-2520. [PubMed: 7629789]

(36). Alaux S, et al. (2005) Chemoenzymatic Synthesis of a Series of 4-Substituted Glutamate Analogues and Pharmacological Characterization at Human Glutamate Transporters Subtypes 13. J. Med. Chem 48, 7980-7992. [PubMed: 16335922]

(37). Bunch L, et al. (2009) Pharmacological characterization of (4R)-alkyl glutamate analogues at the ionotropic glutamate receptors — Focus on subtypes iGlu5-7. Eur. J. Pharmacol 609, 1-4. [PubMed: 19285062]

(38). Bunch L, et al. (2001) Synthesis and receptor binding affinity of new selective GluR5 ligands. Bioorg. Med. Chem 9, 875-879. [PubMed: 11354670]

(39). Bunch L, et al. (2009) 4,4-Dimethyl- and diastereomeric 4-hydroxy-4-methyl- (2S)-glutamate analogues display distinct pharmacological profiles at ionotropic glutamate receptors and excitatory amino acid transporters. ChemMedChem 4, 1925-9. [PubMed: 19731281]

(40). Assaf Z, et al. (2013) Chemoenzymatic Synthesis of New 2,4-syn-Functionalized (S)-Glutamate Analogues and Structure-Activity Relationship Studies at Ionotropic Glutamate Receptors and Excitatory Amino Acid Transporters. J. Med. Chem 56, 1614-1628. [PubMed: 23414088]

(41). Venskutonyte R, et al. (2014) Molecular Recognition of Two 2,4-syn-Functionalized (S)Glutamate Analogues by the Kainate Receptor GluK3 Ligand Binding Domain. ChemMedChem 9, 2254-2259. [PubMed: 25044437]

(42). Sagot E, et al. (2008) Chemo-enzymatic synthesis of a series of 2,4-syn-functionalized (S)glutamate analogues: new insight into the structure-activity relation of ionotropic glutamate receptor subtypes 5, 6, and 7. J. Med. Chem 51, 4093-103. [PubMed: 18578478]

(43). Escribano AM, et al. (1998) (2S,4S)-2-Amino-4-(2,2-diphenylethyl)pentanedioic acid selective group 2 metabotropic glutamate receptor antagonist. Bioorg. Med. Chem. Lett 8, 765-770. [PubMed: 9871538]

(44). Erreger K, et al. (2007) Subunit-Specific Agonist Activity at NR2A-, NR2B-, NR2C-, and NR2D-Containing N-Methyl-D-aspartate Glutamate Receptors. Mol. Pharmacol 72, 907-920. [PubMed: 17622578]

(45). Small B, et al. (1998) LY339434, a GluR5 kainate receptor agonist. Neuropharmacology 37, 1261-1267. [PubMed: 9849663]

(46). Baker SRR, et al. (2000) 4-Alkylidenyl glutamic acids, potent and selective GluR5 agonists. Bioorg. Med. Chem. Lett 10, 1807-1810. [PubMed: 10969973]

(47). Pedregal C, et al. (2000) 4-Alkyl- and 4-Cinnamylglutamic Acid Analogues Are Potent GluR5 Kainate Receptor Agonists. J. Med. Chem 43, 1958-1968. [PubMed: 10821708]

(48). Larsen AM, and Bunch L (2011) Medicinal Chemistry of Competitive Kainate Receptor Antagonists. ACS Chem. Neurosci 2, 60-74. [PubMed: 22778857]

(49). Byskov Vogensen S, Greenwood JR, Bunch L, and Clausen RP (2011) Glutamate receptor agonists: stereochemical aspects. Curr. Top. Med. Chem 11, 887-906. [PubMed: 21291400]

(50). Todeschi N, et al. (1997) Conformational analysis of glutamic acid analogues as probes of glutamate receptors using molecular modelling and NMR methods. Comparison with specific agonists. Bioorg. Med. Chem 5, 335-352. [PubMed: 9061198]

(51). Stawski P, Janovjak H, and Trauner D (2010) Pharmacology of ionotropic glutamate receptors: A structural perspective. Bioorg. Med. Chem 18, 7759-7772. [PubMed: 20947363]

(52). Møllerud S, Frydenvang K, Pickering DS, and Kastrup JS (2017) Lessons from crystal structures of kainate receptors. Neuropharmacology 112, 16-28. [PubMed: 27236079]

(53). Todeschi N, Gharbi-Benarous J, Acher F, Azerad R, and Girault J-P (1996) Conformational analysis by NMR spectroscopy and molecular simulation in water of methylated glutamic acids, agonists at glutamate receptors. J. Chem. Soc., Perkin Trans. 22 (7), 1337-1351.

(54). Acevedo CM, Kogut EF, and Lipton MA (2001) Synthesis and analysis of the sterically constrained l-glutamine analogues (3S,4R)-3,4-dimethyl-1-glutamine and (3S,4R)-3,4-dimethyl-1pyroglutamic acid. Tetrahedron 57, 6353-6359. 
(55). Coldham I, Fernández J-C, Price KN, and Snowden DJ (2000) Intramolecular Carbolithiation Reactions for the Preparation of Azabicyclo[2.2.1]heptanes. J. Org. Chem 65, 3788-3795. [PubMed: 10864766]

(56). Tojo G, and Fernández M (2007) Ruthenium Tetroxide and Other Ruthenium Compounds. In Oxidation of Primary Alcohols to Carboxylic Acids, pp 61-78, Springer 10.1007/0-387-35432-8_5.

(57). Yoo S-E, Lee S-H, and Kim N-J (1988) An efficient synthesis of the basic pyrrolidine ring for the kainoids. Tetrahedron Lett 29, 2195-2196.

(58). Moss WO, Bradbury RH, Hales NJ, and Gallagher T (1990) Generation of $a$-amino acid homoenolate equivalents. Synthesis of 3-substituted prolines. Tetrahedron Lett 31, 5653-5656.

(59). Lunglois N, and Andriamialisoa RZ (1991) Diastereoselective synthesis of (2S,3R) 2-carboxy-3pyrrolidine acetic acid, a simple kainic acid analogue. Tetrahedron Lett 32, 3057-3058.

(60). Carpes MJ, Miranda PCML, and Correia CRD (1997) Stereoselective synthesis of conformationally restricted analogues of aspartic and glutamic acids from endocyclic enecarbamates. Tetrahedron Lett 38, 1869-1872.

(61). Karoyan P, and Chassaing G (2002) Short asymmetric synthesis of (2S,3S)- and (2S,3R)-3prolinoglutamic acids: 2-carboxy-3-pyrrolidine-acetic acids (CPAA). Tetrahedron Lett 43, 253255.

(62). Oba M, Saegusa T, Nishiyama N, and Nishiyama K (2009) Synthesis of non-proteinogenic amino acids using Michael addition to unsaturated orthopyroglutamate derivative. Tetrahedron 65, 128 133.

(63). Felluga F, et al. (2012) First chemoenzymatic synthesis of (+)-2-carboxypyrrolidine-3-acetic acid, the nucleus of kainoid amino acids. Chirality 24, 112-118. [PubMed: 22180179]

(64). Huy P, Neudörfl J-M, and Schmalz H-G (2011) A Practical Synthesis of Trans -3-Substituted Proline Derivatives through 1,4-Addition. Org. Lett 13, 216-219. [PubMed: 21158419]

(65). Tay NES, and Nicewicz DA (2017) Cation Radical Accelerated Nucleophilic Aromatic Substitution via Organic Photoredox Catalysis. J. Am. Chem. Soc 139, 16100-16104. [PubMed: 29068677]

(66). Pallandre J-R, et al. (2015) Novel aminotetrazole derivatives as selective STAT3 non-peptide inhibitors. Eur. J. Med. Chem 103, 163-174. [PubMed: 26352675]

(67). Sonnenberg JD, et al. (1996) The role of the C-4 side chain of kainate and dihydrokainate in EAA receptor and transporter selectivity. Bioorg. Med. Chem. Lett 6, 1607-1612.

(68). Pedersen D, and Rosenbohm C (2001) Dry Column Vacuum Chromatography. Synthesis 2001, 2431-2434.

(69). Alcaide A, et al. (2016) Synthesis and pharmacological characterization of the selective GluK1 radioligand (S)-2-amino-3-(6-[3H]-2,4-dioxo-3,4-dihydrothieno[3,2-d]pyrimidin-1(2H)-yl)propanoic acid ([3H]-NF608). MedChemComm 7, 2136-2144.

(70). Jensen AA, and Bräuner-Osborne H (2004) Pharmacological characterization of human excitatory amino acid transporters EAAT1, EAAT2 and EAAT3 in a fluorescence-based membrane potential assay. Biochem. Pharmacol 67, 2115-2127. [PubMed: 15135308]

(71). Hansen KB, Ogden KK, Yuan H, and Traynelis SF (2014) Distinct Functional and Pharmacological Properties of Triheteromeric GluN1/GluN2A/GluN2B NMDA Receptors. Neuron 81, 1084-1096. [PubMed: 24607230]

(72). Yi F, et al. (2016) Structural Basis for Negative Allosteric Modulation of GluN2A-Containing NMDA Receptors. Neuron 91, 1316-1329. [PubMed: 27618671]

(73). Williams K (1993) Ifenprodil discriminates subtypes of the N-methyl-D-aspartate receptor: selectivity and mechanisms at recombinant heteromeric receptors. Mol. Pharmacol 44, 851-859. [PubMed: 7901753]

(74). Lind GEE, et al. (2017) Structural basis of subunit selectivity for competitive NMDA receptor antagonists with preference for GluN2A over GluN2B subunits. Proc. Natl. Acad. Sci. U. S. A 114, E6942-E6951. [PubMed: 28760974] 
A

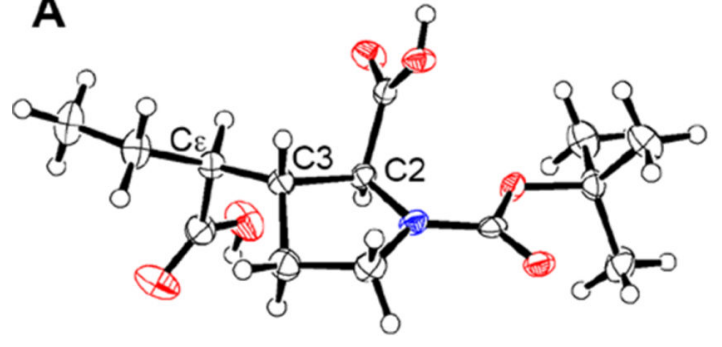

B

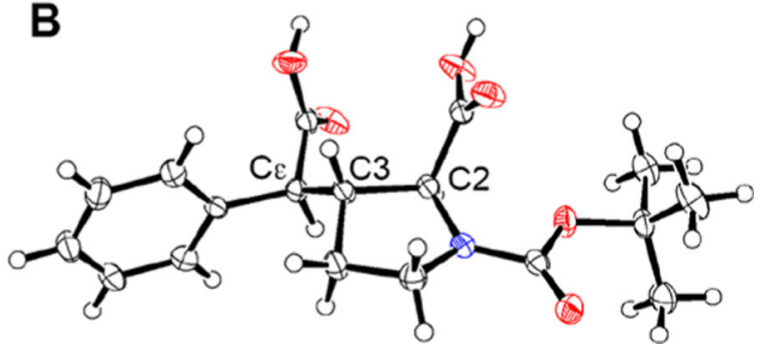

Figure 1.

Crystal structures of Boc-protected 3c-s1 (9c-s1, A) and 3d-s2 (9d-s2, B). Displacement ellipsoids of the non-hydrogen atoms are shown at the 50\% probability level. Hydrogen atoms are represented by spheres of arbitrary size. Oxygen atoms are in red and nitrogen atoms in blue. 
A
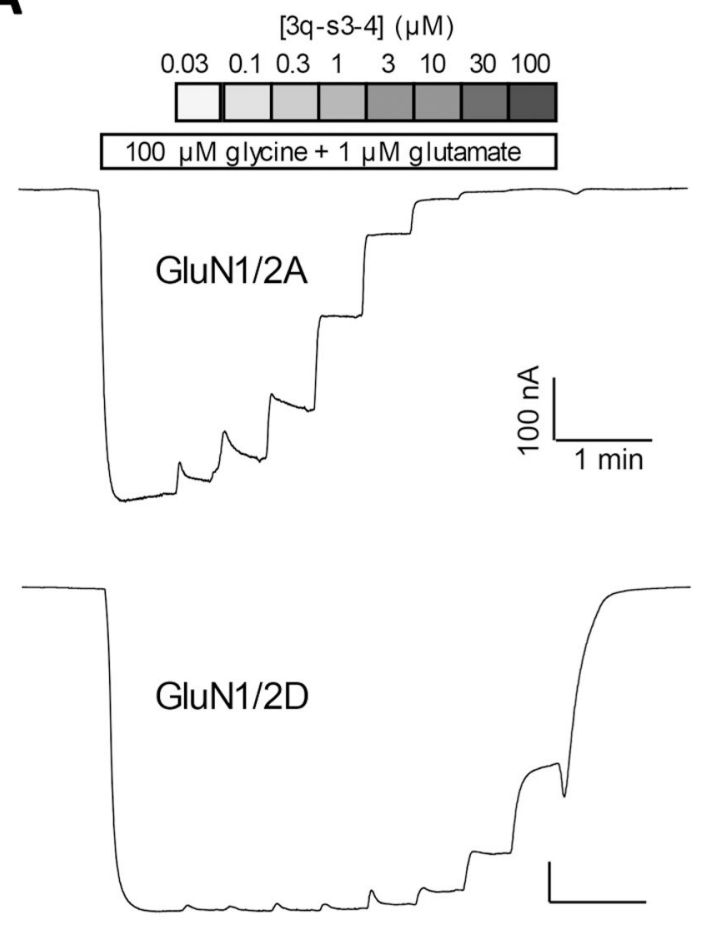

B

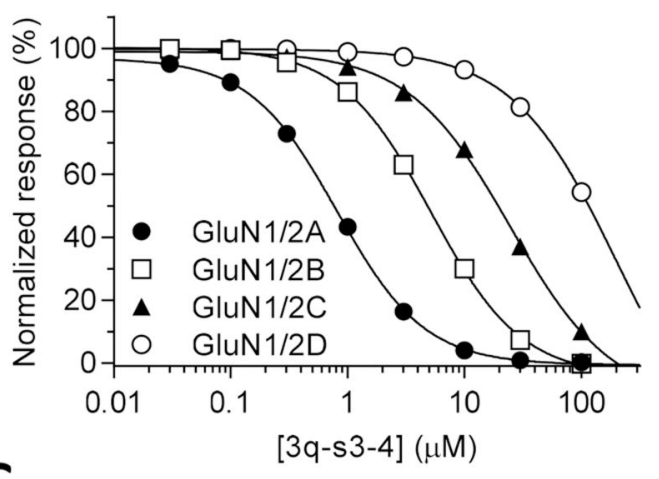

C

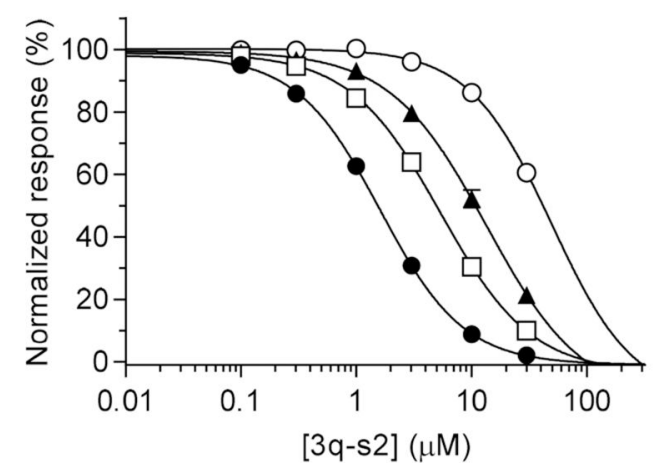

Figure 2.

Concentration-inhibition data of 3q-s1-4 and 3q-s2 at NMDA receptor subtypes. (A) Representative two-electrode voltage-clamp recordings showing inhibition of GluN1/2A and GluN1/2D by 3q-s1-4. Receptors were activated by $100 \mu \mathrm{M}$ glycine and $1 \mu \mathrm{M}$ glutamate. (B) Concentration-inhibition data for 3q-s1-4 at different NMDA receptor subtypes (GluN1/2A-D). (C) Concentration-inhibition data for 3q-s2 at different NMDA receptor subtypes (GluN1/2A-D). Data points are shown as mean \pm SEM from six oocytes. The $K_{\mathrm{i}}$ values were derived from the $\mathrm{IC}_{50}$ values using the Cheng-Prusoff relationship (Table 1). 


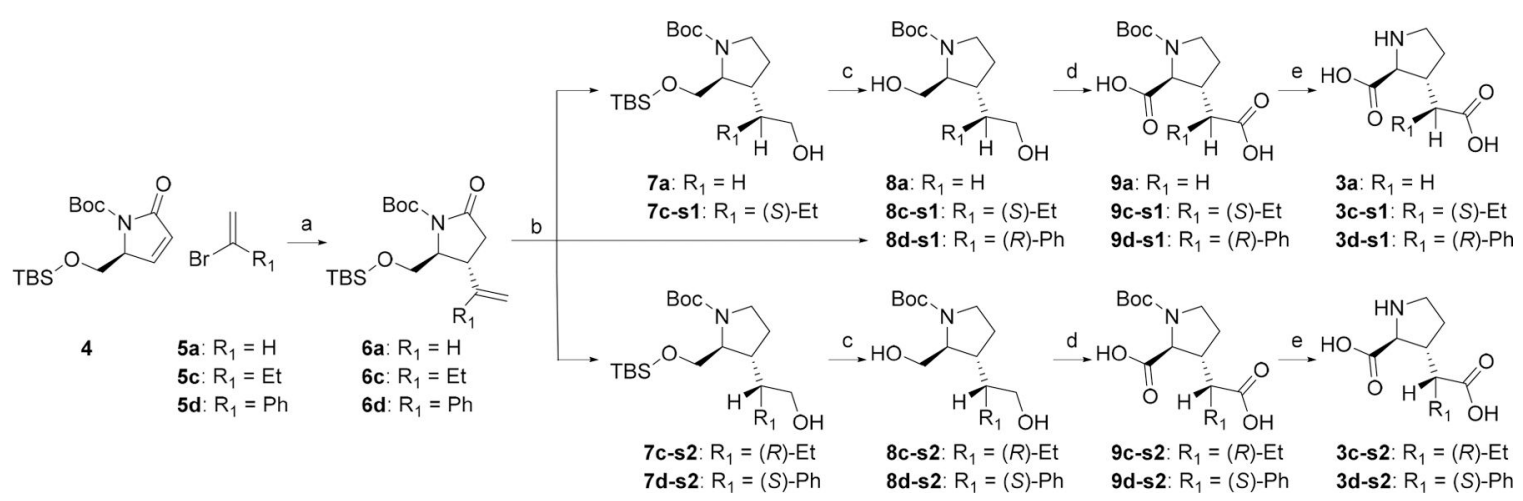

Scheme 1. Synthesis of 3a, 3c-s1, 3c-s2, 3d-s1, and 3d-s2 ${ }^{a}$

${ }^{a}$ Reagents and conditions: (a) $t$-butyllithium, $\mathrm{CuCN}$, THF, -78 to $-50{ }^{\circ} \mathrm{C}$, followed by 4 , TMSCl, $-50{ }^{\circ} \mathrm{C}, 1 \mathrm{~h}, 61-82 \%$; (b) $\mathrm{BH}_{3} \cdot \mathrm{THF}$, THF, rt, 20h, followed by $\mathrm{H}_{2} \mathrm{O}, \mathrm{NaOH}, \mathrm{H}_{2} \mathrm{O}_{2}$, $0{ }^{\circ} \mathrm{C}$ to $\mathrm{rt}, 1 \mathrm{~h}$, separation of the two diastereomers by DCVC, 17-52\%; (c) TBAF, THF, rt, 56-84\%; (d) $\mathrm{RuCl}_{3}, \mathrm{NaIO}_{4}, \mathrm{H}_{2} \mathrm{O}, \mathrm{MeCN}$, EtOAc, rt, 7 h, 23-75\%; (e) TFA, DCM, rt, 2 h, followed by $1 \mathrm{M} \mathrm{HCl}, 13-60 \%$. 
<smiles>COC(=O)C1=C[CH+]CCN1C(=O)OCc1ccccc1</smiles>

10

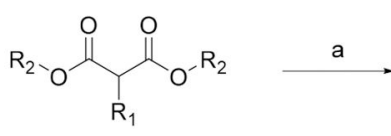

11a: $\mathrm{R}_{1}=\mathrm{H} ; \mathrm{R}_{2}=\mathrm{Me}$

11e: $\mathrm{R}_{1}=n-\mathrm{Pr} ; \mathrm{R}_{2}=\mathrm{Et}$

11f: $\mathrm{R}_{1}=i-\mathrm{Pr} ; \mathrm{R}_{2}=\mathrm{Et}$

11g: $R_{1}=B n ; R_{2}=E t$

11h: $\mathrm{R}_{1}=\left(\mathrm{CH}_{2}\right)_{2} \mathrm{Ph} ; \mathrm{R}_{2}=\mathrm{Et}$

11i: $R_{1}=F ; R_{2}=M e$

11j: $R_{1}=O M e ; R_{2}=M e$

$11 \mathrm{k}: \mathrm{R}_{1}=\mathrm{NH}-\mathrm{Boc}: \mathrm{R}_{2}=\mathrm{Et}$

11I: $R_{1}=\mathrm{CH}_{2} \mathrm{COOEt} ; \mathrm{R}_{2}=\mathrm{Et}$

$11 \mathrm{~m}: \mathrm{R}_{1}=\left(\mathrm{CH}_{2}\right)_{2} \mathrm{CN} ; \mathrm{R}_{2}=\mathrm{Et}$

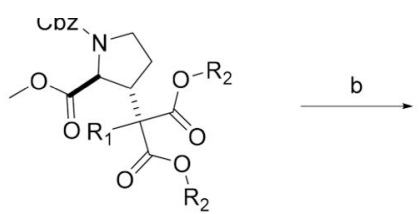

12a: $R_{1}=H ; R_{2}=M e$

12e: $\mathrm{R}_{1}=n-\mathrm{Pr} ; \mathrm{R}_{2}=\mathrm{Et}$

12f: $\mathrm{R}_{1}=i-\mathrm{Pr} ; \mathrm{R}_{2}=\mathrm{Et}$

12g: $R_{1}=B n ; R_{2}=E t$

12h: $\mathrm{R}_{1}=\left(\mathrm{CH}_{2}\right)_{2} \mathrm{Ph} ; \mathrm{R}_{2}=\mathrm{Et}$

12i: $R_{1}=F ; R_{2}=M e$

12j: $R_{1}=O M e ; R_{2}=M e$

12k: $R_{1}=\mathrm{NH}-\mathrm{Boc} ; \mathrm{R}_{2}=\mathrm{Et}$

12I: $R_{1}=\mathrm{CH}_{2} \mathrm{COOEt} ; \mathrm{R}_{2}=\mathrm{Et}$

12m: $R_{1}=\left(\mathrm{CH}_{2}\right)_{2} \mathrm{CN} ; \mathrm{R}_{2}=\mathrm{Et}$

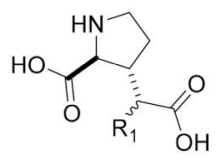

3a: $\mathrm{R}_{1}=\mathrm{H}$

3e: $\mathrm{R}_{1}=n-\mathrm{Pr}$

3f: $\mathrm{R}_{1}=i-\mathrm{Pr}$

3g: $\mathrm{R}_{1}=\mathrm{Bn}$

3h: $\mathrm{R}_{1}=\left(\mathrm{CH}_{2}\right)_{2} \mathrm{Ph}$

3i: $R_{1}=F$

3j: $\mathrm{R}_{1}=\mathrm{OMe}$

3k: $\mathrm{R}_{1}=\mathrm{NH}_{2}$

3I: $\mathrm{R}_{1}=\mathrm{CH}_{2} \mathrm{COOH}$

$3 \mathrm{~m}: \mathrm{R}_{1}=\left(\mathrm{CH}_{2}\right)_{2} \mathrm{COOH}$

Scheme 2. Synthesis of 3a and 3e-m by Conjugate Addition of Substituted Malonic Ester 11a and $11 \mathrm{e}-\mathrm{m}$ to Enone $10^{a}$

${ }^{a}$ Reagents and conditions: (a) NaH, THF, $50{ }^{\circ} \mathrm{C}, 3-24$ h, 35-99\%; (b) $6 \mathrm{M} \mathrm{HCl}$, reflux, 4-9

days, $6-87 \%$. 
<smiles>COC(=O)C1=CCCN1C</smiles>

10

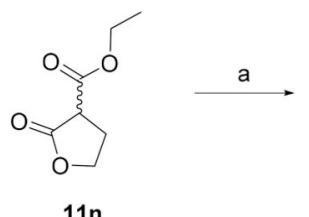

$11 n$

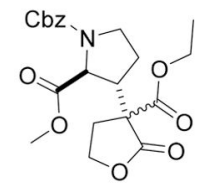

$12 n$

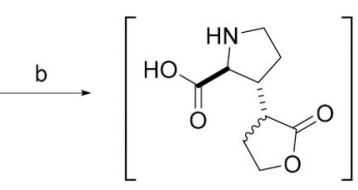

13

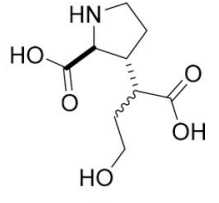

$3 n$

Scheme 3. Synthesis of 3n from Enone 10 ${ }^{a}$

${ }^{a}$ Reagents and conditions: (a) $\mathrm{NaH}, \mathrm{THF}, 50{ }^{\circ} \mathrm{C}, 4 \mathrm{~h}, 71 \%$; (b) $6 \mathrm{M} \mathrm{HCl}$, reflux, 4 days. (c) $\mathrm{NaOH}$ (42\% over two steps). 


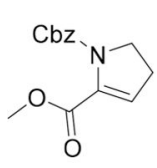

10

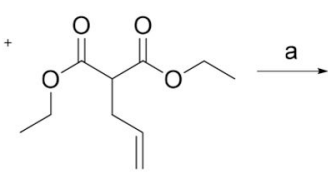

110

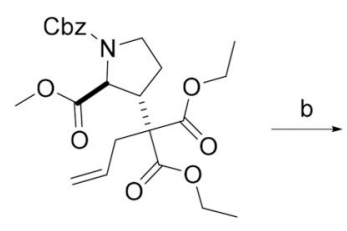

14

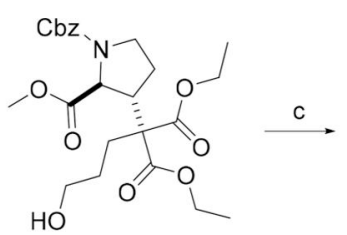

120

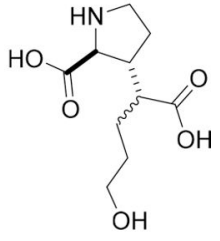

30

Scheme 4. Synthesis of 30 from Intermediate $14^{a}$

${ }^{a}$ Reagents and conditions: (a) NaH, THF, $50{ }^{\circ} \mathrm{C}, 4 \mathrm{~h}, 93 \%$; (b) $\mathrm{BH}_{3} \cdot \mathrm{THF}, \mathrm{THF}, 0{ }^{\circ} \mathrm{C}, 2 \mathrm{~h}$,

followed by $\mathrm{H}_{2} \mathrm{O}, \mathrm{NaOH}, \mathrm{H}_{2} \mathrm{O}_{2}, 0{ }^{\circ} \mathrm{C}, 1 \mathrm{~h}, 49 \%$; (c) $6 \mathrm{M} \mathrm{HCl}$, reflux, 3 days, $28 \%$. 


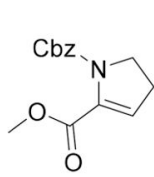

10

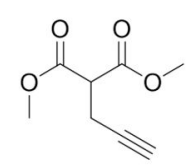

$11 p$

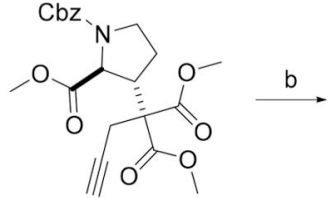

15

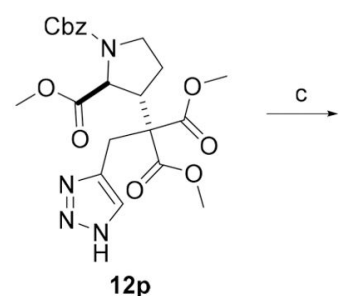

$12 p$

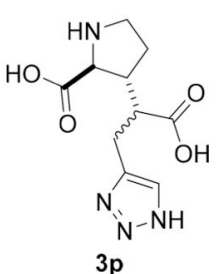

Scheme 5. Synthesis of $3 p$ from Alkyne $15^{a}$

${ }^{a}$ Reagents and conditions: (a) NaH, THF, $50{ }^{\circ} \mathrm{C}, 4$ h, 89\%; (b) $\mathrm{TMSN}_{3}$, CuI, DMF, MeOH, reflux, $18 \mathrm{~h}, 71 \%$; (c) $6 \mathrm{M} \mathrm{HCl}$, reflux, 3 days, $78 \%$. 
A<smiles>COC(=O)C1CCN([13C](=O)[O-])C1C(=O)OC</smiles>

$( \pm)-12 a$

$( \pm)-16$

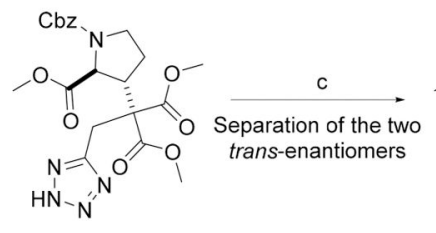

$( \pm)-17$
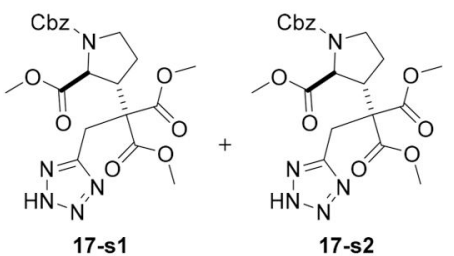

B
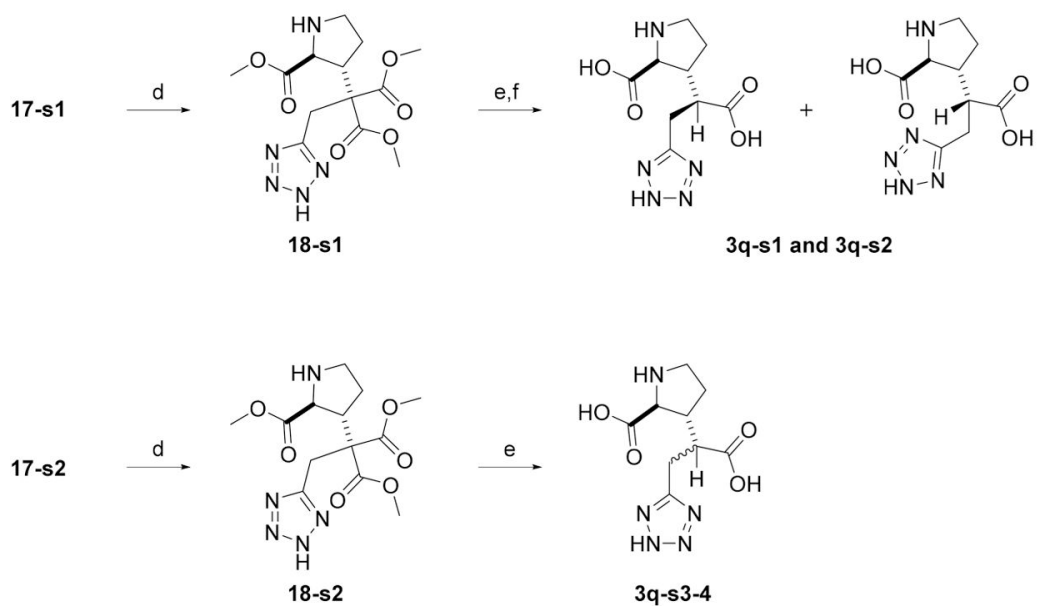

Scheme 6. Synthesis of $3 q$ and Separation of Stereoisomers ${ }^{a}$

${ }^{a}$ Reagents and conditions: (a) $\mathrm{NaH}, \mathrm{BrCH}_{2} \mathrm{CN}$, THF, $50{ }^{\circ} \mathrm{C}, 23 \mathrm{~h}, 83 \%$; (b) $\mathrm{NaN}_{3}, \mathrm{Et}_{3} \mathrm{NHCl}$, toluene, $115^{\circ} \mathrm{C}, 19 \mathrm{~h}, 55 \%$ (c) separation of the 2,3-trans enantiomers by preparative HPLC using a ChiralPak AD column, 26-29\%; (d) $\mathrm{Pd} / \mathrm{C}, \mathrm{H}_{2}$, $\mathrm{MeOH}$, r.t. 24 h, quant.; (e) $6 \mathrm{M} \mathrm{HCl}$, reflux, 4 days, 99\%; (f) separation of diastereoisomers by preparative HPLC using Chirobiotic T column, 18-80\%. 


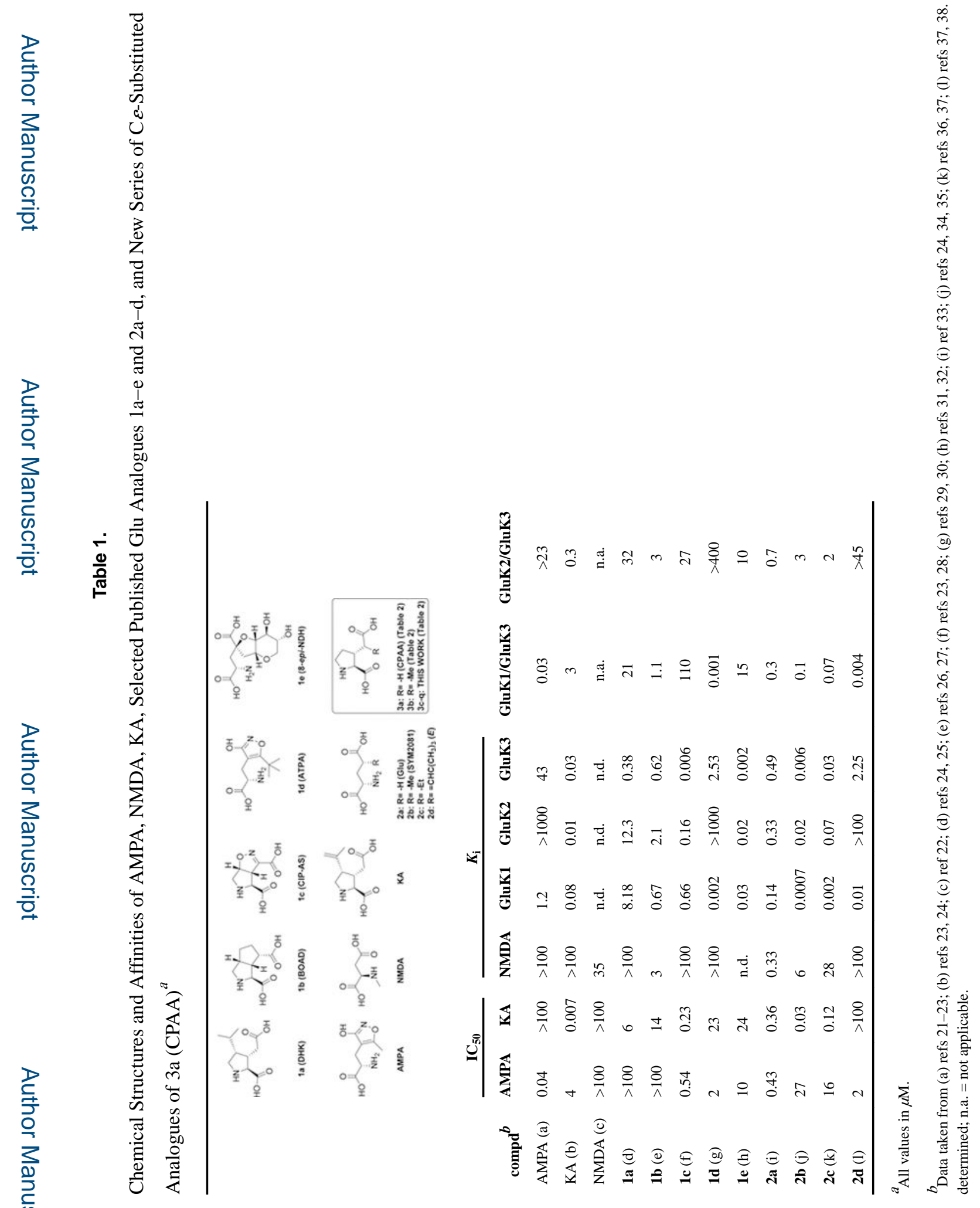




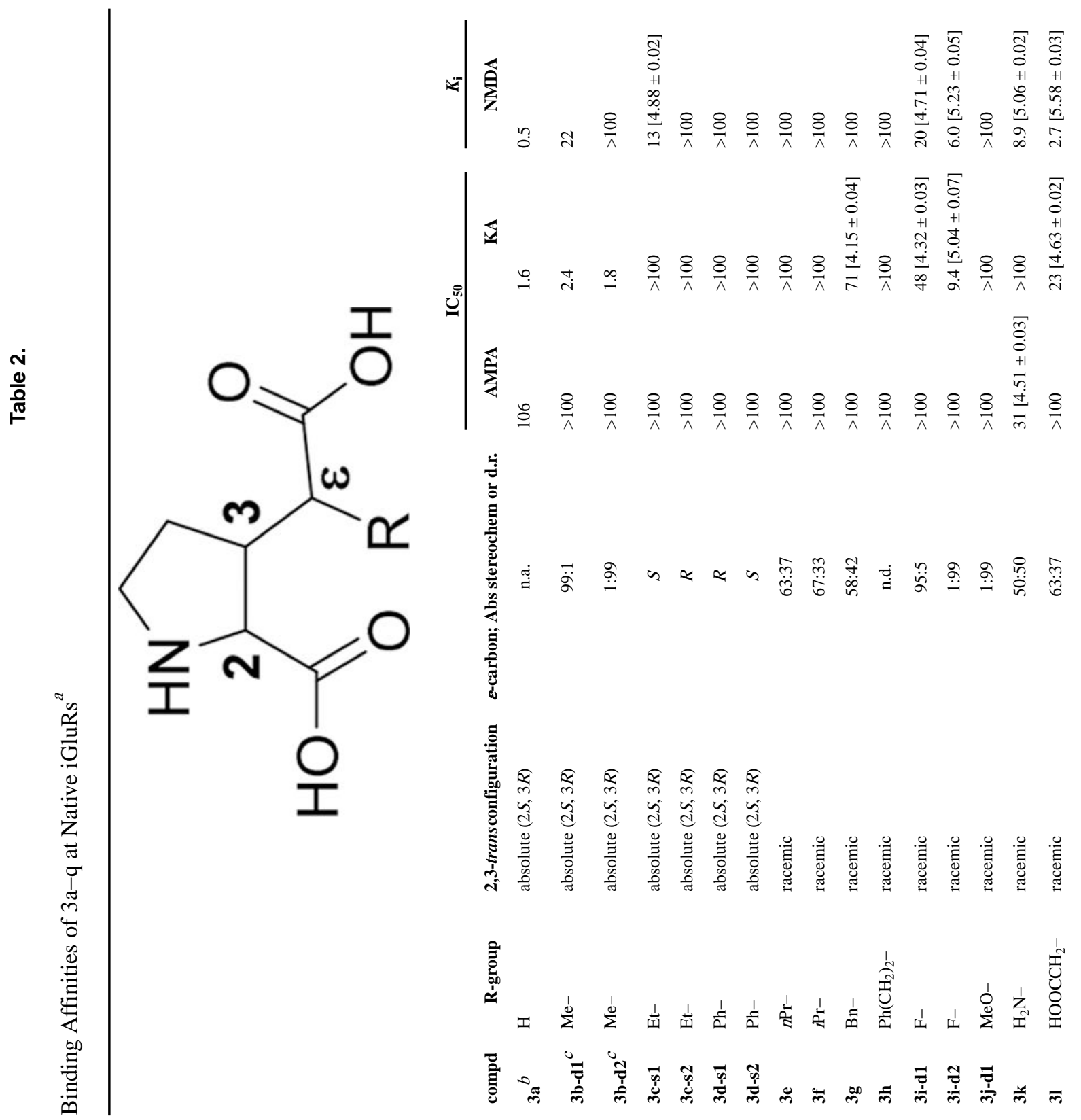

ACS Chem Neurosci. Author manuscript; available in PMC 2020 June 19. 


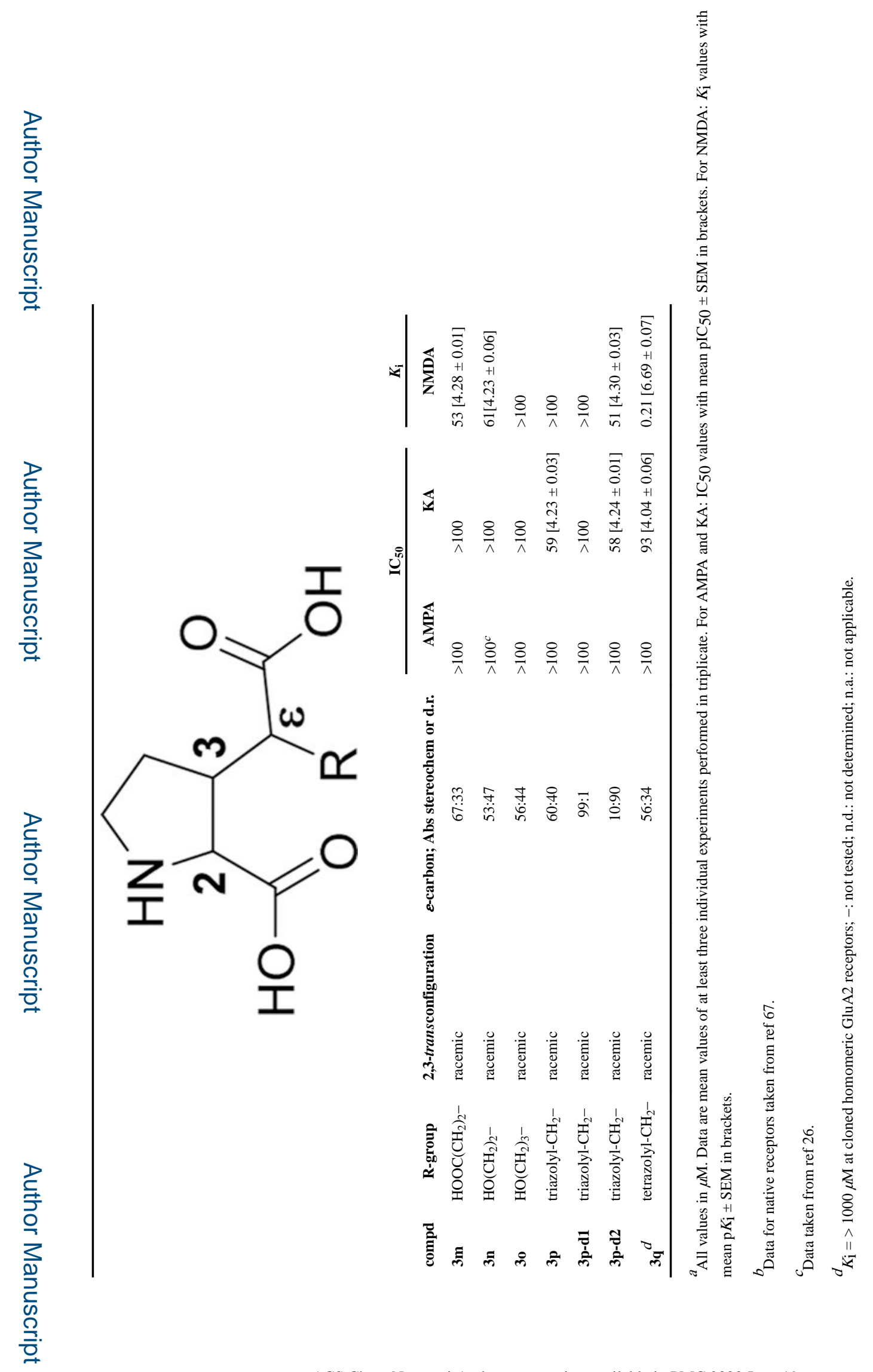

ACS Chem Neurosci. Author manuscript; available in PMC 2020 June 19. 


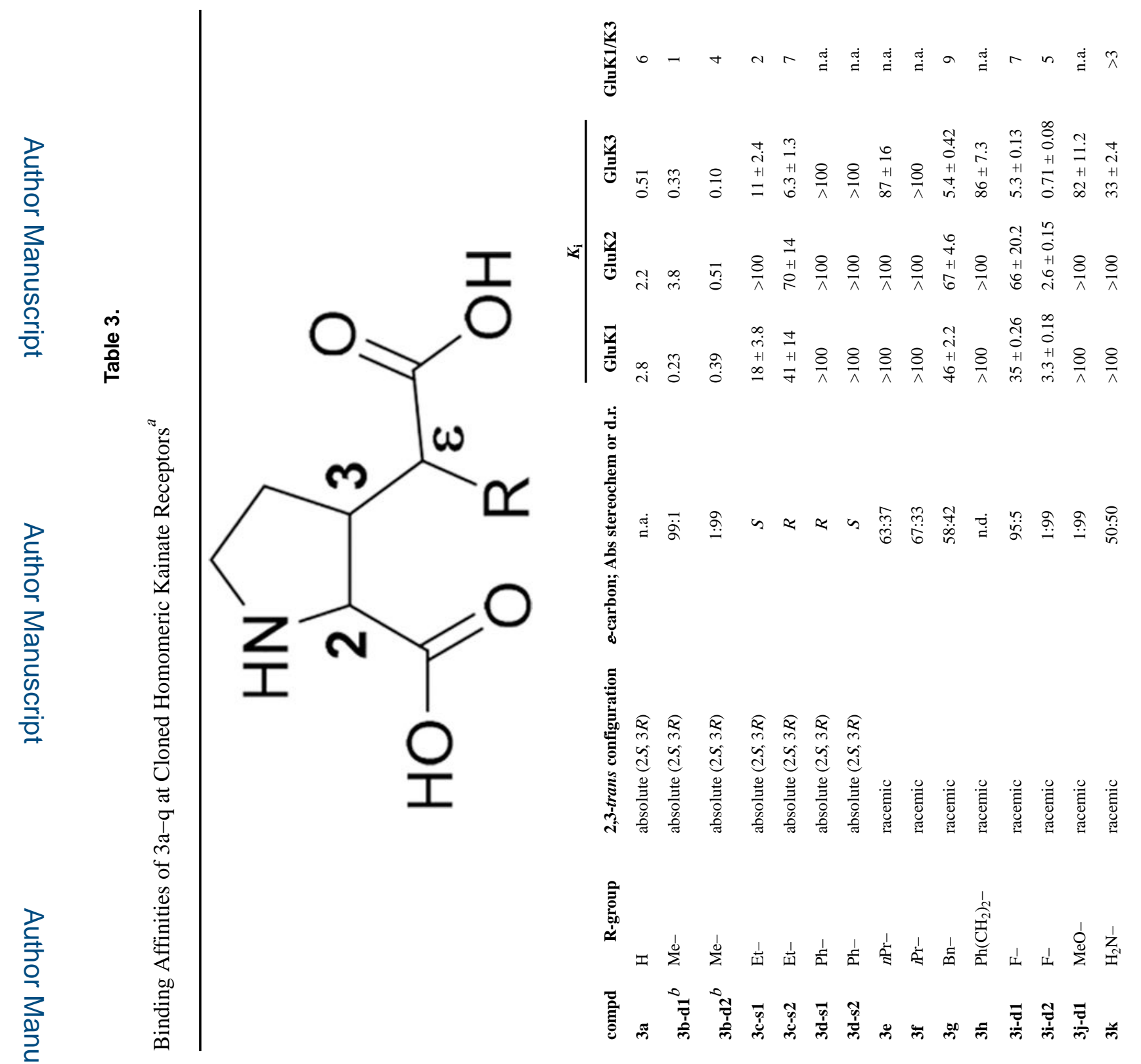




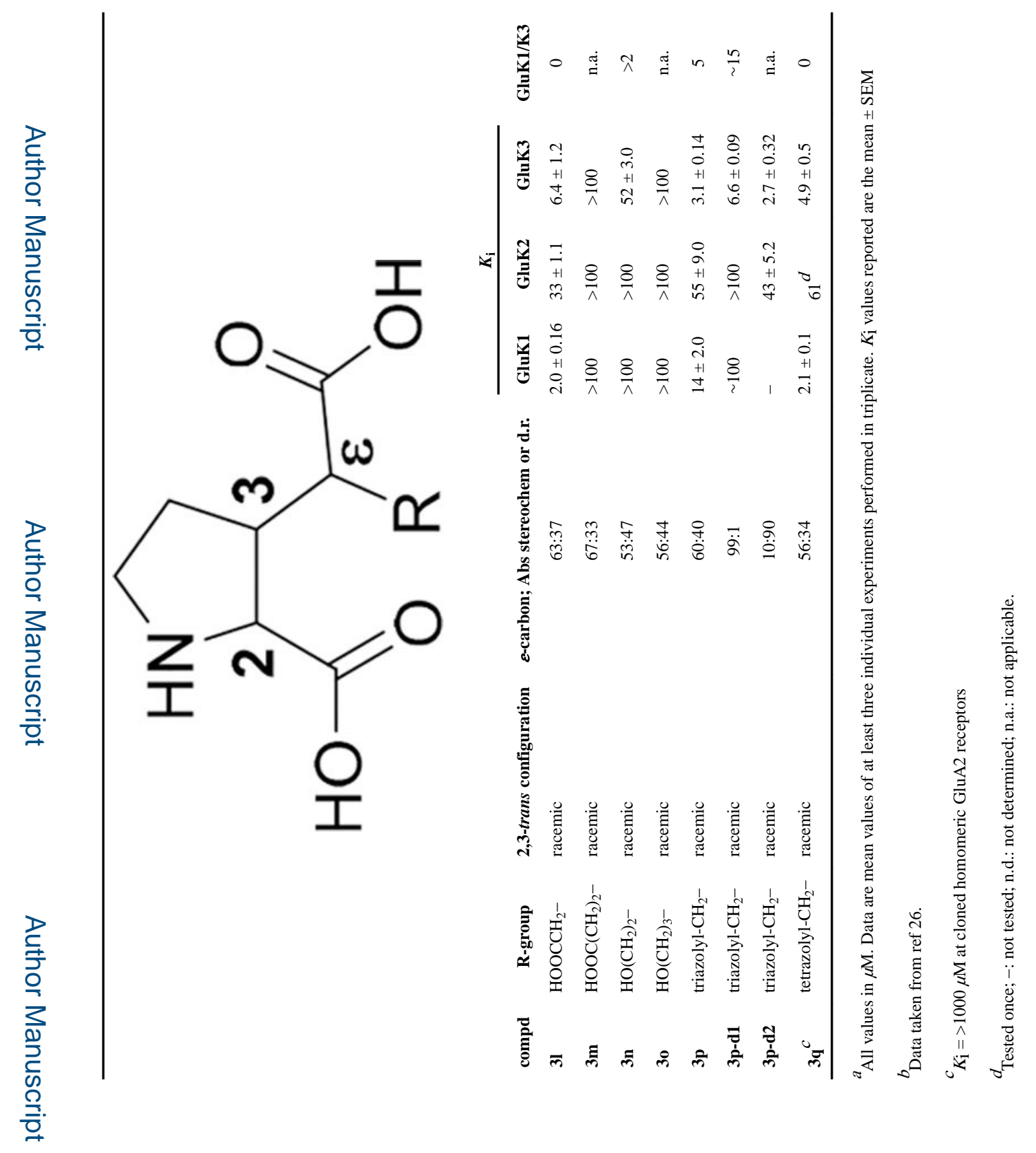

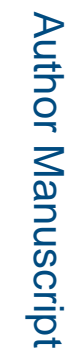




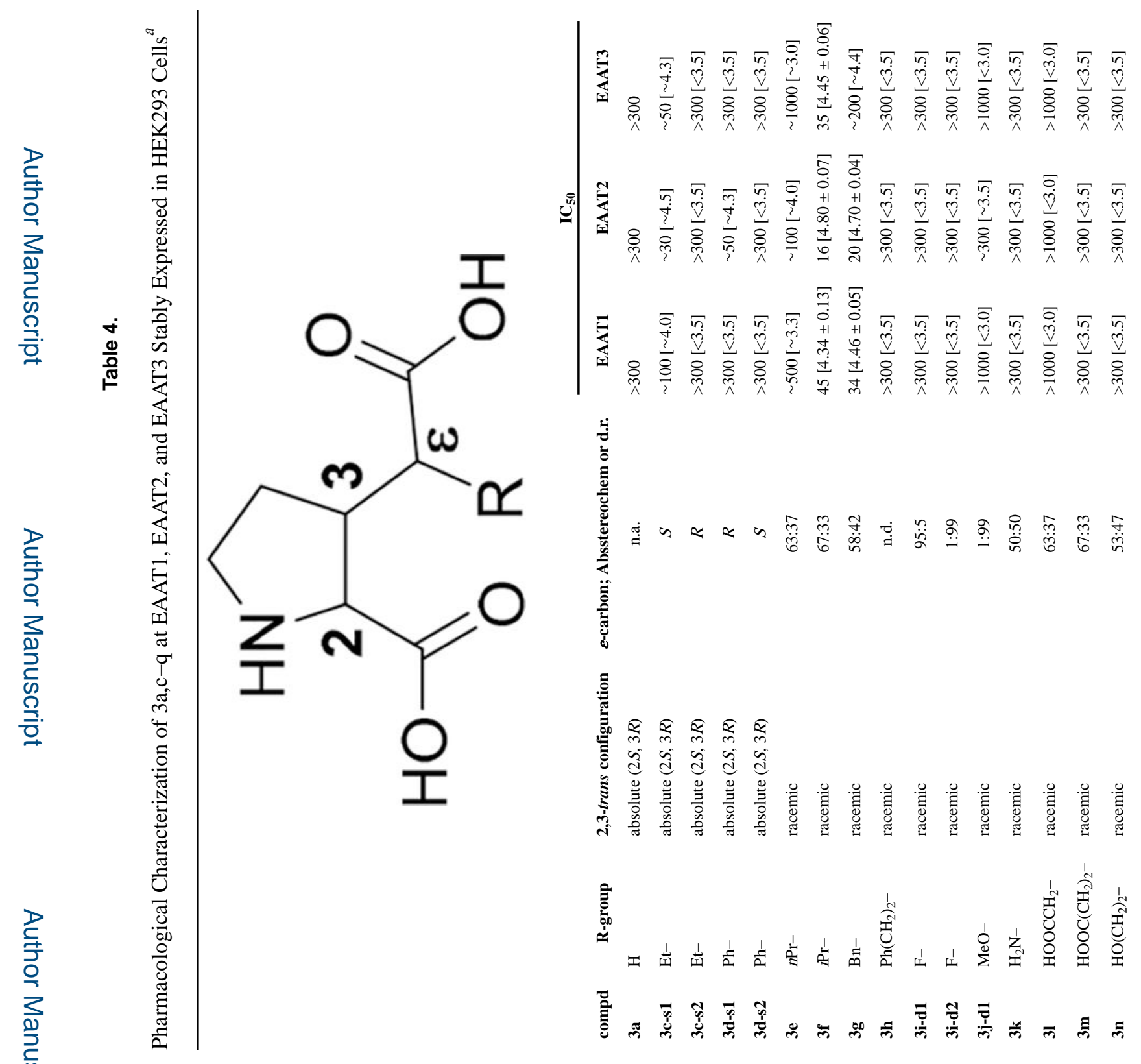




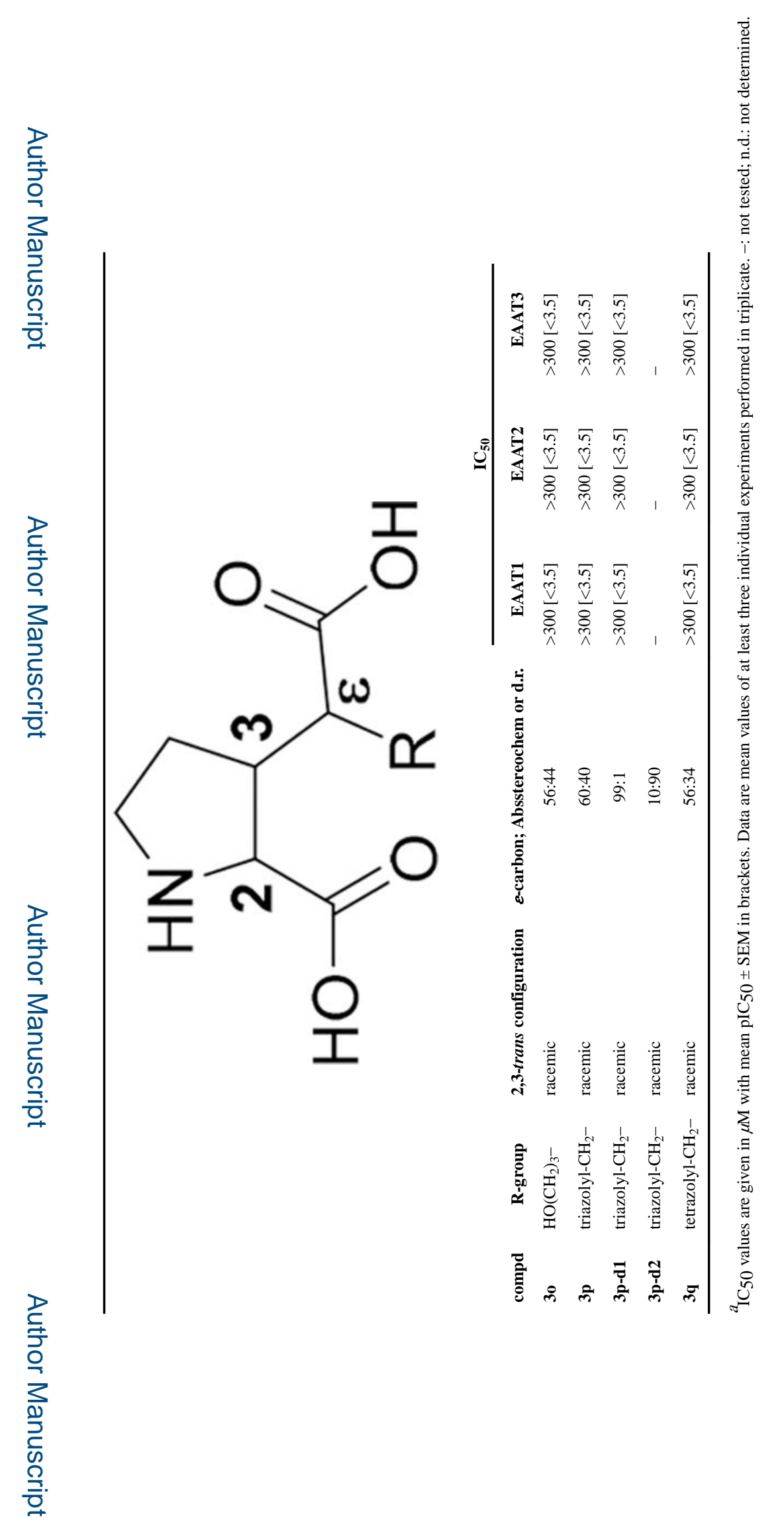

ACS Chem Neurosci. Author manuscript; available in PMC 2020 June 19. 


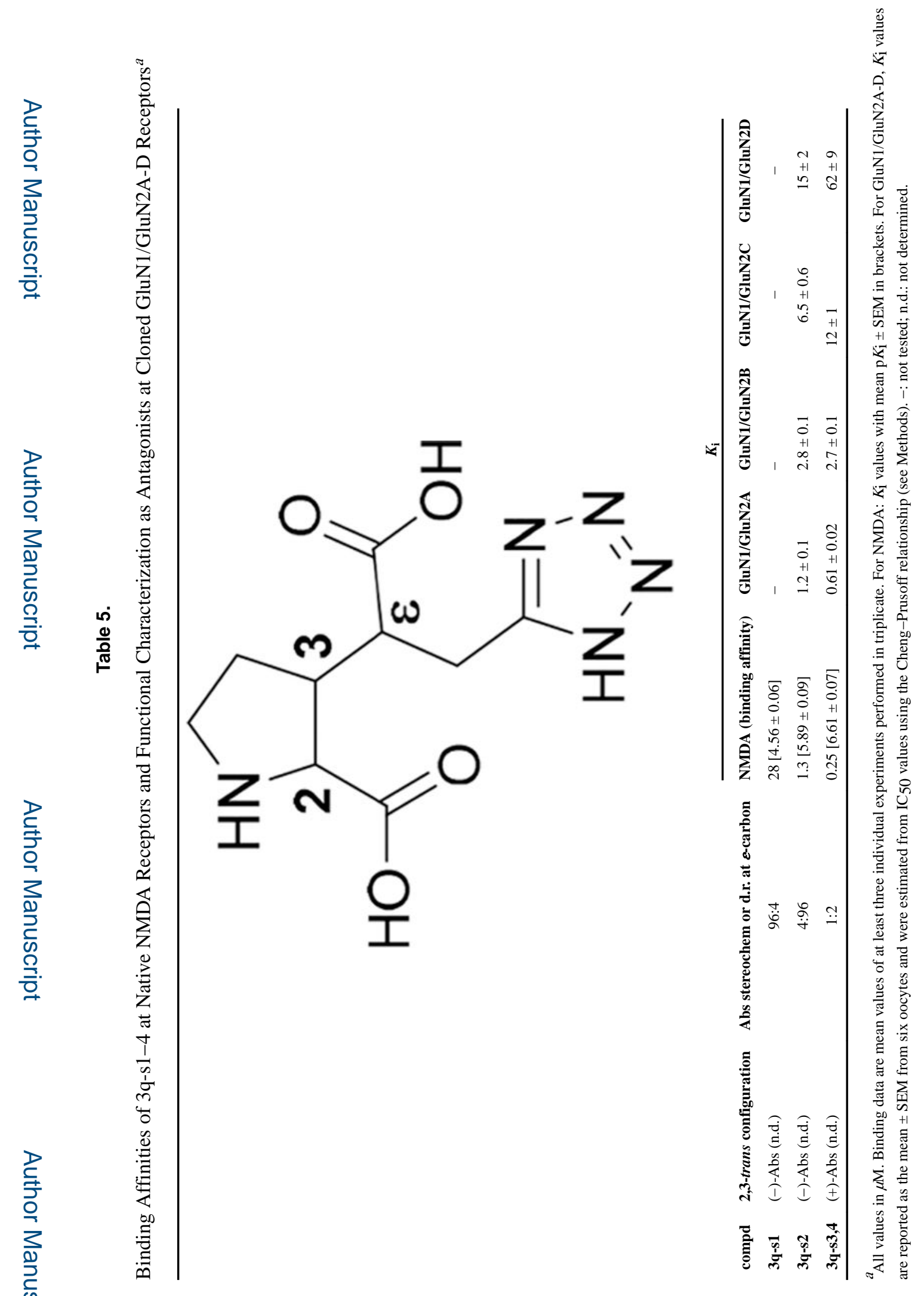

ACS Chem Neurosci. Author manuscript; available in PMC 2020 June 19. 